Genotype by environment interaction for feed efficiency in growing-finishing pigs in Brazil versus the Netherlands 


\section{Thesis committee}

\section{Promotors}

Prof. Dr J. Komen

Personal chair at Animal Breeding and Genomics

Wageningen University \& Research

Prof. Dr S.E.F. Guimarães

Professor of Animal Breeding and Genetics

Universidade Federal de Viçosa, Brazil

\section{Co-promotor}

Dr J.W.M. Bastiaansen

Researcher, Animal Breeding and Genomics

Wageningen University \& Research

\section{Other members}

Prof. Dr W.J.J. Gerrits, Wageningen University \& Research

Dr F.F. Cardoso, EMBRAPA, Brazil

Prof. Dr J. Jensen, Aarhus University, Tjele, Denmark

Dr K. Peeters, Hendrix Genetics, Boxmeer

This research was conducted under the auspices of the Graduate School of Wageningen Institute of Animal Sciences (WIAS). 


\title{
Genotype by environment interaction for feed efficiency in growing- finishing pigs in Brazil versus the Netherlands
}

\author{
Rodrigo Mezêncio Godinho
}

\section{Thesis}

submitted in fulfillment of the requirements for the degree of doctor at Wageningen University by the authority of the Rector Magnificus,

$$
\text { Prof. Dr A.P.J. Mol, }
$$

in the presence of the

Thesis Committee appointed by the Academic Board to be defended in public on Friday 21 December 2018 at 1.30 p.m. in the Aula. 
Godinho, R.M.

Genotype by environment interaction for feed efficiency in growing-finishing pigs in Brazil versus the Netherlands,

144 pages.

PhD thesis, Wageningen University, Wageningen, the Netherlands (2018)

With references, with summaries in English and Portuguese

ISBN 978-94-6343-552-9

DOI: $10.18174 / 465136$ 


\begin{abstract}
Godinho, R.M. (2018). Genotype by environment interaction for feed efficiency in growing-finishing pigs in Brazil versus the Netherlands. PhD thesis, Wageningen University, the Netherlands.
\end{abstract}

In pig breeding programs, purebred (PB) boars are selected in a nucleus, and mated with crossbred $(\mathrm{CB})$ dams to produce $\mathrm{CB}$ growing-finishing pigs used for pork production in commercial farms. The majority of the cost of pork production comes from feeding CB pigs. Therefore, increasing attention is given to selection for feed efficiency and to include in the genetic evaluations the performance records of $C B$ pigs in commercial production circumstances. In addition, sustainability should be at the top of the agenda for all livestock production systems, and thus, improving the feed efficiency of $C B$ pigs farmed around the globe is necessary. Differences between the genetic background of $\mathrm{PB}$ and $\mathrm{CB}$, as well as differences between the nucleus and the commercial farms environments will lower the genetic correlation of feed efficiency for PB performance in the nucleus level and CB performance in the commercial level $\left(r_{p c}\right)$. My main aim in this thesis was to investigate the possible causes of an $r_{p c}$ in growing-finishing pigs between the feed efficiency in $C B$ pigs kept under Brazilian commercial production circumstances and PB pigs kept under Dutch circumstances being below 1 . Another aim was to compare the properties of different traits to represent feed efficiency and the implications of their adoption by pig breeding programs. The results of this thesis show that the collection of feed intake data on $\mathrm{CB}$ at commercial farms is worthwhile to increase genetic progress in $\mathrm{CB}$ feed efficiency and that residual energy intake is an attractive trait for pig breeding programs. Depending on the definition of feed efficiency, this trait is variably sensitive to changes in the ingredients of the two most common pig commercial rations (corn/soy or wheat/barley/co-products). Breeding for feed efficiency under lower-input diets, such as wheat/barley/coproducts, should be considered as feed efficiency will become more important, and lower-input diets will become more widespread in the near future. Feed efficiency can be improved by changing the trajectory of feed intake as a function of body weight, i.e., the feed intake curves. A flatter feed intake curve, and high feed intake precocity (higher feed intake in early stages of growth associated with a higher growth maturation rate and a consequent lower feed intake later on the finishing period) is a desired profile in pig breeding. Collection of production data in a tropical climate is worthwhile, and feed efficiency is expected to be sensitive to climate. 



\section{Contents}

$9 \quad 1-$ General introduction

212 - Genetic correlations between feed efficiency traits, and growth performance and carcass traits in purebred and crossbred pigs

433 - Genotype by feed interaction for feed efficiency and growth performance traits in pigs

634 - Genetic parameters for feed intake and growth curves of three-way crossbred pigs fed two different diets

855 - Genetic correlations between growth performance and carcass traits of purebred and crossbred pigs raised in tropical and temperate climates

$1036-$ General discussion

121 Summary

125 Sumário

129 Acknowledgements

135 Curriculum vitae

139 Training and supervision plan

143 Colophon 

1

General introduction 



\subsection{Genotype by environment interaction}

Genotype by environment interaction $(\mathrm{G} \times \mathrm{E})$ is the phenomenon whereby different genotypes respond differently to environmental changes, also known as environmental sensitivity of genotypes (Falconer and Mackay, 1996). A genotype is the particular assemblage of genes possessed by an individual. A phenotype is the ensemble of observable characteristics displayed by an individual and is a result of the expression of the genotype and the influence of the environment. The environment is all the non-genetic circumstances that influence a phenotype. The phenotypic value $(P)$ of an individual for a given trait is a function of its genetic value $(G)$ and the environmental effect $(E)$, and is traditionally represented as $P=G$ $+E$. In this model, it is assumed that a given change in E will result in the same change in $\mathrm{P}$, independently of $\mathrm{G}$. When this is not true, there is genotype by environment interaction, commonly abbreviated as "GxE" (Falconer and Mackay, 1996). When GxE is present, a specific change in the environment can have a bigger effect in the expression of one genotype than in another one.

GXE has two main consequences: heterogeneity of genetic variance and re-ranking of genotypes (Figure 1.1). When heterogeneity of genetic variance is present, the differences between genotypes are larger in one environment than in another while the ranking of the genotypes remain the same (Figure 1.2). When re-ranking of genotypes is present, the best genotype in one environment might not be the best in another environment (Figure 1.3). If re-ranking of genotypes or heterogeneity of genetic variance is present, GxE should be considered in genetic evaluations.

To estimate GxE under a multi-trait mixed model approach, the same phenotype, taken in two different environments, is considered to be two distinct traits and the genetic correlation between them is estimated. The genetic correlation is a useful parameter to study how much of the improvement made in one environment is expressed in another environment (Falconer and Mackay, 1996). Values of genetic correlations below 1 indicate GxE. Robertson (1959) suggested that GXE is biologically meaningful when genetic correlations are below 0.80 , a threshold that is widely applied in animal breeding.

\subsection{GxE in pigs}

Pig production is mostly based on a three-way crossbreeding scheme where purebred $(\mathrm{PB})$ sires of different breeds and lines, are mated with crossbred ( $C B$ ) dams to exploit heterosis and complementarity, producing $C B$ fattening pigs. While the lines that produce $C B$ dams are highly specialised for maternal instinct, large 
litter sizes, and high milk production, sire lines are highly specialised for growth, yield of lean meat, and other production traits. Pork is mainly produced from CB pigs, grown on commercial farms. In pig breeding, consolidation has resulted in a reduced number of global breeding programmes with similar breeding goals. Selection takes place in nucleus farms in mainly temperate climates where PB are kept under highly sanitised and standard controlled environmental conditions (Knap, 2005).

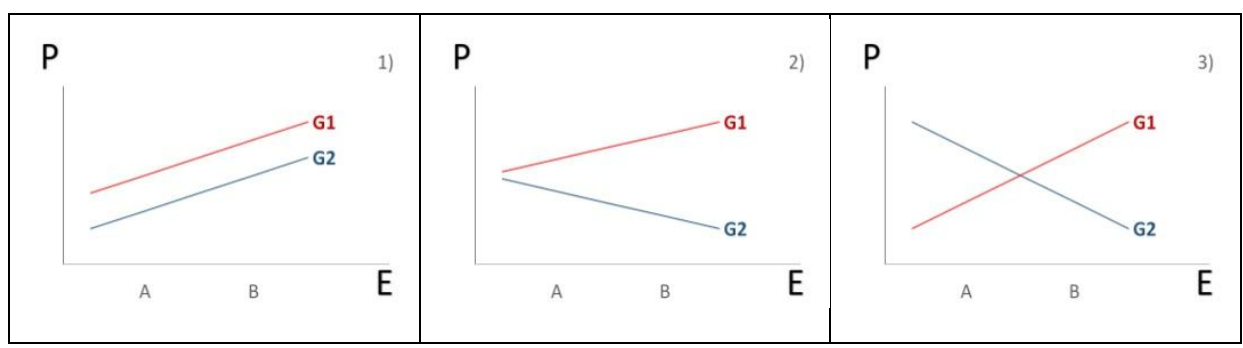

Figure 1.1 Genotype by environment interaction (GxE). $P$ = phenotypic level; $E$ = given environmental gradient with environments $A$ and $B$; G1, genotype 1; G2, genotype 2. 1) Absence of GxE, the $G 1$ has a superior expression to $G 2$ in both environments and heterogeneity of genetic variance is absent, i.e., the same phenotypic deviations are observed for both genotypes; 2 ) Heterogeneity of genetic variance, where the differences between genotypes are higher in environment $B$ compared with $A$, but the ranking of the genotypes remain the same in both environments, i.e. $G 1$ has a higher $P$ in both environments; and 3) Re-ranking of the genotypes $G 1$ and G2, i.e. $G 1$ is the best genotype in environment $B$, and $G 2$ is the best genotype in environment $A$.

The majority of the total production cost of a slaughter pig originates from the growing-finishing phase. Therefore, there is an increasing trend to give attention to the performance of $\mathrm{CB}$ pigs in order to better select $\mathrm{PB}$ for $\mathrm{CB}$ performance. $\mathrm{CB}$ pigs are raised in all kinds of environments, differing in climate, management systems, and health status and diet composition, among others. Therefore, pig breeding programmes do not necessarily select the best pigs for specific local circumstances (Bloemhof et al., 2008).

The success of selecting PB with the aim to improve CB performance depends on the purebred-crossbred genetic correlation $\left(r_{p c}\right)$, a parameter which is not very well know due to the limited availability of reliable records in CB pigs. There are three main reasons why $r_{p c}$ in pigs can be lower than unity (Wientjes and Calus, 2017): 1) a genotype by genotype interaction $(\mathrm{G} x \mathrm{G})$, given the different genetic backgrounds of $P B$ and $C B ; 2)$ a genotype by environment interaction $(G \times E)$, given the differences 
between nucleus and commercial farms; and 3) differences in the way the traits are recorded in $\mathrm{PB}$ and $\mathrm{CB}$.

Feed efficiency is the single most important trait in pig breeding and there is evidence for a very low $r_{p c}$ for feed efficiency in pigs due to environmental sensitivity (Knap and Wang, 2012). The $r_{p c}$ may also be this low due to differences in trait recording. It is unlikely that $\mathrm{PB}$ and $\mathrm{CB}$ pigs have feed intake recorded in the same way when $\mathrm{PB}$ pigs are kept in nucleus farms and $C B$ pigs are kept in commercial environments. The PB are kept in highly controlled conditions, including closed barns where temperature and humidity are set to suit the physiological comfort of the pigs, and where the highest levels of sanitary control, health status, and management are applied. However, $C B$ pigs are kept in nonstandardised commercial production farms where, even in the best scenario, control of environmental conditions will be less strict than in nucleus farms. In general, selection for production under nucleus conditions has been shown to lead to increased environmental sensitivity (Van der Waaij, 2004). When the goal is to improve $C B$ performance, the value of having $C B$ information increases when the $r_{p c}$ decreases (Wei and van der Werf, 1994; Bijma and van Arendonk, 1998). Combined CB and PB selection (CCPS) for improved CB performance was suggested to be worthwhile, instead of PB selection only, when the $r_{p c}$ is lower than 0.8 (Wei and van der Werf, 1994).

\subsection{Feed efficiency in pigs}

A third of the grains produced in the world are used to feed livestock (FAO, 2012). The increasing demand for grains for human consumption and other uses puts pressure on livestock production systems to use diet inputs in a more effective way. Among the most important strategies to improve sustainability of pig production are selection for improved feed efficiency (Knap and Wang, 2012; Patience, 2012) and the use of alternative ingredients, i.e. locally produced, human food wastage or co-products of milling and seed-oil industries (Westendorf, et al., 1998; Myer et al., 1999; Márquez and Ramos, 2007; Stein and Shurson, 2009; Zijlstra and Beltranena, 2013).

Feed efficiency means the amount of product output per unit of feed input. In brief, more efficient growing-finishing pigs use a smaller amount of feed to produce the same amount of meat. Feed efficiency is affected by a broad spectrum of factors including nutrition, genetics, physiology, feeding behaviour, and the environment in which pigs are raised (Young and Dekkers, 2012). The future of pork production is centred on pigs that efficiently convert feed into lean meat. Feeding 
may account for over $75 \%$ of pork production costs (Ali et al., 2017). Thus, improving feed efficiency traits is a priority in pig breeding programs to reduce environmental impact, and also, to reduce the cost per unit produced and to improve lean growth.

There is a trend to give more attention to novel feed efficiency traits as the traditional way to represent it, using the feed conversion ratio or the gain to feed ratio, don't account for variation in size, growth rate, and body composition of animals (Knap and Wang, 2012; Young and Dekkers, 2012). The residual feed intake (RFI) (Koch et al., 1963), defined as the difference between the observed feed intake and the expected feed intake based on the expected requirements for production and maintenance, is a powerful alternative (Knap and Wang, 2012; Young and Dekkers, 2012). Genetic improvement of RFI has been shown in experimental lines, including decreasing feed requirements for a given production rate (e.g. Gilbert et al., 2007; Cai et al., 2008). GxE for RFI has not been widely investigated and $r_{p c}$ estimates for RFI are lacking from the literature.

GxE for feed efficiency becomes important when selection for feed efficiency is combined with using alternative diet ingredients. The use of alternative ingredients, besides being a possible strategy to reduce environmental impact of livestock production systems, might reduce the cost of producing pork by lowering the prices of feed or the costs associated with transportation of diet inputs. In addition, the risk associated with producing pork may be reduced by decreasing the dependency on international prices of commodities. When exchanging high-input diets, e.g. energy-dense grains, for lower-input diets, it is important to know the interaction between genotypes and feed ingredients. Moreover, it is important to know the interaction between feed and climate. Alternative ingredients are usually less dense in energy and contain higher amounts of fibre. Higher fibre ingestion increases heat production.

\subsection{Brazil versus the Netherlands}

GxE is important for pig breeding (Mathur, 2018), and has been described for environmental conditions such as heat stress (Bloemhof et al., 2008; Zumbach et al., 2008; Bergsma and Hermesch, 2012; Fragomeni et al., 2017; Rosé et al., 2017); seasonality (Sevillano et al., 2016); the outbreak of disease, and challenge load (Mathur et al., 2014; Rashidi et al., 2014; Herrero-Medrano et al., 2015). However, very few of these studies analysed growing-finishing traits (Zumbach et al., 2008; Fragomeni et al., 2017; Rosé et al., 2017), and only one included progeny of common sires in temperate and tropical climate (Rosé et al., 2017). Half of the 
world's pork production occurs in temperate climates, e.g. Europe, North America, North of China, and Russia; while the other half occurs in the tropical climates, e.g. Brazil, Mexico, South of China, and Vietnam (FAO, 2012). It is likely that the expansion of agriculture to meet the increasing requirement for animal protein will occur in the tropics.

When comparing nucleus and commercial farms, in Brazil and in the Netherlands, several environmental factors can be responsible for GxE, e.g. the management and hygiene status of the farms, the climate conditions, and, also, the ingredients in the diets. Brazilian pork production, like in the rest of the Americas, is based mainly on feeding high-input diets of corn and soybean meal, of which Brazil and the United States are among the major producers. In the Netherlands and other Western-European countries, pigs are commonly fed lower-input diets based on alternative grains, e.g. wheat and barley, with high amounts of added protein-rich co-products of industry, like milling and oil-seed industries. The consequences of using these diets for selection for feed efficiency are still largely unknown.

\section{Box 1.1 LocalPork Project}

Efficient local production of pork in Brazil is essential to meet the increasing internal demand for animal protein, and to make the Brazilian pork sector competitive and sustainable towards the future. Two important threats are: 1) Brazilian pork production relies on feeding corn and soybeans that are becoming more expensive due to large demand for alternative uses and increasing transport distances, and 2) consolidation of pig breeding businesses has resulted in global breeding programs that do not necessarily select the best pigs for specific local circumstances (such as tropical climate or alternative feed). This multidisciplinary project aimed to quantify these threats, develop and evaluate alternatives involving feeding by-products from more locally produced sources and breeding strategies that allow global breeding plans to serve specific local breeding goals.

Thesis "Enhancing the environmental and economic sustainability of pig farming: The case of Brazil"

Brazilian pig production heavily relies on high quality feed ingredients (corn and soybean), and exotic pig breeds that are not bred for local production circumstances. This has caused economic and environmental problems. Economic problems follow from the growing competition for corn and soybeans between the pig industry and other 
sectors which ultimately resulting in rising feed costs and shrinking farm profits. The problems are exacerbated by feed and pork prices' volatility, which brings uncertainty that affects investment, production and other business decisions of farmers. Environmental problems follow from the strong dependence on scarce resources (e.g. cropland, fossil fuel and water), and the release of pollutants to air, water and soil. This thesis assessed the contributions of locally produced alternative feed sources and genetic improvement of pigs in enhancing the environmental and economic sustainability of Brazilian pig production system.

Thesis "Genotype by environment interaction for feed efficiency in growing-finishing pigs in Brazil versus the Netherlands" (this thesis)

Improving feed efficiency of crossbred pigs in commercial environments is a priority in pig breeding programs. Selection for feed efficiency, like for other traits, traditionally relies on measuring performance of purebred pigs in the nucleus environment, while the aim is to improve the crossbred performance in the commercial environment. Thus, the differences between these two environments may give rise to genotype by environment interaction (GXE). When comparing nucleus farms in the Netherlands and commercial farms in Brazil, several environmental factors can be responsible for GxE, e.g., the management and hygiene status of the farms, the ingredients of the diets and the climate conditions. This thesis investigated the genetic correlation between purebred and crossbred performance and the GXE interactions for feed efficiency traits in pigs raised in different conditions and fed different diets.

\section{Thesis "Genomic evaluation considering the mosaic genome of the crossbred pig"}

Feed efficiency plays an important role in the breeding goal of the current pig industry and it is one of the most important traits for efficient local production. However, if traits included in the breeding goal have genetic correlations between purebred and crossbred performance different from unity, selection response at the nucleus level (purebred animals) will not be fully expressed in the rate of genetic change at the commercial level (crossbred animals). The success of breeding programs in the near future will rely on the use of phenotypes and genotypes taken from crossbred animals at local commercial levels and the use of newly developed genomic models for handling this new type of information. This thesis investigated and developed new methodologies for using crossbred genomic information to increase the genetic change at the commercial level. 
Besides the differences in pig diets, another important difference between pork production in the Netherlands and Brazil are the climatic conditions. Almost $70 \%$ of Brazilian pork production is concentrated in the southern region of the country (ABPA, 2017). This area is just below the Tropic of Capricorn and so has a subtropical climate. Pig husbandry in the area, therefore, is not expected to be highly hampered by heat load. In the areas with the greatest potential for expansion of pork production, namely the Southeast and Central-West regions of the country (which currently account for $16 \%$ and $14 \%$ of Brazilian pork production, respectively), heat load is of great concern.

\subsection{Objectives and outline of the thesis}

My PhD project is part of the LocalPork Project (Box 1.1). My main objective in this thesis was to investigate the possible causes of a genetic correlation in growingfinishing pigs between the purebred performance on the nucleus level and the crossbred performance in the commercial level $\left(r_{p c}\right)$ for feed efficiency being below 1 , and to compare the properties of different traits to represent feed efficiency and the implications of their adoption by pig breeding programs.

In Chapter 2, I assessed the $r_{p c}$ in a large group of PB pigs, comprising five sire lines and four dam lines housed at 23 nucleus farms in the Netherlands, France, Spain, Hungary, and Canada, and their CB progenies in three farms in the Netherlands where research is conducted under near commercial production conditions. I compared three traits representative of feed efficiency, i.e. feed conversion rate, residual energy intake, and residual feed intake and estimated their correlations with growth performance and carcass traits, both in $\mathrm{PB}$ and $\mathrm{CB}$. In Chapter 3, I investigated the genotype by feed interactions using data of $C B$ pigs. Pigs from the same litter were evenly distributed between a diet based on corn and soybean meal, as is common in the Americas, or a diet based on wheat and barley with high amounts of added protein-rich co-products, as is common in Western Europe. I also assessed and compare the expected responses to direct selection and indirect selection under both diets. In Chapter 4, I estimated the feed intake curves of CB pigs fed two different diets to investigate the presence of genotype by feed interaction for feed related traits. I estimated genetic correlations of the feed intake curve parameters with parameters of the growth curve, growth performance traits, and residual feed intake traits, to assess the potential of improving feed efficiency by selecting for the shape of the feed intake curve. In Chapter 5, I investigated the interaction of genotype with climate and estimated the $r_{p c}$ for carcass and growth performance traits when $P B$ and $C B$ pigs are both 
raised in two different climatic environments. The PB pigs were located in eight farms in a temperate climate (the Netherlands, France, and Canada), and four farms in a tropical climate (Brazil). The CB pigs were located in five farms in a temperate climate (the Netherlands and Canada), and two farms in a tropical climate (Brazil). In the general discussion (Chapter 6), I placed my work in a broader context, discussed the implications and formulated recommendations for future breeding for feed efficiency in growing-finishing pigs, with special attention to feed efficiency in the tropics, and recommended future research.

\section{References}

ABPA, Brazilian association of animal protein. 2017. Annual report 2017. http://abpa-

br.com.br/storage/files/final_abpa_relatorio_anual_2017_ingles_web.pdf

Bergsma, R. and S. Hermesch. 2012. Exploring breeding opportunities for reduced thermal sensitivity of feed intake in the lactating sow. J. Anim. Sci. 90:85-98.

Bijma, P., and J. A. van Arendonk. 1998. Maximizing genetic gain for the sire line of a crossbreeding scheme utilizing both purebred and crossbred information. J. Anim. Sci. 66:529-542.

Bloemhof, S., E.H. Van der Waaij, J.W.M. Merks, and E.F. Knol. 2008. Sow line differences in heat stress tolerance expressed in reproductive performance traits. J. Anim. Sci. 86:3330-3337.

Cai, W. 2010. Quantitative genetic and statistical aspects of feed efficiency by analysis of the selection experiment for residual feed intake in Yorkshire pigs. PhD Thesis, lowa State University, Ames, lowa, 119p.

Falconer, D.S. and T.F.C. Mackay. 1996. Introduction to Quantitative Genetics. Longman, Essex, UK.

FAO. 2012. World agriculture towards 2030/2050, The 2012 Revision. Rome, Italy: FAO

Fragomeni, B. O., D. A. L. Lourenco, S. Tsuruta, K. Gray, Y. Huang, and I. Misztal. 2016. Modeling response to heat stress in pigs from nucleus and commercial farms in different locations. J. Anim. Sci. 94:4789-4798.

Gilbert, H., J.P. Bidanel, J. Gruand, J.C. Caritez, Y. Billon, P. Guillouet, H. Lagant, J. Noblet, and P. Sellier. 2007. Genetic parameters for residual feed intake in growing pigs, with emphasis on genetic relationships with carcass and meat quality traits. J. Anim. Sci. 85:3182-3188.

Herrero-Medrano, J. M., P. K. Mathur, J. ten Napel, H. Rashidi, P. Alexandri, E. F. $\mathrm{Knol}$, and $\mathrm{H}$. Mulder. 2015. Estimation of genetic parameters and breeding values 
across challenged environments to select for robust pigs. J. Anim. Sci. 93:14941502.

Knap, P. W. 2005. Breeding robust pigs. Austr. J. Exp. Agric. 45:763-773.

Knap, P. W., and L. Wang. 2012. Pig breeding for improved feed efficiency. Pages 167-181 in Feed efficiency in swine. J. F. Patience, eds. Wageningen Academic Publishers, Wageningen, the Netherlands.

Koch, R. M., L. A. Swiger, D. Chambers, and K. E. Gregory. 1963. Efficiency of feed use in beef cattle. J. Anim. Sci. 22:486-494.

Márquez, M. C., and P. Ramos. 2007. Effect of the inclusion of food waste in pigs diets on growth performance, carcass and meat quality. Animal. 1:595-599.

Mathur, P. K., J. M. Herrero-Medrano, P. Alexandri, E. F. Knol, J. ten Napel, H. Rashidi, and H. A. Mulder. 2014. Estimating challenge load due to disease outbreaks and other challenges using reproduction records of sows. J. Anim. Sci. 92:5374-5381.

Mathur, P. K. 2018. Genotype-environment interactions in pig breeding. In: Proceedings of $11^{\circ}$ World Congress on Genetics Applied to Livestock Production. Proceedings, Auckland, New Zealand, 668.

Myer, R. O., J. H. Brendemuhl, and D. D. Johnson. 1999. Evaluation of dehydrated restaurant food waste products as feedstuffs for finishing pigs. J. Anim. Sci. 77:685-692.

Neeteson-van Nieuwenhoven, A.M., P. Knap, and S. Avendaño. 2013. The role of sustainable commercial pig and poultry breeding for food security. Anim. Front. 3:52-57.

Patience, J. P. 2012. The influence of dietary energy on feed efficiency in growfinish swine. Pages 101-129 In: J. F. Patience, Feed efficiency in swine. Wageningen Academic Publishers, Wageningen, the Netherlands. p. 101-129.

Rashidi, H., H. A. Mulder, P. Mathur, J. A. Van Arendonk, and E. F. Knol. 2014. Variation among sows in response to porcine reproductive and respiratory syndrome. J. Anim. Sci. 92:95-105.

Robertson, A. 1959. The sampling variance of the genetic correlation coefficient. Biometrics. 15:469-485.

Rosé, R., H. Gilbert, T. Loyau, M. Giorgi, Y. Billon, J. Riquet, D. Renaudeau, J.-L. Gourdine. Interactions between sire family and production environment (temperate vs. tropical) on performance and thermoregulation responses in growing pigs. J. Anim. Sci. 95:4738-4751.

Sevillano, C. A., H. A. Mulder, H. Rashidi, P. K. Mathur, and E. F. Knol. 2016. Genetic variation for farrowing rate in pigs in response to change in photoperiod and ambient temperature. J. Anim. Sci. 94:3185-3197. 
Stein, H. H., and G. C. Shurson. 2009. Board-invited review: the use and application of distillers dried grains with solubles in swine diets. J. Anim. Sci. 87:1292-1303.

USITC, United States International Trade Commission. 2014. Pork \& Swine Industry \& Trade Summary. http://www.usitc.gov/publications/332/pork_and_swine_summary_its_11.pdf Van der Waaij, E.H. 2004. A resource allocation model describing consequences of artificial selection under metabolic stress. J. Anim. Sci. 82: 973-981.

Wei, M., and J. H. J. van der Werf. 1994. Maximizing genetic response in crossbreds using both purebred and crossbred information. Anim. Produc. 59:401-413.

Westendorf, M. L., Z. C. Dong, and P. A. Schoknecht. 1998. Recycled cafeteria food waste as a feed for swine: nutrient content, digestibility, growth, and meat quality. J. Anim. Sci. 76:2976-2983.

Wientjes, Y. C. J., and M. P. L. Calus. 2017. Board invited review: The purebredcrossbred correlation in pigs: A review of theory, estimates, and implications. J. Anim. Sci. 95:3467-3478. doi:10.2527/jas.2017.1669.

Young, J. M., and J. C. M. Dekkers. 2012. The genetic and biological basis of residual feed intake as a measure of feed efficiency. Pages 153-166 in Feed efficiency in swine. J. F. Patience, eds. Wageningen Academic Publishers, Wageningen, the Netherlands.

Zijlstra, R. T., and E. Beltranena. 2013. Swine convert co-products from food and biofuel industries into animal protein for food. Anim. Front. 3:48-53.

Zumbach, B., I. Misztal, S. Tsuruta, J. P. Sanchez, M. Azain, W. Herring, J. Holl, T. Long, and M. Culbertson. 2008. Genetic components of heat stress in finishing pigs: Parameter estimation. J. Anim. Sci. 86:2076-2081. 


\title{
2
}

\section{Genetic correlations between feed efficiency traits, and growth performance and carcass traits in purebred and crossbred pigs}

\author{
Rodrigo M Godinho ${ }^{1,2}$, Rob Bergsma ${ }^{3}$, Fabyano $\mathrm{F} \mathrm{Silva}^{1}$, Claudia A Sevillano ${ }^{23}$, \\ Egbert F Knol ${ }^{3}$, Marcos S Lopes ${ }^{3,4}$, Paulo S Lopes ${ }^{1}$, John WM Bastiaansen ${ }^{2}$, \\ Simone EF Guimarães ${ }^{1}$
}

${ }^{1}$ Department of Animal Science, Universidade Federal de Viçosa, 36570-900, Viçosa, Brazil; ${ }^{2}$ Wageningen University \& Research Animal Breeding and Genomics, $6700 \mathrm{AH}$, Wageningen, Gelderland, the Netherlands; ${ }^{3}$ Topigs Norsvin Research Center, 6640 AA, Beuningen, Gelderland, the Netherlands; ${ }^{4}$ Topigs Norsvin, 80420210, Curitiba, Brazil.

Journal of Animal Science (2018) 96:817-829 


\begin{abstract}
Selection for feed efficiency (FE) is a strategy to reduce the production costs per unit of animal product, which is one of the major objectives of current animal breeding programs. In pig breeding, selection for FE and other traits traditionally takes place based on purebred pig (PB) performance at the nucleus level, while pork production typically makes use of crossbred animals (CB). The success of this selection, therefore, depends on the genetic correlation between the performance of $\mathrm{PB}$ and $\mathrm{CB}\left(\mathrm{r}_{\mathrm{pc}}\right)$ and on the genetic correlation $\left(r_{\mathrm{g}}\right)$ between FE and the other traits that are currently under selection. Different traits are being used to account for $\mathrm{FE}$, but the $\mathrm{r}_{\mathrm{pc}}$ have only been reported for feed conversion rate. Therefore, the current study aimed: 1 ) to estimate the $r_{p c}$ for growth performance, carcass and $\mathrm{FE}$ traits; 2) to estimate $r_{g}$ between traits within $P B$ and $C B$ populations; 3 ) and to compare three different traits representing FE: feed conversion rate (FCR), residual energy intake (REI) and residual feed intake (RFI). Phenotypes of 194,445 PB animals from 23 nucleus farms, and 46,328 CB animals from three farms where research is conducted under near commercial production conditions were available for this study. From these, 22,984 PB and 8,657 CB presented records for feed intake. The PB population consisted of five sire and four dam lines; and the $C B$ population consisted of terminal cross progeny generated by crossing sires from one of the five PB sire lines with commercially available two-way maternal sow crosses. Estimates of $r_{p c}$ ranged from 0.61 to 0.71 for growth performance traits, from 0.75 to 0.82 for carcass traits and from 0.62 to 0.67 for FE traits. Estimates of $r_{g}$ between growth performance, carcass and FE traits differed within PB and CB. REI and RFI showed substantial positive $r_{g}$ estimates in PB (0.84) and CB (0.90) populations. The magnitudes of $r_{p c}$ estimates indicate that genetic progress is being realized in $\mathrm{CB}$ at the production level from selection on $\mathrm{PB}$ performance at nucleus level. However, including CB phenotypes recorded on production farms, when predicting breeding values, has the potential to increase genetic progress for these traits in CB. Given the genetic correlations with growth performance traits and the genetic correlation between the performance of $\mathrm{PB}$ and $\mathrm{CB}, \mathrm{REI}$ is an attractive $\mathrm{FE}$ parameter for a breeding program.
\end{abstract}

Key words: breeding program, carcass traits, feed efficiency, growth, genetic correlations, growing-finishing pigs 


\subsection{Introduction}

In an international scenario of increasing demand for animal protein and decreasing availability of natural resources, animal production systems have the challenge to increase productivity and to reduce environmental load (Neeteson-van Nieuwenhoven et al., 2013). Furthermore, continuous growth of human population and increased demand for grains by biofuel industry press animal producers to use diet inputs in a more effective way. Therefore, the future of pork production is centered on pigs that efficiently convert feed into lean meat. Feed efficiency (FE) covers a broad spectrum of factors that in brief means to produce more output using less input (Patience, 2012). Thus, selection based on FE is a strategy to minimize the production cost per unit of animal product, which is one of the major objectives of current animal breeding programs. In pig breeding, selection for $\mathrm{FE}$ and other traits traditionally takes place based on purebred pig (PB) performance at the nucleus level, whereas pork production typically makes use of crossbred animals (CB). Thus, the success of this selection depends on the genetic correlation between the performance of PB and CB ( $\left.r_{p c}\right)$ (Zumbach et al., 2007) and on the genetic correlation $\left(r_{\mathrm{g}}\right)$ between $\mathrm{FE}$ and the other traits that are currently under selection. For traits presenting low values of $r_{p c}$, the use of $C B$ information has the potential to maximize genetic progress for crossbreeding schemes (Wei and van der Werf, 1994; Bijma and van Arendonk, 1998). The $r_{p c}$ of FE was only reported for the trait feed conversion rate (Nakavisut et al., 2005; Habier et al., 2007; Tussel et al.; 2016). Therefore, the current study aimed: 1) to estimate the $r_{p c}$ for growth performance, carcass and FE traits; 2 ) to estimate the $r_{g}$ between traits within PB and $C B$ populations; 3 ) and to compare three different traits representing FE: feed conversion rate (FCR), residual energy intake (REI) and residual feed intake (RFI).

\subsection{Material and methods}

\subsubsection{Ethic statement}

The data used for this study was collected as part of routine data recording in a commercial breeding program. Observations from 26 farms located in different countries (the Netherlands, France, Spain, Hungary and Canada) were used in this study. All these farms are operating in line with the regulations on protection of animals of their countries.

\subsubsection{Data}

Phenotypic records of 194,445 PB and 46,328 CB were available for this study. 
Table 2.1 Number of animals with phenotypes of each line (sire, dam or three-way-cross) by farm.

\begin{tabular}{lrrrr}
\hline Line & Farms & Male & Females & Total \\
\hline Sire 1 & $1,2,3,4,5$ & 36472 & 33988 & 70460 \\
Sire 2 & $1,2,4,6,7$ & 23674 & 21792 & 45466 \\
Sire 3 & $1,2,3,4$ & 20841 & 17977 & 38818 \\
Sire 4 & 1,3 & 860 & 918 & 1778 \\
Sire 5 & 12 & 356 & 1150 & 1506 \\
Dam 1 & $4,8,9,11,12,14,15,17$ & 5749 & 9237 & 14986 \\
Dam 2 & $11,13,18,19,20,21,22$ & 3034 & 8037 & 11071 \\
Dam 3 & $10,12,23$ & 1540 & 3604 & 5144 \\
Dam 4 & $1,2,4,5,7,11,16,23$ & 1522 & 1694 & 3216 \\
CB1 & $24,25,26$ & 11609 & 10958 & 22567 \\
CB2 & 24,25 & 4121 & 3990 & 8111 \\
CB3 & 24,25 & 4254 & 3943 & 8197 \\
CB4 & 24,25 & 1846 & 1702 & 3548 \\
CB5 & 24,25 & 2040 & 1865 & 3905 \\
\hline CB, thr & 1125
\end{tabular}

$\mathrm{CB}$, three-way-cross between the numbered sire line and a crossbred female of two dam lines.

Individual feed intake records were available on 22,984 PB and 8,657 CB. The PB population consisted of five sire and four dam lines, which were located in 23 nucleus farms (Table 2.1). Sire lines were located in eight of these farms. Dam lines were located in 21 of these farms. The CB population consisted of terminal cross progeny generated by crossing sires from one of the five PB sire lines with commercially available two-way maternal sow crosses and were located in three farms where research is conducted under near commercial production conditions: Schothorst Feed Research (SFR) (Lelystad, the Netherlands), Experimental Farm of Institute for Pig Genetics (IPG) (Beilen, the Netherlands) and Varkens Innovatie Centrum (VIC) (Sterkel, the Netherlands). All pigs had a space allowance of at least $1 \mathrm{~m}^{2}$, as this is part of the guidelines for the nucleus farms worldwide, and this rule also applies for commercial farms in the Netherlands. Group size (animals grouped together in the same pen) varied from 6 to 16 with an average of 10.6 and 10.2 pigs per pen for $\mathrm{PB}$ and $\mathrm{CB}$, respectively. Pedigree records were available for all animals, up to a maximum of 21 generations. A total of 272,825 animals were included in the pedigree file with 7,257 different sires and 31,166 different dams. Average number of offspring was 32.9 per sire and 7.7 per dam. The degree of 
connectedness of contemporary groups (CG) estimated using the AMC Program (Roso and Schenkel, 2006) based on the number of genetic ties to the main population group was high ( $98.45 \%$ of the CG and $99.9 \%$ of the animals connected).

\subsubsection{Traits}

Corresponding traits were identified in both PB and CB populations (Table 2.1). All animals were weighed individually at start of the growing-finishing period (ontest), around $25 \mathrm{~kg}$. All PB had their BW $(\mathrm{kg})$ recorded, and back fat thickness (BF, mm) and muscle depth (MD, $\mathrm{mm}$ ) ultrasonically measured at the end of the growingfinishing period (offtest). CB animals had their HCW recorded along with BF and MD using the Hennessy Grading Probe (Hennessy Grading Systems, Auckland, New Zealand) or the Capteur Gras Maigre (CGM, Sydel, France) at slaughter. Average daily gain on test ( $A D G, g / d)$ was obtained in $P B$ as the $B W$ at the end of the growing-finishing period $\left(\mathrm{BW}_{\text {offest }}\right)$ minus penning $\mathrm{BW}\left(\mathrm{BW}_{\text {ontest }}\right)$, divided by the length of the period. ADG was obtained in $C B$ as the calculated $B W$ (CBW) minus $B W_{\text {ontest }}$ divided by the length of the growing-finishing period. For average lifetime daily gain ( $A L D G, g / d)$ the $B W$ at birth $\left(B W_{\text {birth }}\right)$ instead of $B W_{\text {ontest }}$ was considered. The formula used to obtain the CBW based on the HCW (Handboek varkenshouderij, 2004) was the following:

$$
C B W=1.3 \times H C W-0.0025 \times H C W^{2}+0.2075 \times H C W .
$$

Animals were fed ad libitum in both populations (PB and CB). Individual feed intake was recorded using IVOG-stations (Insentec, Marknesse, the Netherlands). Average daily feed intake (ADFI, g/d) was calculated as cumulative feed intake during the total growing-finishing period divided by the length of the period. Lipid deposition $(L D, g / d)$ and protein deposition (PD, g/d) were estimated as the increment in lipid and protein mass content during the phase based on BW and back fat measurements (de Greef et al., 1994):

$$
\begin{aligned}
& \% \text { fat }_{\text {offtest }}=\frac{B F, m m-1.87}{53.3}, \\
& \% \text { fat }_{\text {ontest }}=\% \text { fat } t_{\text {offtest }} \times \frac{-0.000005\left(B W_{\text {ontest }}\right)^{2}+0.0019\left(B W_{\text {ontest }}\right)+0.0665}{-0.000005\left(B W_{\text {offtest }}\right)^{2}+0.0019\left(B W_{\text {offtest }}\right)+0.0665}, \\
& \text { Protein water ratio }=5.39(B W \times 0.14)^{-0.145}, \\
& \text { As } h=0.03 \times B W, \\
& \text { Lipid mass }(L M)=\% \text { fat } \times 0.95 \times B W, \\
& \text { Protein mass }(P M)=\frac{0.95 \times B W-L M-\text { Ash }}{\text { Protein water ratio }+1^{\prime}}
\end{aligned}
$$


Table 2.2 Number of observations, mean, standard deviation, minimum and maximum for covariates $^{1}$ and traits ${ }^{2}$ used to estimate heritabilities and genetic correlations.

\begin{tabular}{|c|c|c|c|c|c|}
\hline & No. & $\mu$ & SD & Min & Max \\
\hline \multicolumn{6}{|c|}{ I. Purebred traits } \\
\hline $\mathrm{BW}_{\text {birth }}, \mathrm{g}$ & & 1441 & 318.70 & 400 & 3150 \\
\hline $\mathrm{BW}_{\text {ontest }}, \mathrm{kg}$ & & 30.47 & 6.79 & 15 & 50 \\
\hline $\mathrm{BW}_{\text {offtest }}, \mathrm{kg}$ & & 114.9 & 13.97 & 70 & 194 \\
\hline$A D G, g / d$ & 182988 & 902 & 150.54 & 443 & 1562 \\
\hline ALDG, $\mathrm{g} / \mathrm{d}$ & 187325 & 673.2 & 97.22 & 305 & 1057 \\
\hline$A D F I, g / d$ & 22984 & 2077 & 236.66 & 1301 & 2700 \\
\hline$L D, g / d$ & 181633 & 157.3 & 62.82 & 9 & 446 \\
\hline$P D, g / d$ & 181633 & 156.8 & 27.17 & 59 & 281 \\
\hline $\mathrm{MD}, \mathrm{mm}$ & 180003 & 57.96 & 7.72 & 23.3 & 90.5 \\
\hline $\mathrm{BF}, \mathrm{mm}$ & 186905 & 10.18 & 2.74 & 2.5 & 24.3 \\
\hline FCR & 22984 & 2.2 & 0.25 & 1.23 & 3.53 \\
\hline REI, g/d & 22822 & 32.07 & 195.28 & -769 & 775 \\
\hline $\mathrm{RFI}, \mathrm{g} / \mathrm{d}$ & 22727 & -11.56 & 182.86 & -803 & 659 \\
\hline \multicolumn{6}{|c|}{ II. Crossbred traits } \\
\hline $\mathrm{BW}_{\text {birth }}, \mathrm{g}$ & & 1396 & 321.92 & 320 & 3160 \\
\hline $\mathrm{BW}_{\text {ontest }}, \mathrm{kg}$ & & 25.98 & 4.87 & 15 & 49.9 \\
\hline $\mathrm{HCW}, \mathrm{kg}$ & & 91.16 & 6.57 & 52 & 130.8 \\
\hline CBW, kg & & 116.55 & 6.91 & 71.63 & 154.41 \\
\hline$A D G, g / d$ & 41632 & 848.7 & 93.49 & 466 & 1182 \\
\hline ALDG, $\mathrm{g} / \mathrm{d}$ & 41976 & 521.1 & 51.59 & 213 & 810 \\
\hline ADFI, g/d & 8657 & 2262 & 240.80 & 1330 & 2700 \\
\hline$L D, g / d$ & 10464 & 197.1 & 54.91 & 47 & 429 \\
\hline$P D, g / d$ & 10464 & 143.4 & 17.38 & 81 & 210 \\
\hline $\mathrm{MD}, \mathrm{mm}$ & 41644 & 60.45 & 7.11 & 34.8 & 88.4 \\
\hline $\mathrm{BF}, \mathrm{mm}$ & 41644 & 14.9 & 3.20 & 4.6 & 28.8 \\
\hline FCR & 8657 & 2.48 & 0.24 & 1.51 & 3.43 \\
\hline REI, g/d & 8381 & 113.3 & 187.99 & -694 & 850 \\
\hline RFI, g/d & 8388 & 34.5 & 178.07 & -741 & 739 \\
\hline
\end{tabular}




$$
\begin{aligned}
& L D=\frac{\left(L M_{\text {offtest }}-L M_{\text {ontest }}\right) \times 1000}{\text { Test lengt } h, d}, \\
& P D=\frac{\left(P M_{\text {offtest }}-P M_{\text {ontest }}\right) \times 1000}{\text { Test lengt } h, d} .
\end{aligned}
$$

Feed efficiency (FE) was calculated as feed conversion rate (FCR), residual energy intake (REI, g/d) and residual feed intake (RFI, g/d). FCR was calculated as the ADFI divided by the ADG. REI represents the efficiency of the energy metabolism, and was calculated as a linear function of energy intake, energy required for maintenance of live BW and energy required for lipid and protein accretion (Bergsma et al., 2013):

$$
R E I=\frac{A D F I \times 13,5-M E_{m}-(L D+P D) \times 53}{13,5},
$$

in which $M E_{m}$ is the metabolizable energy required for maintenance of $\mathrm{BW}$ calculated from the metabolic BW (de Haer et al., 1993):

$$
M E_{m}=\frac{\left(\mathrm{BW}_{\text {offtest }}^{1.75}-\mathrm{BW}_{\text {ontest }}^{1.75}\right) \times 420}{\left(\mathrm{BW}_{\text {offtest }}-\mathrm{BW}_{\text {ontest }}\right) \times 1.75} .
$$

RFI was obtained as the difference between the observed and predicted ADFI (Cai et al., 2008):

$$
\begin{gathered}
A D F I=\mu+b_{1} B W_{\text {ontest }}+b_{2} B W_{\text {offtest }}+b_{3} B F+b_{4} A D G+b_{5} A g e_{\text {ontest }} \\
+e,
\end{gathered}
$$

in which $A g e_{\text {ontest }}$ is the age at which the animal was put on test, $b_{1}, b_{2}, b_{3}, b_{4}$ and $b_{5}$ are the linear coefficients of the regression on covariates, and $e$ is the RFI.

\subsubsection{Genetic Parameters Estimation}

Genetic parameters were estimated under different approaches. Firstly, univariate analyses were performed to estimate the variance components and heritabilities of all traits. Secondly, correlations were estimated using bivariate analyses. Genetic correlation between the performance of $\mathrm{PB}$ and $\mathrm{CB}\left(\mathrm{r}_{\mathrm{pc}}\right)$ were estimated using corresponding traits together (e.g. $A D G$ in $P B$ and $A D G$ in $C B$ ). Genetic $\left(r_{g}\right)$ and phenotypic $\left(r_{p}\right)$ correlations between different traits were estimated within populations ( $P B$ or $C B$ ). The fixed effects included for each trait are presented in Table 2.3. Only significant effects were included in the models for estimating variance components. BF and MD were pre-adjusted for the covariate weight prior to the bivariate analysis.

A linear mixed model implemented in ASReml (Gilmour et al., 2009) was used for the analyses as follows:

$$
y=X b+Z a+W c+V g+U f+e
$$


Table 2.3 Fixed effects ${ }^{1}$ included in the vector $b$ of equation [2.1] for the traits ${ }^{2}$.

\begin{tabular}{ccc}
\hline Model & Dependent trait(s) & Fixed effects $^{1}$ \\
\hline $\mathrm{A}$ & $\mathrm{ADG} ; \mathrm{ALDG} ; \mathrm{LD} ; \mathrm{PD} ; \mathrm{FCR}$ & $\mu+\mathrm{SEX}_{\mathrm{j}}+\mathrm{LINE}_{\mathrm{k}}+\mathrm{HYS}_{\mathrm{I}}+\mathrm{COMP}_{\mathrm{m}}+b_{1} \mathrm{BW}_{\text {birth }}$ \\
$\mathrm{B}$ & $\mathrm{ADFI} ; \mathrm{REI} ; \mathrm{RFI}$ & $\mu+\mathrm{SEX}_{\mathrm{j}}+\mathrm{LINE}_{\mathrm{k}}+\mathrm{HYS}_{\mathrm{I}}+\mathrm{COMP}_{\mathrm{m}}+b_{1} \mathrm{BW}_{\text {ontest }}$ \\
$\mathrm{C}$ & $\mathrm{BF}$ and MD in PB & $\mu+\mathrm{SEX}_{\mathrm{j}}+\mathrm{LINE}_{\mathrm{k}}+\mathrm{HYS}_{\mathrm{I}}+\mathrm{COMP}_{\mathrm{m}}+b_{1} \mathrm{BW}_{\text {offtest }}$ \\
$\mathrm{D}$ & $\mathrm{BF}$ and MD in CB & $\mu+\mathrm{SEX}_{\mathrm{j}}+\mathrm{LINE}_{\mathrm{k}}+\mathrm{HYS}_{\mathrm{I}}+\mathrm{COMP}_{\mathrm{m}}+b_{1} \mathrm{HCW}$ \\
\hline
\end{tabular}

${ }^{1}$ SEX, the sex of the animal; LINE, the line of the animal; HYS, Herd-Year-Season = farm $x$ year of birth; COMP, compartment within barn $\mathrm{x}$ farm; $\mathrm{BW}_{\text {birth }}$, body weight at birth; $\mathrm{BW}_{\text {ontest }}$ body weight ontest; $B W_{\text {offest }}$, body weight offtest; $\mathrm{HCW}$, hot carcass weight. ${ }^{2} \mathrm{ADG}$, average daily gain; ALDG, average lifetime daily gain; ADFI, average daily feed intake; $L D$, lipid deposition; $\mathrm{PD}$, protein deposition; $\mathrm{MD}$, muscle depth; $\mathrm{BF}$, back fat thickness; $F C R$, feed conversion rate; $\mathrm{REI}$, residual energy intake; $\mathrm{RFI}$, residual feed intake; $\mathrm{PB}$, purebred; $\mathrm{CB}$, crossbred.

in which $y$ is the vector of observations; $X, Z, W, V$ and $U$ are known incidence matrices; $b$ is a vector of fixed effects (Table 2.3); $a$ is a vector of random additive genetic effects (breeding values), $a \sim N\left(0, A \otimes \sum_{a}\right) ; c$ is a vector of random nongenetic effects common to individuals born in the same litter, $c \sim N\left(0, I_{c} \otimes \sum_{c}\right) ; g$ is the vector of random pen effects (animals grouped together in the same pen) $g \sim N\left(0, I_{g} \otimes \sum_{g}\right) ; f$ is the vector of random effects common to individuals performance tested in the same compartment of the barn within the same contemporary group, $f \sim N\left(0, I_{f} \otimes \sum_{f}\right)$; and $e$ is a vector of residuals, $e \sim N\left(0, I_{e} \otimes\right.$ $\left.\sum_{e}\right)$. A is a matrix of additive genetic relationships among all individuals, $I_{c}, I_{g}, I_{f}$ and $I_{e}$ are identity matrices of the appropriate dimensions and $\sum_{a}, \sum_{c}, \sum_{g}, \sum_{f}$ and $\sum_{e}$ are covariance matrices related to each effect. In the case of univariate analyses, the covariance matrix $\sum_{i}$ is scalar with the variance component $\sigma_{i}$ associated to the respective effect.

\subsubsection{Response to selection}

The response to direct selection on $C B$ performance $\left(R_{C B}\right)$ and the correlated response for $\mathrm{CB}$ performance $\left(\mathrm{CR}_{\mathrm{CB}}\right)$ to indirect selection on $\mathrm{PB}$ performance were calculated as (Falconer \& Mackay, 1996):

$$
R_{C B}=i_{C B} \times h_{C B} x \sigma_{A_{C B}}
$$

in which $i_{C B}$ is the intensity of selection on $C B$ (assumed to be 1 in this study), $h_{C B}$ is the square root of the heritability of the trait on $\mathrm{CB}$, and $\sigma_{A_{C B}}$ is the genetic standard deviation of the trait on $\mathrm{CB}$.

$$
C R_{C B}=i_{P B} \times h_{P B} \times r_{p c} \times \sigma_{A_{C B}}
$$


in which $i_{P B}$ is the intensity of selection on PB (assumed to be 1 in this study), $h_{P B}$ is the square root of the heritability of the trait on $\mathrm{PB}, r_{p c}$ is the genetic correlation between the performance of $\mathrm{PB}$ and $\mathrm{CB}$, and $\sigma_{A_{C B}}$ is the genetic standard deviation of the trait on $\mathrm{CB}$.

\subsection{RESULTS}

\subsubsection{Variance components}

Heritability estimates (Table 2.4) were larger for carcass traits $(0.35$ to 0.47 for PB and 0.24 to 0.43 for $\mathrm{CB}$ ) than for growth performance traits ( 0.22 to 0.36 for $\mathrm{PB}$ and 0.26 to 0.36 for $\mathrm{CB}$ ) and for FE traits ( 0.15 to 0.17 for $\mathrm{PB}$ and 0.15 to 0.19 for $\mathrm{CB}$ ). The phenotypic variance explained by the common environment among litter mates was larger for growth performance traits ( 5 to $8 \%$ for PB and 3 to $5 \%$ for $C B$ ) than for FE traits ( $4 \%$ for $\mathrm{PB}$ and 2 to $4 \%$ for $\mathrm{CB}$ ) and carcass traits ( 3 to $4 \%$ for PB and 1 to $3 \%$ for $\mathrm{CB}$ ). The phenotypic variance explained by the contemporary pen effect was larger for FE traits (17 to $18 \%$ for $\mathrm{PB}$ and 21 to $23 \%$ for $\mathrm{CB}$ ) than for growth performance traits ( 9 to $14 \%$ for $\mathrm{PB}$ and 7 to $19 \%$ for $\mathrm{CB}$ ) and carcass traits ( 5 to $6 \%$ for $\mathrm{PB}$ and 1 to $2 \%$ for $\mathrm{CB}$ ). The pattern of phenotypic variance explained by the contemporary compartment effect follows that of the contemporary pen effect, being larger for FE traits ( 12 to $18 \%$ for $\mathrm{PB}$ and 17 to $18 \%$ for $\mathrm{CB}$ ) than for growth performance traits ( 8 to $16 \%$ for $\mathrm{PB}$ and 10 to $12 \%$ for $\mathrm{CB}$ ) and carcass traits ( 6 to $10 \%$ for $\mathrm{PB}$ and 2 to $3 \%$ for $\mathrm{CB}$ ).

\subsubsection{Purebred-crossbred genetic correlations}

Estimates of $r_{p c}$ are presented in Table 2.5. The range of estimated values was similar for the three groups of traits, with somewhat higher values for carcass traits. The $r_{p c}$ ranged from 0.61 to 0.71 for growth performance traits, from 0.75 to 0.82 in carcass traits and from 0.62 to 0.67 for FE traits.

\subsubsection{Genetic correlations between traits within $P B$ and $C B$}

Estimates of $r_{g}$ within $\mathrm{PB}$ and within $\mathrm{CB}$ in Table 2.6. High growth was genetically associated with a high ADFI, LD and PD in PB and in CB. The $r_{g}$ of growth with LD was stronger in $\mathrm{PB}$ than in $\mathrm{CB}$. The $\mathrm{r}_{\mathrm{g}}$ of growth with carcass traits were moderate in $P B$ and low in $C B$ and these correlations were different in direction being unfavorable in $\mathrm{PB}$ but favorable in $\mathrm{CB}$. Like growth, high $\mathrm{ADFI}$ is also genetically associated with high $L D$ in $P B$ and in $C B$. The $r_{g}$ between ADFI and PD were moderate in $\mathrm{PB}$ as well as $\mathrm{CB}$, between $\mathrm{ADFI}$ and carcass traits they were moderate in $C B$, and between $A D F I$ and $M D$ it was low in PB. All $r_{g}$ between the three traits 
Table 2.4 Contribution (standard error) of different random effects ${ }^{1}$ to the estimation of the traits $^{2}$ in $\mathrm{PB}(\mathrm{I})$ and $\mathrm{CB}(\mathrm{II})$.

\begin{tabular}{lllll}
\hline & $h^{2}$ & $\frac{\sigma_{l t r}^{2}}{\sigma_{P}^{2}}$ & $\frac{\sigma_{p e n}^{2}}{\sigma_{P}^{2}}$ & $\frac{\sigma_{c o}^{2}}{\sigma_{P}^{2}}$ \\
\hline I. Purebred & & & & \\
ADG & $0.23(0.01)$ & $0.06(0.01)$ & $0.12(0.01)$ & $0.11(0.01)$ \\
ALDG & $0.23(0.01)$ & $0.08(0.01)$ & $0.14(0.01)$ & $0.08(0.01)$ \\
ADFI & $0.23(0.02)$ & $0.05(0.01)$ & $0.14(0.01)$ & $0.16(0.01)$ \\
LD & $0.36(0.01)$ & $0.05(0.01)$ & $0.09(0.01)$ & $0.08(0.01)$ \\
PD & $0.22(0.01)$ & $0.06(0.01)$ & $0.11(0.01)$ & $0.13(0.01)$ \\
MD & $0.35(0.01)$ & $0.03(0.01)$ & $0.06(0.01)$ & $0.10(0.01)$ \\
BF & $0.47(0.01)$ & $0.04(0.01)$ & $0.05(0.01)$ & $0.06(0.01)$ \\
FCR & $0.17(0.01)$ & $0.04(0.01)$ & $0.18(0.01)$ & $0.12(0.01)$ \\
REI & $0.16(0.01)$ & $0.04(0.01)$ & $0.17(0.01)$ & $0.15(0.01)$ \\
RFI & $0.15(0.01)$ & $0.04(0.01)$ & $0.18(0.01)$ & $0.18(0.01)$ \\
\hline II. Crossbred & & & & \\
ADG & $0.26(0.01)$ & $0.05(0.01)$ & $0.08(0.01)$ & $0.10(0.01)$ \\
ALDG & $0.28(0.01)$ & $0.05(0.01)$ & $0.08(0.01)$ & $0.10(0.01)$ \\
ADFI & $0.28(0.03)$ & $0.05(0.01)$ & $0.19(0.01)$ & $0.11(0.02)$ \\
LD & $0.36(0.03)$ & $0.03(0.01)$ & $0.07(0.01)$ & $0.10(0.01)$ \\
PD & $0.33(0.03)$ & $0.05(0.01)$ & $0.07(0.01)$ & $0.12(0.02)$ \\
MD & $0.24(0.02)$ & $0.01(0.01)$ & $0.01(0.01)$ & $0.03(0.01)$ \\
BF & $0.43(0.02)$ & $0.03(0.01)$ & $0.02(0.01)$ & $0.02(0.01)$ \\
FCR & $0.19(0.02)$ & $0.04(0.01)$ & $0.22(0.01)$ & $0.18(0.03)$ \\
REI & $0.02(0.01)$ & $0.21(0.01)$ & $0.17(0.02)$ \\
RFI & $0.02(0.01)$ & $0.23(0.01)$ & $0.18(0.03)$ \\
\hline 1
\end{tabular}

${ }^{1} h^{2}$ is the heritability; $\sigma_{\text {ltr }}^{2}$ is the variance of the common litter; $\sigma_{\text {pen }}^{2}$ is the variance of the contemporary pen; $\sigma_{c o}^{2}$ is the variance of the contemporary compartment; $\sigma_{P}^{2}$ is the phenotypic variance. ${ }^{2} A D G$, average daily gain; ALDG, average lifetime daily gain; ADFI, average daily feed intake; LD, lipid deposition; PD, protein deposition; MD, muscle depth; BF, back fat thickness; FCR, feed conversion rate; $\mathrm{REI}$, residual energy intake; RFI, residual feed intake.

LD, PD and MD were low. BF was strongly negative associated (-0.84) with PD in PB while this association was moderate in CB (-0.47). The $r_{g}$ between LD and BF was almost unity in PB and high in CB. 
Table 2.5 Genetic correlations (standard errors) between purebred and crossbred traits ${ }^{1}$.

\begin{tabular}{ccccccccccc}
\hline & ADG & ALDG & \multirow{2}{*}{ ADFI } & LD & PD & MD & BF & FCR & REI & RFI \\
\hline \multirow{2}{*}{$\mathrm{r}_{\mathrm{pc}}$} & 0.61 & 0.63 & 0.65 & 0.71 & 0.64 & 0.75 & 0.82 & 0.67 & 0.67 & 0.62 \\
& $(0.06)$ & $(0.06)$ & $(0.15)$ & $(0.07)$ & $(0.08)$ & $(0.04)$ & $(0.03)$ & $(0.18)$ & $(0.18)$ & $(0.18)$ \\
\hline
\end{tabular}

${ }^{1} A D G$, average daily gain; ALDG, average lifetime daily gain; ADFI, average daily feed intake; LD, lipid deposition; PD, protein deposition; MD, muscle depth; BF, back fat thickness; FCR, feed conversion rate; $\mathrm{REI}$, residual energy intake; $\mathrm{RFI}$, residual feed intake.

Between FE traits and growth performance and carcass traits, we observed that the $r_{g}$ of FCR with LD, MD and BF were moderate in both $P B$ and $C B$. In PB, FCR had high $r_{g}$ with ADFI, and low $r_{g}$ with growth and PD. In contrast, FCR in CB presented a high $r_{\mathrm{g}}$ with $\mathrm{PD}$, and moderate $r_{\mathrm{g}}$ with growth and ADFI. REI presented moderate $r_{\mathrm{g}}$ with $A D F I, L D, P D$ and $B F$, low $r_{g}$ with $M D$, and was not genetically associated with growth in $\mathrm{PB}$ and $\mathrm{CB}$. The $\mathrm{r}_{\mathrm{g}}$ of RFI was high with ADFI, moderate with growth, PD and $M D$, and low with LD and BF. Among FE traits, we observed that, FCR in PB had high $r_{g}$ with REI and RFI. In contrast, FCR in CB presented moderate $r_{g}$ with REI and RFI. The $r_{g}$ between REI and RFI was 0.84 in PB and 0.90 in CB.

\subsubsection{Response to selection}

The expected response to direct selection on $C B$ performance $\left(R_{C B}\right)$, the expected correlated response for $C B$ performance $\left(C R_{C B}\right)$ to indirect selection on $P B$ performance, and the ratio between them $\left(R_{C B} / C_{C B}\right)$ are presented on Table 2.8. The $R_{C B}$ compared to the $C R_{C B}$ were between 41 and $91 \%$ larger for growth performance traits, 10 and $17 \%$ larger for carcass traits and between 40 and $82 \%$ larger for FE traits.

\subsection{Discussion}

\subsubsection{Variance Components}

The random effects related to the grouping of animals (pen and contemporary compartment) were shown to be important especially for ADFI and FE traits. For FE traits, the amount of the total phenotypic variance that could be attributed to the variance of common group (30 to 41\%) was much higher than the amount accounted for by the additive variance (15 to $19 \%$ ). The variation of these phenotypes was highly influenced by the housing and animal interactions. For FE, the proportion of the variance due to group was higher in $\mathrm{CB}(\approx 40 \%)$ than in $\mathrm{PB}$ ( $\approx 33 \%)$. These results are in agreement with Bergsma et al. (2013) who reported $46 \%$ of the phenotypic variance of REI being accounted for by group effect in a CB 
population and Cai et al. (2008) who reported $30 \%$ of the phenotypic variance of RFI explained by the effect of group in PB.

Comparisons between models that include or exclude the effect of group were presented for traits in growing pigs. If a non-genetic covariance among group mates exists, the group effect should be included in the model to avoid biased genetic parameters estimates (Bijma et al., 2007). Lu et al. (2017) reported around $72 \%$ of the phenotypic variance of six different measures of RFI being accounted for by group effect in a PB population. They concluded that the inclusion of a group effect in mixed animal models is necessary to improve the estimation of genetic parameters in growing pigs. By accounting for the group effect, the amount of the total phenotypic variance of RFI that could be attributed to the additive variance was reduced from around $54 \%$ to around $6 \%$. This reduction was lower for ADG (from $35 \%$ to $23 \%$ ) and for ADFI (from $18 \%$ to $14 \%$ ). The group effect accounted for $55 \%$ and $59 \%$ of the phenotypic variance in ADG and ADFI, respectively. The inclusion of a group effect in the model was also shown to be necessary by Bergsma et al. (2008), to avoid biased estimates of genetic parameters in a population of $C B$ growing pigs. They reported $27.5 \%$ and $42 \%$ of the phenotypic variance accounted for by the group effect in ADG and ADFI, respectively. By accounting for this group effect, the amount of the total phenotypic variance that could be attributed to the additive variance was reduced from $36 \%$ to $25 \%$ for ADG, and from $41 \%$ to $18 \%$ for ADFI.

\subsubsection{Genetic correlation between the performance of $P B$ and $C B$}

The values estimated for $r_{p c}$ (Table 2.5) indicate that genetic progress is being realized in $\mathrm{CB}$ at the production level from selection on $\mathrm{PB}$ performance at nucleus level. When the goal is to improve $C B$ performance, the value of having $C B$ information increases when the $r_{p c}$ decreases (Wei and van der Werf, 1994; Bijma and van Arendonk, 1998). Combined CB and PB selection (CCPS) for CB improved performance was suggested to be worthwhile over $P B$ selection when the $r_{p c}$ is lower than 0.8 (Wei and van der Werf, 1994). Estimate of $r_{p c}$ for BF (0.82) indicate that we should expect less benefit from having $C B$ information combined with $P B$ information for the improvement of the $C B$ performance for BF. For all other traits the values of $r_{p c}$ estimates are 0.75 or lower. Including $C B$ phenotypes recorded on production farms, when predicting breeding values, has the potential to lead to higher genetic progress on these traits in $C B$.

Besides $A D F I$, all other traits are corresponding traits, meaning that they were obtained in different ways in PB or CB. To calculate ADG and ALDG, and thus also $F C R$, the $B W_{\text {offtest }}$ is recorded in $P B$ but in $C B$ it is estimated from the HCW. The 
traits $\mathrm{BF}$ and $\mathrm{MD}$ are measured ultrasonically in live $\mathrm{PB}$ but estimated with a probe in the carcass of $C B$. The traits LD, PD, REI and RFI, are calculated using BW, ADG and $\mathrm{BF}$, traits that are measured differently in $\mathrm{PB}$ and $\mathrm{CB}$. The use of corresponding traits to estimate correlations may have lowered the values of the $r_{p c}$ estimates because they may not fully behave as the same trait. The impact of this is expected to be small.

The values of $r_{p c}$ estimates for growth performance and carcass traits presented in this study are in the range of literature. For the trait FCR, high values ( 0.66 to 0.92 ) have also been obtained in other studies (Nakavisut et al., 2005; Habier et al., 2007; Tussel et al., 2016). To the best of our knowledge, this is the first report of $r_{p c}$ for ADFI, REI and RFI in pigs. The limited number of studies is due to the fact that feed intake, and thus $\mathrm{FE}$, are expensive to measure and therefore not broadly available. Especially in $\mathrm{CB}$, the availability of feed intake data is very low. In the present study, estimation of $r_{p c}$ for these traits was possible given the high number of records on ADFI of crossbreds.

Although records on feed intake are not broadly available in pigs, the expectation was that $r_{p c}$ for ADFI, REI and RFI would not be high given differences concerning health status and housing between nucleus and production farms, among other differences between PB and CB. Knap and Wang (2012) concluded that ADFI as it is recorded in nucleus conditions is not very useful for breeding value estimation of FE in a system that aims to produce commercially fattened pigs. They reported correlations between univariate EBVs of two lines of PB in nucleus farm and their halfsib $C B$ in production conditions. They found moderate correlations between EBV for ADFI ( 0.55 for line S1 and 0.54 for line S2) and extremely low EBVs correlations for RFI (-0.06 for line S1 and 0.06 for line S2). Because these values are based on EBV, they could have been higher depending on the EBV accuracies. Also, no information about the production environment for $C B$ was provided. Large differences from nucleus conditions could have lowered the correlations values. In the current data, management on the current $C B$ farms was better than the average production farm. Our estimates of $r_{p c}$ for ADFI and FE traits are all between 0.62 and 0.67 (Table 2.5), in the same range as other production traits. Part of genetic progress from selection in PB for ADFI, FCR, REI and RFI is therefore being realized in CB performance.

Reduction of $r_{p c}$ below one may not purely be attributable to genetic factors but also to genotype by environment interaction (GxE) given the usual differences between environments where PB and CB are raised (Wei and van der Werf, 1994; Bijma and van Arendonk, 1998; Zumbach et al., 2007; Tussel et al., 2016). When considering estimates of genetic correlations between the performance of PB and 
$\mathrm{CB}$, it is important to remark that this methodology also detects genotype by environment interaction ( $\mathrm{GXE}$ ) considering the same trait as different traits in both environments. In this study, the reduction of $r_{p c}$ estimates below one may also be caused by GXE given the differences between the nucleus environment where PB are maintained and production farms where $\mathrm{CB}$ were raised. Production farms have lower levels of hygiene status and may have different housing systems compared to nucleus farms. These factors affect performance and therefore lower the $r_{p c}$ estimate. Besides the fact that $\mathrm{PB}$ and $\mathrm{CB}$ are not in the same environment, the limited number of $C B$ farms may give raise to $G \times E$ by chance.

Tussel et al. (2016) reported $r_{p c}$ estimates for PB and CB raised at the same time and in the same test station facility. They obtained higher $r_{p c}$ estimated values for ADG (0.79) and FCR (0.89). Habier et al. (2007) also presented $r_{p c}$ estimates of PB and $C B$ raised in the same two stations over a 5 years period with values of 0.88 for $A D G$ and 0.74 for FCR. Stamer et al. (2007) presented $r_{g}$ estimates for 17 growth performance, carcass and meat quality traits of $\mathrm{PB}$ and $\mathrm{CB}$ pigs raised in two housing systems, either in groups of 2 (g2) or 10 pigs (g10). Average $r_{g}$ estimates were 0.87 between the performance of $\mathrm{CB}(\mathrm{g} 2)$ and $\mathrm{CB}(\mathrm{g} 10), 0.72$ between the performance of $\mathrm{PB}(\mathrm{g} 2)$ and $\mathrm{CB}(\mathrm{g} 2)$, and 0.63 between the performance of $\mathrm{PB}(\mathrm{g} 2)$ and $\mathrm{CB}(\mathrm{g} 10)$. The value of 0.63 represents the $r_{\mathrm{g}}$ between traits measured on $\mathrm{PB}$ in one environment ( $\mathrm{g} 2$ ) and measured on $\mathrm{CB}$ in another environment (g10). Effects of $r_{p c}<1$ as well as GxE are possible contributors to the $r_{g}$ of 0.63 being smaller than unity. Indeed, when only $r_{p c}$ was expected to contribute $(\mathrm{PB}(\mathrm{g} 2)$ versus $\mathrm{CB}(\mathrm{g} 2))$ or when only GxE is expected to contribute ( $\mathrm{CB}(\mathrm{g} 2)$ versus $\mathrm{CB}(\mathrm{g} 10)$ ) the genetic correlation was higher than 0.63 . The situation where the performance of $\mathrm{PB}(\mathrm{g} 2)$ and $\mathrm{CB}(\mathrm{g} 10)$ was compared approximates the reality where selection takes place in $\mathrm{PB}$ performance in improved environment and the $\mathrm{CB}$ are raised in larger groups in production farms. In this comparison, an $r_{p c}$ estimate of 0.65 was reported for the trait ADG, which is close to our value for the same trait (0.61). In our $r_{p c}$ estimates, the effects of GxE are likely to be present as shown in Stamer et al (2007).

Moreover, a distinction between effects due to GXE or a truly lowered $r_{p c}$ is not necessary in CCPS, since optimal breeding decisions in both cases are taken based on the same model (Wei and van der Werf, 1994). In our data, we cannot disentangle the effects of $r_{p c}$ and GxE. However, because in practical pork production the environments typically vary together with the breed composition, $\mathrm{PB}$ or $\mathrm{CB}$, our estimates of $r_{p c}$ are relevant measures, even without knowing which part is caused by the different genetic background of the growing animal and which part by the environmental differences between the $\mathrm{PB}$ and $\mathrm{CB}$ growing environment. 
Table 2.6 Genetic correlations ${ }^{1}$ (standard errors) among purebred and crossbred traits ${ }^{2}$.

\begin{tabular}{|c|c|c|c|c|c|c|c|c|c|c|}
\hline & ADG & ALDG & ADFI & LD & PD & MD & $\mathrm{BF}$ & FCR & REI & RFI \\
\hline ADG & & $\begin{array}{c}0.96 \\
(0.01\end{array}$ & $\begin{array}{c}0.66 \\
(0.04)\end{array}$ & $\begin{array}{c}\mathbf{0 . 5 7} \\
(0.04)\end{array}$ & $\begin{array}{c}0.78 \\
(0.02)\end{array}$ & $\begin{array}{c}\mathbf{0 . 1 0} \\
(0.04)\end{array}$ & $\begin{array}{c}-0.05 \\
(0.04)\end{array}$ & $\begin{array}{c}-0.29 \\
(0.07)\end{array}$ & $\begin{array}{c}0.04 \\
(0.07)\end{array}$ & $\begin{array}{c}0.27 \\
(0.07)\end{array}$ \\
\hline ALDG & $\begin{array}{c}0.96 \\
(0.01)\end{array}$ & & $\begin{array}{c}0.67 \\
(0.04)\end{array}$ & $\begin{array}{c}0.58 \\
(0.04)\end{array}$ & $\begin{array}{c}0.73 \\
(0.03)\end{array}$ & $\begin{array}{c}0.07 \\
(0.04)\end{array}$ & $\begin{array}{c}-0.04 \\
(0.04)\end{array}$ & NC & $\begin{array}{c}-0.05 \\
(0.07)\end{array}$ & $\begin{array}{c}0.20 \\
(0.07)\end{array}$ \\
\hline ADFI & $\begin{array}{c}0.71 \\
(0.03)\end{array}$ & $\begin{array}{c}0.72 \\
(0.03)\end{array}$ & & $\begin{array}{c}0.75 \\
(0.03)\end{array}$ & $\begin{array}{c}0.28 \\
(0.07)\end{array}$ & $\begin{array}{l}-0.32 \\
(0.06)\end{array}$ & $\begin{array}{c}0.48 \\
(0.05)\end{array}$ & $\begin{array}{c}\mathbf{0 . 4 9} \\
(0.06)\end{array}$ & $\frac{0.33}{(0.07)}$ & $\frac{0.65}{(0.05)}$ \\
\hline LD & $\begin{array}{c}\mathbf{0 . 6 9} \\
(0.01)\end{array}$ & $\begin{array}{c}0.70 \\
(0.01)\end{array}$ & $\begin{array}{c}0.76 \\
(0.02)\end{array}$ & & $\begin{array}{c}-0.02 \\
(0.06)\end{array}$ & $\begin{array}{c}-0.11 \\
(0.05)\end{array}$ & $\begin{array}{c}0.80 \\
(0.02)\end{array}$ & $\begin{array}{c}0.25 \\
(0.08)\end{array}$ & $\frac{-0.54}{(0.03)}$ & $\frac{0.05}{(0.08)}$ \\
\hline PD & $\begin{array}{c}0.79 \\
(0.01)\end{array}$ & $\begin{array}{c}0.74 \\
(0.01)\end{array}$ & $\begin{array}{c}0.36 \\
(0.04)\end{array}$ & $\begin{array}{c}0.09 \\
(0.02)\end{array}$ & & $\begin{array}{c}0.07 \\
(0.06)\end{array}$ & $\begin{array}{c}-0.49 \\
(0.03)\end{array}$ & $\begin{array}{c}-0.69 \\
(0.03)\end{array}$ & $\begin{array}{c}0.31 \\
(0.08)\end{array}$ & $\begin{array}{c}0.41 \\
(0.07)\end{array}$ \\
\hline $\mathrm{MD}$ & $\begin{array}{l}-0.22 \\
(0.02)\end{array}$ & $\begin{array}{l}-0.24 \\
(0.02)\end{array}$ & $\begin{array}{l}-0.17 \\
(0.04)\end{array}$ & $\begin{array}{l}-0.15 \\
(0.02)\end{array}$ & $\begin{array}{l}-0.14 \\
(0.02)\end{array}$ & & $\begin{array}{l}-0.07 \\
(0.04)\end{array}$ & $\begin{array}{c}-0.33 \\
(0.07)\end{array}$ & $\begin{array}{c}-0.18 \\
(0.04)\end{array}$ & $\begin{array}{c}-0.32 \\
(0.06)\end{array}$ \\
\hline BF & $\begin{array}{c}0.24 \\
(0.02)\end{array}$ & $\begin{array}{c}0.27 \\
(0.02)\end{array}$ & NC & $\begin{array}{c}0.99 \\
(0.01)\end{array}$ & $\begin{array}{c}-0.84 \\
(0.01)\end{array}$ & $\begin{array}{l}-0.07 \\
(0.01)\end{array}$ & & $\begin{array}{c}0.49 \\
(0.06)\end{array}$ & $\frac{-0.29}{(0.06)}$ & $\frac{-0.06}{(0.06)}$ \\
\hline FCR & $\begin{array}{c}0.08 \\
(0.05)\end{array}$ & $\begin{array}{c}0.19 \\
(0.05)\end{array}$ & $\begin{array}{c}0.71 \\
(0.03)\end{array}$ & $\begin{array}{c}0.34 \\
(0.04)\end{array}$ & $\begin{array}{c}-0.15 \\
(0.05)\end{array}$ & $\begin{array}{l}-0.19 \\
(0.04)\end{array}$ & $\begin{array}{c}0.37 \\
(0.04)\end{array}$ & & $\begin{array}{c}0.53 \\
(0.07)\end{array}$ & $\begin{array}{c}0.55 \\
(0.06)\end{array}$ \\
\hline REI & $\frac{0.02}{(0.05)}$ & $\frac{-0.04}{(0.05)}$ & $\frac{0.37}{(0.05)}$ & $\frac{-0.32}{(0.04)}$ & $\begin{array}{c}0.24 \\
(0.05)\end{array}$ & $\begin{array}{l}-0.12 \\
(0.04)\end{array}$ & $\frac{-0.45}{(0.04)}$ & $\frac{0.70}{(0.03)}$ & & $\begin{array}{c}0.90 \\
(0.02)\end{array}$ \\
\hline RFI & $\frac{0.34}{(0.05)}$ & $\frac{0.32}{(0.05)}$ & $\frac{0.73}{(0.03)}$ & $\frac{0.20}{(0.05)}$ & $\begin{array}{c}0.32 \\
(0.05)\end{array}$ & $\begin{array}{l}-0.21 \\
(0.04)\end{array}$ & $\frac{-0.03}{(0.05)}$ & $\frac{\mathbf{0 . 8 2}}{(0.02)}$ & $\begin{array}{c}0.84 \\
(0.02)\end{array}$ & \\
\hline
\end{tabular}

${ }^{1}$ Genetic correlations among purebred traits below and among crossbred traits above diagonal. ${ }^{2} A D G$, average daily gain; ALDG, average lifetime daily gain; ADFI, average daily feed intake; LD, lipid deposition; PD, protein deposition; MD, muscle depth; BF, back fat thickness; FCR, feed conversion rate; REI, residual energy intake; RFI, residual feed intake. $\mathrm{NC}$, analysis has not converged. Correlations in italic do not differ significantly from zero, in bold do differ in PB and CB and underlined do differ in both REI and RFI $(p<0.01)$.

\subsubsection{Genetic correlation between growth performance and carcass traits within PB and CB}

Depending on the genetic background of the animals ( $P B$ or $C B$ ), the genetic association between traits changes between favorable and unfavorable or values are changing (Table 2.6). The differences in signs and magnitudes of $r_{g}$ in PB and CB are relevant for a breeding program aiming at $C B$ performance. Less $B F$ is genetic associated with more PD with the estimate being higher in PB than in CB. On the other hand, more growth was associated with more LD with the estimate being higher in $\mathrm{PB}$ than in CB. Differences in the sign of $r_{\mathrm{g}}$ were found between gain and $M D$, gain and $B F$, and $M D$ and $P D$ with the favorable values in $C B$. In a multitrait breeding program, these favorable correlations could lead to a larger overall genetic response with data collection in CB compared to the same program in PB.

\subsubsection{Comparison between FE traits}


Table 2.7 Phenotypic correlations ${ }^{1}$ (standard errors) among purebred and crossbred traits ${ }^{2}$.

\begin{tabular}{|c|c|c|c|c|c|c|c|c|c|c|}
\hline & ADG & ALDG & ADFI & LD & PD & MD & $\mathrm{BF}$ & FCR & REI & RFI \\
\hline ADG & & $\begin{array}{c}\mathbf{0 . 8 5} \\
(0.01)\end{array}$ & $\begin{array}{c}\mathbf{0 . 5 2} \\
(0.01)\end{array}$ & $\begin{array}{c}\mathbf{0 . 6 3} \\
(0.01)\end{array}$ & $\begin{array}{c}\mathbf{0 . 7 8} \\
(0.01)\end{array}$ & $\begin{array}{c}0.05 \\
(0.01)\end{array}$ & $\begin{array}{c}\mathbf{0 . 1 2} \\
(0.01)\end{array}$ & $\begin{array}{c}-0.32 \\
(0.02)\end{array}$ & NC & $\begin{array}{c}0.05 \\
(0.02)\end{array}$ \\
\hline ALDG & $\begin{array}{c}0.92 \\
(0.01)\end{array}$ & & $\begin{array}{c}0.50 \\
(0.02)\end{array}$ & $\begin{array}{c}0.63 \\
(0.01)\end{array}$ & $\begin{array}{c}\mathbf{0 . 6 9} \\
(0.01)\end{array}$ & $\begin{array}{c}\mathbf{0 . 0 4} \\
(0.01)\end{array}$ & $\begin{array}{c}0.09 \\
(0.01)\end{array}$ & NC & $\frac{-0.20}{(0.02)}$ & $\frac{0.02}{(0.02)}$ \\
\hline ADFI & $\begin{array}{c}\mathbf{0 . 4 7} \\
(0.01)\end{array}$ & $\begin{array}{c}0.47 \\
(0.01)\end{array}$ & & $\begin{array}{c}0.56 \\
(0.01)\end{array}$ & $\begin{array}{c}0.25 \\
(0.02)\end{array}$ & $\begin{array}{l}-0.08 \\
(0.01)\end{array}$ & $\begin{array}{c}0.30 \\
(0.01)\end{array}$ & $\begin{array}{c}\mathbf{0 . 5 4} \\
(0.01)\end{array}$ & $\frac{\mathbf{0 . 5 1}}{(0.01)}$ & $\frac{\underline{0.70}}{(0.01)}$ \\
\hline LD & $\begin{array}{c}\mathbf{0 . 7 2} \\
(0.01)\end{array}$ & $\begin{array}{c}\mathbf{0 . 7 0} \\
(0.01)\end{array}$ & $\begin{array}{c}0.54 \\
(0.01)\end{array}$ & & $\begin{array}{c}0.09 \\
(0.02)\end{array}$ & $\begin{array}{l}-0.13 \\
(0.01)\end{array}$ & $\begin{array}{c}0.59 \\
(0.01)\end{array}$ & $\begin{array}{c}0.05 \\
(0.02)\end{array}$ & $\frac{-0.44}{(0.01)}$ & $\frac{-0.09}{(0.02)}$ \\
\hline PD & $\begin{array}{c}\mathbf{0 . 8 7} \\
(0.01)\end{array}$ & $\begin{array}{c}\mathbf{0 . 7 9} \\
(0.01)\end{array}$ & $\begin{array}{c}0.29 \\
(0.01)\end{array}$ & $\begin{array}{c}0.33 \\
(0.01)\end{array}$ & & $\begin{array}{l}-0.02 \\
(0.01)\end{array}$ & $\begin{array}{c}-0.30 \\
(0.01)\end{array}$ & $\begin{array}{c}-0.47 \\
(0.01)\end{array}$ & $\frac{\mathbf{0 . 0 4}}{(0.02)}$ & $\frac{\underline{0.13}}{(0.02)}$ \\
\hline MD & $\begin{array}{c}-0.08 \\
(0.01)\end{array}$ & $\begin{array}{c}-0.09 \\
(0.01)\end{array}$ & $\begin{array}{l}-0.06 \\
(0.01)\end{array}$ & $\begin{array}{c}-0.01 \\
(0.01)\end{array}$ & $\begin{array}{l}-0.07 \\
(0.01)\end{array}$ & & $\begin{array}{c}-0.03 \\
(0.01)\end{array}$ & $\begin{array}{c}-0.07 \\
(0.01)\end{array}$ & $\begin{array}{c}-0.08 \\
(0.01)\end{array}$ & $\begin{array}{c}-0.08 \\
(0.01)\end{array}$ \\
\hline BF & $\begin{array}{c}0.20 \\
(0.01)\end{array}$ & $\begin{array}{c}\mathbf{0 . 1 8} \\
(0.01)\end{array}$ & $\mathrm{NC}$ & $\begin{array}{c}0.98 \\
(0.01)\end{array}$ & $\begin{array}{c}-0.77 \\
(0.01)\end{array}$ & $\begin{array}{c}0.01 \\
(0.01)\end{array}$ & & $\begin{array}{c}0.16 \\
(0.01)\end{array}$ & $\frac{-0.17}{(0.01)}$ & $\frac{-0.04}{(0.01)}$ \\
\hline FCR & $\begin{array}{l}-0.23 \\
(0.01)\end{array}$ & $\begin{array}{l}-0.11 \\
(0.01)\end{array}$ & $\begin{array}{c}0.64 \\
(0.01)\end{array}$ & $\begin{array}{c}0.03 \\
(0.01)\end{array}$ & $\begin{array}{c}-0.29 \\
(0.01)\end{array}$ & $\begin{array}{l}-0.03 \\
(0.01)\end{array}$ & $\begin{array}{c}0.19 \\
(0.01)\end{array}$ & & $\begin{array}{c}\mathbf{0 . 7 7} \\
(0.01)\end{array}$ & $\begin{array}{c}\mathbf{0 . 7 7} \\
(0.01)\end{array}$ \\
\hline REI & $\frac{-0.25}{(0.01)}$ & $\frac{-0.28}{(0.01)}$ & $\frac{0.57}{(0.01)}$ & $\frac{-0.36}{(0.01)}$ & $\frac{-0.09}{(0.01)}$ & $\begin{array}{l}-0.05 \\
(0.01)\end{array}$ & $\frac{-0.28}{(0.01)}$ & $\begin{array}{c}0.85 \\
(0.01)\end{array}$ & & $\begin{array}{c}0.95 \\
(0.01)\end{array}$ \\
\hline RFI & $\frac{0.03}{(0.01)}$ & $\frac{-0.02}{(0.01)}$ & $\frac{\mathbf{0 . 7 7}}{(0.01)}$ & $\frac{-0.01}{(0.01)}$ & $\frac{\underline{0.05}}{(0.01)}$ & $\begin{array}{l}-0.06 \\
(0.01)\end{array}$ & $\frac{-0.04}{(0.01)}$ & $\begin{array}{c}\mathbf{0 . 8 4} \\
(0.01)\end{array}$ & $\begin{array}{c}0.92 \\
(0.01)\end{array}$ & \\
\hline
\end{tabular}

${ }^{1}$ Phenotypic correlations among purebred traits below and among crossbred traits above diagonal. ${ }^{2} A D G$, average daily gain; ALDG, average lifetime daily gain; ADFI, average daily feed intake; LD, lipid deposition; PD, protein deposition; MD, muscle depth; BF, back fat thickness; FCR, feed conversion rate; REI, residual energy intake; RFI, residual feed intake. $\mathrm{NC}$, analysis has not converged. Correlations in italic do not differ significantly from zero, in bold do differ in PB and CB and underlined do differ in both REI and RFI $(p<0.01)$.

The high $r_{\mathrm{g}}$ between REI and RFI indicate that they largely explain the same genetic variance, both in $\mathrm{PB}$ and $\mathrm{CB}$ (Table 2.6). In addition, the high $r_{\mathrm{g}}$ found between these traits and FCR indicates that genetic progress based on any one of them will improve the other traits. However, we observe differences between the FE traits when it comes to their $r_{g}$ with growth performance and carcass traits. Thus, the total genetic gain on the breeding goal can be influenced by the choice of trait that is used to measure FE.

In contrast with FCR and REI, RFI was phenotypically independent from growth performance and carcass traits, both in PB and CB (Table 2.7). This independency has been reported as an advantage of RFI over FCR (de Haer et al., 1993; Kennedy et al., 1993) because it captures variance on FE not accounted for by its component traits. FCR presented a favorable genetic correlation with all other traits in PB and $\mathrm{CB}$ with moderate or high values. The favorable correlations with all other production traits mean that selection on production traits will result in progress for FCR. Therefore, FCR is of limited interest to breeders because the trait has low 
potential to capture variance in FE due to others effects rather than its components traits (Patience, 2012).

The pattern of $r_{g}$ estimates of REI with the other studied traits in PB and CB are preferable over the pattern of $r_{g}$ estimates of RFI with those other traits for several reasons. First, REI shows no $r_{\mathrm{g}}$ with growth while RFI has an unfavorable moderate $r_{g}$. Second, values of $r_{g}$ between REI and the traits MD, PD, and ADFI were lower than between these traits and RFI. Lower values of $r_{g}$ with production traits imply that REI captures other sources of variance. It is remarkable that the $r_{\mathrm{g}}$ between REI and ADFI is only half the size of $r_{g}$ between RFI and ADFI. Finally, we note that $r_{g}$ of PD with RFI as well as PD with REI were unfavorable with higher values for the correlation with RFI. On the other hand, RFI shows no genetic association with BF and $L D$ in $C B$, and with BF in PB. The $r_{g}$ between RFI and LD in PB was favorable and of low magnitude. In contrast, unfavorable $r_{g}$ were found between REI and BF and between REI and LD in both $\mathrm{PB}$ and $\mathrm{CB}$ with moderate values. Phenotypic correlations between these traits were also unfavorable with moderate values. Except for the unfavorable correlations with BF and LD, our findings indicate that $\mathrm{REI}$ is an attractive trait since it is genetically independent from growth and present lower correlations with ADFI and thus has a great potential to capture other sources of variation in FE that is not explained by ADFI.

In grower-finishers, energy usage is divided into energy used for growth (lipid and protein deposition) and for maintenance. One third of the total daily supply of energy is devoted to maintenance (Patience, 2012), which makes variation in energy required for animal maintenance a major factor in the variation in FE. From this point of view, energy for maintenance should be in the equation of FE. Henken et al. (1991) showed the presence of genetic variation in maintenance requirements in pigs being due to differences in physical activity and heat production. This fits with our results that leaner animals have higher REI. A possible explanation is that leaner animals are more active and thus have a higher energy requirement for maintenance. This hypothesis is supported by Boddicker et al. (2011) who also indicated maintenance requirement as one of the main factors contributing for variation in RFI. Low RFI pigs spent less time in feeders, have reduced numbers of meals and high consumption rate when in feeders (De Haer et al., 1993). Selection on RFI has been shown to be associated with animal characteristics that are related to energy cost (Shirali, 2014). Reduced maintenance energy requirements, reduced physical activity, and thus reduced heat production of pigs selected downward for RFI has shown to greatly contributed to the gain in energy efficiency (Gilbert et al., 2016). Low RFI pigs are therefore desired because 
of the advantages of spending less energy on feed consumption, interacting with others, heat production and maintenance requirements.

\subsubsection{Response to selection}

Differences between the additive genetic variance (not shown) and the heritability estimates in PB and CB (Table 2.4), the intensity of selection applied in PB and CB, and the $r_{p c}$ (Table 2.5) will impact the genetic gain (Table 2.8) that can be achieved in $\mathrm{CB}$ performance when selecting based on $\mathrm{PB}$ or $\mathrm{CB}$ performance. When the goal is the $C B$ performance, the benefit of direct selection on $C B$ performance $\left(R_{C B}\right)$ over the indirect selection on $\mathrm{PB}$ performance $\left(\mathrm{CR}_{\mathrm{CB}}\right)$ can be assessed by the ratio between them $\left(R_{C B} / C_{C B}\right)$. When the intensity of selection is equal in $P B$ and $C B$, this ratio is assessed by $h_{C B}$ divided by $h_{P B} \times r_{p c}$ (Falconer and Mackay, 1996). Thus, with higher $h_{C B}$, relative to $h_{P B}$, and with lower $r_{p c}$, the benefit of direct selecting based on $C B$ performance increases. $R_{C B}$ was higher than $C R_{C B}$ for all traits meaning that direct selection on $\mathrm{CB}$ performance would lead to higher response to selection for all traits.

Carcass traits presented lower heritability estimates in CB than in PB. Also, the $r_{p c}$ were higher compared to growth performance and FE traits. Therefore, While $R_{C B}$ was still superior, it was lower for these traits (10 to 17\%). Traditionally, data recording for breeding programs in pigs is organized at the nucleus level on PB animals. Given the limited benefit in response from direct selection on $C B$ performance, the extra cost of data recording on $C B$ may not be worthwhile for carcass traits. Because heritability estimates in $C B$ are higher compared to $P B$ for ADG, ALDG, PD, ADFI and RFI (Table 2.4), and given the values of $r_{p c}$ (Table 2.5), the direct selection on $C B$ performance will lead to between 70 and $91 \%$ higher genetic gain for these traits. Because heritability estimates in $\mathrm{PB}$ and $\mathrm{CB}$ are equal or similar for $L D, F C R$ and $R E I$, and given the values of $r_{p c}$ (Table 2.5), the direct selection on CB performance will lead to between 40 and $49 \%$ higher genetic gain.

\section{5 conclusions}

Genetic progress is being realized in $C B$ at the production level from selection on PB performance at nucleus level for growth and carcass traits and also for FE traits. Including CB phenotypes recorded on production farms, when predicting breeding values, has the potential to increase genetic progress for the performance in $C B$. Given the $r_{g}$ between growth performance and carcass traits, a larger overall genetic response in a multitrait breeding program could be expected with data collection in $\mathrm{CB}$ compared to the same program in PB. Group effects are major sources of variation in ADFI and FE traits. Given the $r_{g}$ with growth performance 
traits and the genetic correlation between the performance of $\mathrm{PB}$ and $\mathrm{CB}$, residual energy intake is an attractive FE parameter for a breeding program.

\subsection{References}

Bergsma, R., E. Kanis, E. F. Knol, and P. Bijma. 2008. The contribution of social effects to heritable variation in finishing traits of domestic pigs (Sus scrofa). Genetics 178:1559-1570.

Bergsma, R., P. K. Mathur, E. Kanis, M. W. A. Verstegen, E. F. Knol, and J. A. M. van Arendonk. 2013. Genetic correlations between lactation performance and growing-finishing traits in pigs. J. Anim. Sci. 91:3601-3611.

Bijma, P., and J. A. van Arendonk. 1998. Maximizing genetic gain for the sire line of a crossbreeding scheme utilizing both purebred and crossbred information. J. Anim. Sci. 66:529-542.

Bijma, P., W. M. Muir, E. D. Ellen, J. B. Wolf, and J. A. van Arendonk. 2007. Multilevel selection 2: Estimating the genetic parameters determining inheritance and response to selection. Genetics 175:289-299.

Boddicker, N., N. K. Gabler, M. E. Spurlock, D. Nettleton, and J. C. M. Dekkers. 2011. Effects of ad libitum and restricted feeding on early production performance and body composition of Yorkshire pigs selected for reduced residual feed intake. Animal 5:1344-1353.

Cai, W., D. S. Casey, and J. C. M. Dekkers. 2008. Selection response and genetic parameters for residual feed intake in Yorkshire swine. J. Anim. Sci. 86:287-298.

De Greef, K. H., M. W. A. Verstegen, B. Kemp, and P. L. van der Togt. 1994. The effect of body weight and energy intake on the composition of deposited tissue in pigs. Anim. Prod. 58:263-270.

De Haer, L., L. C. M. Luiting, and H. L. M. Aarts. 1993. Relations among individual (residual) feed intake, growth performance and feed intake pattern of growing pigs in group housing. Livest. Prod. Sci. 36:223-232.

Falconer, D.S. and T.F.C. Mackay. 1996. Introduction to Quantitative Genetics. Longman, Essex, UK.

Gilbert, H., Y. Billon, L. Brossard, J. Faure, P. Gatellier, F. Gondret, E. Labussière, B. Lebret, L. Lefaucheur, N. le Floch, I. Louveau, E. Merlot, M. -C. Meunier-Salaün, L. Montagne, P. Mormede, D. Renaudeau, J. Riquet, C. Rogel-Gaillard, J. van Milgen, A. Vincent, and J. Noblet. 2017. Review: divergent selection for residual feed intake in the growing pig. Animal 1-13.

Gilmour, A. R., B. J. Gogel, B. R. Cullis, and R. Thompson. 2009. ASReml User Guide Release 3.0 VSN International Ltd, Hemel Hempstead, HP1 1ES, UK. 
Habier, D., K. -U Götz, and L. Dempfle. 2007. Estimation of genetic parameters on test stations using purebred and crossbred progeny of sires of the Bavarian Piétrain. J. Livest. Sci. 107:142-151.

Handboek varkenshouderij. 2004. ISSN 1570-8632. p. 312.

Henken, A. M., W. van der Hel, H. A. Brandsma, and M. W. A. Verstegen. 1991. Difference in energy metabolism and protein retention of limit-fed growing pigs of several breeds. J. Anim. Sci. 69:1443-1453.

Kennedy, B. W., J. H. J. van der Werf, and T. H. E. Meuwissen. 1993. Genetic and statistical properties of residual feed intake. J. Anim. Sci. 71:3239-3250.

Knap, P., and L. Wang. 2012. Pig breeding for improved feed efficiency. In: J. F. Patience, Feed efficiency in swine. Wageningen Academic Publishers, Wageningen, the Netherlands. p. 167-181.

Lu, D., S. Jiao, F. Tiezzi, M. Knauer, Y. Huang, K. A. Gray, and C. Maltecca. 2017. The relationship between different measures of feed efficiency and feeding behaviour traits in Duroc pigs. J. Anim. Sci. 95:3370-3380.

Nakavisut, S., R. Crump, M. Suarez, and H-U. Graser. 2005. Genetic correlations between the performance of purebred and crossbred pigs. Proc. Assoc. Advmt. Anim. Breed. Genet. 16:99-102.

Neeteson-van Nieuwenhoven, A. M., P. Knap, and S. Avendano. 2013. The role of sustainable commercial pig and poultry breeding for food security. Anim. Front. 3:52-57.

Patience, J. P. 2012. The influence of dietary energy on feed efficiency in growfinish swine. Pages 101-129 In: J. F. Patience, Feed efficiency in swine. Wageningen Academic Publishers, Wageningen, the Netherlands. p. 101-129.

Roso, V. M. and F. S. Schenkel. 2006. AMC - A computer program to assess the degree of connectedness among contemporary groups. In: Proc. 8th World Congr. Genet. Appl. Livest., Belo Horizonte, Brazil. p.27-26.

Shirali, M. 2014. Improvement of energy and nitrogen utilization in pork production -genetics and growth models-. PhD Thesis, Wageningen University and Research, Wageningen, the Netherlands.

Stamer, E., W. Brade, and E. Kalm. 2007. Genetische Beziehungen zwischen Reinzucht- und Kreuzungsleistungen sowie verschiedenen Prüfumwelten beim Schwein, untersucht am Material niedersächsischer Prüfstationen. Züchtungskunde. 79:298-308.

Tusell, L., H. Gilbert, J. Riquet, M. J. Mercat, A. Legarra, and C. Larzul. 2016. Pedigree and genomic evaluation of pigs using a terminal-cross model. Genet. Sel. Evol. 48:32. 
Wei, M., and J. H. J. van der Werf. 1994. Maximizing genetic response in crossbreds using both purebred and crossbred information. Anim. Produc. 59:401-413.

Zumbach, B., I. Misztal, S. Tsuruta, J. Holl, W. Herring, and T. Long. 2007. Genetic correlations between two strains of Durocs and crossbreds from differing production environments for slaughter traits. J. Anim. Sci. 85: 901-908. 


\section{Genotype by feed interaction for feed efficiency and growth performance traits in pigs}

Rodrigo M Godinho ${ }^{1,2}$, John WM Bastiaansen ${ }^{2},+$ Claudia A Sevillano ${ }^{2,3}$, Fabyano F Silva ${ }^{1}$, Simone EF Guimarães ${ }^{1}$, Rob Bergsma ${ }^{3}$

${ }^{1}$ Department of Animal Science, Universidade Federal de Viçosa, 36570-900, Viçosa, Brazil; 'Wageningen University \& Research Animal Breeding and Genomics, $6700 \mathrm{AH}$, Wageningen, the Netherlands; ${ }^{3}$ Topigs Norsvin Research Center, 6640 AA, Beuningen, the Netherlands.

Journal of Animal Science (2018) doi.org/10.1093/jas/sky304 


\begin{abstract}
A major objective of pork producers is to reduce production cost. Feeding may account for over $75 \%$ of pork production costs. Thus, selecting pigs for feed efficiency (FE) traits is a priority in pig breeding programs. While in the Americas, pigs are typically fed high-input diets, based on corn and soybean meal (CS); in Western Europe, pigs are commonly fed diets based on wheat and barley with high amounts of added protein rich co-products (WB); e.g., from milling and seed-oil industries. These two feeding scenarios provided a realistic setting for investigating a specific type of genotype by environment interaction; thus, we investigated the genotype by feed interaction (GxF). In the presence of a GxF, different feed compositions should be considered when selecting for FE. This study aimed to 1 ) verify the presence of a GXF for FE and growth performance traits in different growth phases (starter, grower and finisher) of three-way crossbred growingfinishing pigs fed either a CS (547 boars and 558 gilts) or WB (567 boars and 558 gilts) diet; and 2) assess and compare the expected responses to direct selection under the two diets and the expected correlated responses for one diet to indirect selection under the other diet. We found that GxF did not interfere in the ranking of genotypes under both diets for growth, protein deposition, feed intake, energy intake, or feed conversion rate. Therefore, for these traits, we recommend changing the diet of growing-finishing pigs from high-input feed (i.e., CS) to feed with less valuable ingredients, as WB, to reduce production costs and the environmental impact, regardless of which diet is used in selection. We found that GxF interfered in the ranking of genotypes and caused heterogeneity of genetic variance under both diets for lipid deposition (LD), residual energy intake (REI), and residual feed intake (RFI). Thus, selecting pigs under a diet different from the diet used for growing-finishing performance could compromise the LD in all growth phases, compromise the REI and RFI during the starter phase, and severely compromise the REI during the grower phase. In particular, when pigs are required to consume a WB diet for growing-finishing performance, pigs should be selected for FE under the same diet. Breeding pigs for FE under lower-input diets should be considered, because FE traits will become more important and lower-input diets will become more widespread in the near future.
\end{abstract}

Key words: breeding program, correlated response, feed efficiency, genetic gain, genotype by feed interaction 


\subsection{Introduction}

A major objective of pork producers is to reduce production costs. Feeding may account for over $75 \%$ of pork production costs (Ali et al., 2017). Thus, selecting pigs based on feed efficiency (FE) traits is a priority in pig breeding programs. Average daily feed intake (ADFI) and residual feed intake (RFI), were shown to be more environmentally sensitive than the average daily gain (ADG) and back-fat thickness (BF) in growing-finishing pigs (Knap and Wang, 2012). Indeed, in addition to differences in climate (Bloemhof et al., 2012; Sevillano et al., 2016) and typical differences in health status and farm management (Mathur et al., 2014; HerreroMedrano et al., 2015), feed content can be a major source of environmental variation. Differences in feed content can give rise to a specific type of genotype by environment interaction (GXE), the interaction between genotype and feed (GxF). While in the Americas, pigs are typically fed high-input diets based on corn and soybean meal (corn/soy); in Western Europe, pigs are commonly fed diets based on wheat and barley, with high amounts of added protein-rich co-products, like rapeseed and sunflower seed meals (wheat/barley/co-products). Thus, in the presence of GxF, selecting pigs for FE should take into account the different feed compositions.

It is widely known that the nutritional requirements of pigs change during the growing-finishing period, and thus, different diets are designed to meet the requirements of pigs in each growth phase. However, there is a lack of information about the genetic characteristics of FE during different growth phases (Shirali et al., 2014). In addition, because pigs are fed different diets in the different growth phases, the level of GxF can be expected to change in the different phases. Therefore, the current study aimed to 1) verify the presence of GxF for FE and growth performance traits in different growth phases (starter, grower and finisher) of three-way crossbred pigs fed diets of corn/soy or wheat/barley/co-products; and 2 ) assess and compare the expected responses to direct selection under the two diets, and the expected correlated response in one diet to indirect selection under the other diet.

\subsection{Material and methods}

\subsubsection{Ethic statement}

Data for this study were collected at the Schothorst Feed Research B.V. farm during data recordings routinely performed in a commercial breeding program. All farm 
operations strictly adhered to Dutch legal regulations regarding the protection of animals (Gezondheids- en welzijnswetvoordieren).

\subsubsection{Data}

We retrieved phenotypic records for 2,230 three-way crossbred pigs offspring of F1 sows (product of a Large White line crossed with one of two Landrace lines) sired by a synthetic sire line. The experiments were conducted in Schothorst Feed Research facilities (Lelystad, the Netherlands), under near commercial production conditions. We tested 29 successive batches of pigs. Each batch comprised a single contemporary group entrance on test and was allocated entirely in one of seven compartments on the farm available for the experiment. Each compartment had 8 pens and, a minimum of 7 and maximum of 10 pigs were allocated per pen. Pigs were put on test at around $22 \mathrm{~kg}$, and were taken off test and slaughtered at around $122 \mathrm{~kg}$ (Table 3.1). The test period lasted around 106 days. The experimental design was a split-plot $2 \times 2$ factorial arrangement. The factors were diet (corn/soy and wheat/barley/co-products) and sex (boars and gilts). Littermates were evenly distributed between the diets to ensure no difference in the genetic background of pigs fed either diet. In total, 547 boars and 558 gilts were fed corn/soy, and 567 boars and 558 gilts were fed wheat/barley/co-products. Pedigree records were available for all animals, up to a maximum of 9 generations. A total of 3,991 animals were included in the pedigree file, with 608 different sires and 1,065 different dams.

\subsubsection{Diets}

Pigs were fed ad libitum according to a 3-phase feeding program that mirrored the three growth phases: starter from day 0 to day 25, grower from day 26 to day 67, and finisher from day 68 to slaughter, when pigs achieved around $120 \mathrm{~kg}$. For details on the feeding program and the diet formulations, see Sevillano et al. (2018). In brief, pigs were assigned to one of two target diets (TD). One diet was based on corn/soy, and the other diet was based on wheat/barley/co-products. Both diets were formulated to supply sufficient digestible amino acids in each growth phase to meet or exceed the nutrient requirements of growing-finishing pigs, according to CVB (Centraal Veevoederbureau, 2011). To ensure a fair comparison between the two feeding scenarios, the two diets were formulated with a similar NE/digestible-lysine ratio and similar NE and crude protein contents. The corn/soy diet had a higher starch content than the wheat/barley/co-products diet. Conversely, compared to the corn/soy diet, the wheat/barley/co-products diet had a higher non-starch polysaccharide content, due to the high amount of co- 
products, and a higher crude fat content, due to the lipids added to increase the final NE content.

\subsubsection{Traits}

BW (kg) was recorded in individuals at the start (day 0), in the middle (day 54), and at the end (around day 107) of the test period. At the end of the test period, BF was measured in all animals with the CGM (Capteur Gras Maigre, Sydel, France) at slaughter (Table 3.1). Individual daily feed intake was recorded with IVOG feeding stations (Insentec, Marknesse, the Netherlands). The test period was divided into 3 periods, according to the feeding program, which followed the growth phases; i.e., starter, grower and finisher phases. Pigs' BW were adjusted to the pig's age at the time the feeding phase changed (Table 3.1). Traits were calculated for each feeding phase and for the overall test period (Table 3.2).

Table 3.1 Mean, standard deviation, minimum and maximum for pigs' age, performance on test, body weight and back fat thickness.

\begin{tabular}{|c|c|c|c|c|c|c|c|c|}
\hline \multirow[b]{2}{*}{ Traits } & \multicolumn{4}{|c|}{ CS } & \multicolumn{4}{|c|}{ WB } \\
\hline & $\mu$ & SD & Min & Max & $\mu$ & SD & Min & Max \\
\hline Age_ontest, d & 62 & 2.1 & 54 & 69 & 62 & 2.1 & 54 & 68 \\
\hline Age_midtest, $d$ & 117 & 2.4 & 109 & 124 & 117 & 2.4 & 109 & 123 \\
\hline Age_offtest, d & 169 & 8.3 & 141 & 188 & 168 & 8.3 & 141 & 187 \\
\hline Test_length, d & 107 & 8.3 & 81 & 125 & 106 & 8.5 & 81 & 125 \\
\hline BW_starter, kg & 22 & 3.2 & 12 & 39 & 23 & 3.3 & 14 & 34 \\
\hline BW_grower ${ }^{1}, \mathrm{~kg}$ & 45 & 4.8 & 30 & 62 & 46 & 4.8 & 31 & 63 \\
\hline BW_midtest, kg & 70 & 7.6 & 44 & 93 & 71 & 7.6 & 45 & 98 \\
\hline BW_finisher ${ }^{1}$, kg & 84 & 7.9 & 59 & 114 & 85 & 8.1 & 50 & 115 \\
\hline BW_slaughter, kg & 122 & 8.2 & 91 & 155 & 122 & 8.6 & 64 & 147 \\
\hline BF_offtest, mm & 12 & 2.1 & 7 & 20 & 11 & 1.8 & 6 & 18 \\
\hline
\end{tabular}

$\mathrm{CS}$, diet based on corn and soybean meal; WB, diet based on wheat and barley with high addition of co-products; $\mathrm{BF}$, back fat thickness; ${ }^{1} \mathrm{BW}$ adjusted for the age pig had when feeding program changed.

We analyzed traits related to the FE, including the feed conversion rate (FCR), residual energy intake (REI), and residual feed intake (RFI). In addition, we analyzed other growing-finishing traits, including the average daily gain on test (ADG), average daily feed intake (ADFI), average daily energy intake (ADEI), lipid deposition (LD), and protein deposition (PD). The latter traits were included to 
assess whether GxF was detectable in traits that were potentially less environmentally sensitive. The ADG (g/d) was defined as the change in the live BW from the beginning to the end of the phase, divided by the length of the phase. ADFI $(g / d)$ was defined as the cumulative feed intake during the phase, divided by the length of the phase. The ADEI $(\mathrm{MJ} / \mathrm{d})$ was defined as the cumulative metabolizable energy ( $M E$ ) intake during the phase, divided by the length of the phase. $L D(g / d)$ and PD $(g / d)$ were estimated as the increments in lipid and protein masses, respectively, during the phase, based on the BW and BF measurements (de Greef et al., 1994), as follows:

$\%$ fat $_{\text {end }}=\frac{B F, m m-1.87}{53.3}$,

$\%$ fat $_{\text {start }}=\%$ fat $_{\text {end }} \times \frac{-0.000005\left(B W_{\text {start }}\right)^{2}+0.0019\left(B W_{\text {start }}\right)+0.0665}{-0.000005\left(B W_{\text {end }}\right)^{2}+0.0019\left(B W_{\text {end }}\right)+0.0665}$,

Protein water ratio $=5.39(B W \times 0.14)^{-0.145}$,

Ash $=0.03 \times B W$,

Lipid mass $(L M)=\%$ fat $\times 0.95 \times B W$,

Protein mass $(P M)=\frac{0.95 \times B W-L M-\text { Ash }}{\text { Protein water ratio }+1^{\prime}}$

$L D=\frac{\left(L M_{\text {end }}-L M_{\text {start }}\right) \times 1000}{\text { Test length,d }}$,

$P D=\frac{\left(P M_{\text {end }}-P M_{\text {start }}\right) \times 1000}{\text { Test length,d }}$

The FCR was calculated as the ADFI divided by the ADG. The REI $(g / d)$, which represents the efficiency of energy metabolism, was calculated as a linear function of energy intake, energy required for maintenance of live BW and energy required for lipid and protein accretion (Bergsma et al., 2013), as follows:

$$
R E I=\frac{A D F I \times M E_{\text {diet }}-M E_{m}-(L D+P D) \times 53}{M E_{\text {diet }}},
$$

where, the $M E_{\text {diet }}$ is the ME provided by the diet, calculated as $\left(N E_{\text {diet }}, M J / \mathrm{kg}\right.$ $/ 74) * 100$, and the $M E_{m}$ is the average $M E$ intake required for maintenance of live BW calculated based on the metabolic BW (de Haer et al., 1993) using a ME intake value for maintenance of $420 \mathrm{~kJ} \mathrm{ME} \mathrm{per} \mathrm{kg}^{0.75}$, as follows:

$$
M E_{m},=\frac{\left(B W_{\text {end }}^{1.75}-B W_{\text {start }}^{1.75}\right) \times 420}{\left(B W_{\text {end }}-B W_{\text {start }}\right) \times 1.75} .
$$


Table 3.2 Mean, standard deviation, minimum and maximum for the traits $^{1}$ by feeding phase.

\begin{tabular}{|c|c|c|c|c|c|c|c|c|}
\hline \multirow[b]{2}{*}{ Traits } & \multicolumn{4}{|c|}{ CS } & \multicolumn{4}{|c|}{ WB } \\
\hline & $\mu$ & SD & Min & Max & $\mu$ & SD & Min & Max \\
\hline \multicolumn{9}{|c|}{ Starter phase } \\
\hline$A D G, g / d$ & $887^{a}$ & 98 & 515 & 1225 & $895^{a}$ & 98 & 450 & 1353 \\
\hline$A D F I, g / d$ & $1354^{a}$ & 237 & 604 & 2169 & $1401^{b}$ & 216 & 716 & 1981 \\
\hline ADEI, MJ/d & $17.9^{a}$ & 3.1 & 8 & 29 & $18.9^{b}$ & 2.9 & 9.7 & 27 \\
\hline$L D, g / d$ & $128^{b}$ & 36 & 44 & 297 & $122^{\mathrm{a}}$ & 33 & 40 & 310 \\
\hline$P D, g / d$ & $146^{b}$ & 16 & 88 & 196 & $149^{a}$ & 16 & 77 & 212 \\
\hline FCR & $1.53^{\mathrm{a}}$ & 0.2 & 0.8 & 2.2 & $1.57^{b}$ & 0.2 & 1.0 & 2.9 \\
\hline REI, g/d & $-185^{a}$ & 193 & -815 & 539 & $-102^{b}$ & 176 & -717 & 476 \\
\hline $\mathrm{RFI}, \mathrm{g} / \mathrm{d}$ & $-16^{a}$ & 175 & -655 & 640 & $15^{b}$ & 159 & -451 & 545 \\
\hline \multicolumn{9}{|c|}{ Grower phase } \\
\hline$A D G, g / d$ & $915^{a}$ & 94 & 577 & 1259 & $917^{a}$ & 96 & 379 & 1346 \\
\hline$A D F I, g / d$ & $2160^{a}$ & 312 & 1169 & 3332 & $2248^{b}$ & 312 & 1208 & 3420 \\
\hline ADEI, MJ/d & $29^{a}$ & 4.2 & 16 & 45 & $30^{b}$ & 4.1 & 16 & 45 \\
\hline$L D, g / d$ & $185^{b}$ & 52 & 74 & 448 & $173^{a}$ & 46 & 36 & 430 \\
\hline$P D, g / d$ & $150^{b}$ & 15 & 100 & 212 & $154^{\mathrm{a}}$ & 16 & 68 & 204 \\
\hline FCR & $2.36^{a}$ & 0.3 & 1.7 & 4.0 & $2.45^{\mathrm{a}}$ & 0.3 & 1.7 & 4.8 \\
\hline REI, g/d & $138^{a}$ & 227 & -513 & 1244 & $204^{b}$ & 202 & -410 & 965 \\
\hline $\mathrm{RFI}, \mathrm{g} / \mathrm{d}$ & $-38^{a}$ & 195 & -647 & 695 & $38^{\mathrm{b}}$ & 182 & -554 & 715 \\
\hline \multicolumn{9}{|c|}{ Finisher phase } \\
\hline$A D G, g / d$ & $977^{a}$ & 122 & 562 & 1437 & $975^{a}$ & 123 & 286 & 1478 \\
\hline$A D F I, g / d$ & $2911^{a}$ & 450 & 1593 & 4759 & $3130^{b}$ & 424 & 1269 & 4605 \\
\hline ADEI, MJ/d & $40^{a}$ & 6.1 & 22 & 65 & $40^{a}$ & 5.4 & 16 & 58 \\
\hline$L D, g / d$ & $236^{b}$ & 66 & 90 & 610 & $219^{a}$ & 57 & 32 & 512 \\
\hline$P D, g / d$ & $160^{b}$ & 20 & 99 & 244 & $164^{a}$ & 21 & 52 & 243 \\
\hline FCR & $2.98^{a}$ & 0.3 & 2.0 & 4.7 & $3.22^{b}$ & 0.3 & 2.1 & 5.2 \\
\hline REI, g/d & $377^{a}$ & 277 & -669 & 1785 & $457^{b}$ & 248 & -478 & 2073 \\
\hline $\mathrm{RFI}, \mathrm{g} / \mathrm{d}$ & $-125^{a}$ & 263 & -1110 & 1324 & $123^{b}$ & 240 & -891 & 1681 \\
\hline \multicolumn{9}{|c|}{ Overall Period } \\
\hline$A D G, g / d$ & $938^{a}$ & 98 & 593 & 1300 & $941^{a}$ & 100 & 396 & 1388 \\
\hline$A D F I, g / d$ & $2256^{a}$ & 252 & 1510 & 3071 & $2379^{b}$ & 249 & 1335 & 3254 \\
\hline ADEI, MJ/d & $31^{a}$ & 3.4 & 20 & 42 & $31^{a}$ & 3.3 & 17 & 42 \\
\hline $\mathrm{LD}, \mathrm{g} / \mathrm{d}$ & $191^{b}$ & 52 & 80 & 449 & $179^{a}$ & 45 & 36 & 419 \\
\hline$P D, g / d$ & $154^{\mathrm{b}}$ & 16 & 103 & 219 & $158^{a}$ & 16 & 70 & 213 \\
\hline $\mathrm{FCR}$ & $2.41^{a}$ & 0.2 & 1.9 & 3.2 & $2.54^{b}$ & 0.2 & 2.0 & 4.0 \\
\hline REI, g/d & $147^{\mathrm{a}}$ & 159 & -477 & 943 & $217^{\mathrm{b}}$ & 155 & -383 & 1105 \\
\hline $\mathrm{RFI}, \mathrm{g} / \mathrm{d}$ & $-66^{a}$ & 145 & -673 & 479 & $65^{b}$ & 145 & -439 & 910 \\
\hline
\end{tabular}

$\mathrm{CS}$, diet based on corn and soybean meal; WB, diet based on wheat and barley with high addition of co-products; ${ }^{1)} A D G$, average daily gain; ADFI, average daily feed intake; ADEI, average daily energy intake; FCR, feed conversion rate; LD, lipid deposition; PD, protein deposition; REI, residual energy intake; $\mathrm{RFI}$, residual feed intake. Means followed by different letters differ according to T-test $(P<0.05)$. 
$\mathrm{RFI}(\mathrm{g} / \mathrm{d})$ was defined as the difference between the observed and predicted ADFI (Cai et al., 2008), calculated as follows:

$$
A D F I=\mu+b_{1} B W_{\text {start }}+b_{2} B W_{\text {end }}+b_{3} B F+b_{4} A D G+b_{5} A g e_{\text {ontest }}+e,
$$

where $A g e_{\text {ontest }}$ is the age at which the animal was put on test, $b_{1}, b_{2}, b_{3}, b_{4}$, and $b_{5}$ are the linear coefficients of the regression on covariates, and $e$ is the RFI.

\subsubsection{Genetic Parameter Estimation and GxF Analyses}

For the GxF analyses, each trait was considered a different trait when observed in pigs fed corn/soy and when observed in pigs fed wheat/barley/co-products. Univariate analyses were performed to estimate the variance components and heritabilities of all traits. Differences observed in these estimates when traits were measured under different diet conditions indicated the presence of heterogeneity of genetic variance, due to the presence of GxF. Genetic correlations $\left(r_{\mathrm{g}}\right)$ were estimated with bivariate analyses. Values of $r_{g}$ below 1 indicated the presence of GxF (Falconer \& Mackay, 1996).

A linear mixed model, implemented in ASReml (Gilmour et al., 2009), was used to the univariate and bivariate analyses, as follows:

$$
y=X b+Z a+W I+V g+e,
$$

where $y$ is the vector of observations; $X, Z, W$, and $V$ are known incidence matrices; $b$ is a vector of fixed effects (Table 3.3); $a$ is a vector of random additive genetic effects (breeding values), $a \sim N\left(0, A \otimes \sum_{a}\right) ; l$ is a vector of random non-genetic effects common to individuals born in the same litter, $l \sim N\left(0, I_{l} \otimes \sum_{l}\right) ; g$ is a vector of of random contemporary group effects (contemporary pen-mates nested within batch-mates), $g \sim N\left(0, I_{g} \otimes \sum_{g}\right)$; and $e$ is a vector of residuals, $e \sim N\left(0, I_{e} \otimes\right.$ $\left.\sum_{e}\right)$. A is a matrix of additive genetic relationships among all individuals; $I_{l}, I_{g}$, and $I_{e}$ are identity matrices of the appropriate dimensions; and $\sum_{a}, \sum_{l}, \sum_{g}$, and $\sum_{e}$ are covariance matrices related to each effect. In the case of univariate analyses, the covariance matrix, $\sum_{i}$, is a scalar, with the variance component, $\sigma_{i}$, associated with the respective effect.

\subsubsection{Responses to selection}

To assess the genetic progress a breeding program can obtain with data collected in the two feeding scenarios herein studied, we use the breeders' equation to calculated the response to selection, i.e., the expected change of the population mean for the trait that will be observed in the next generation after selection. As a trait was considered two different traits when measured under either diet, we 
calculated and compared two different responses to selection: 1) the response $\left(R_{T D}\right)$ of the trait to be improved (target trait) to direct selection, i.e., when selection is conducted under the diet pigs will be required to perform, the target diet (TD); and 2) the correlated response $\left(\mathrm{CR}_{\mathrm{TD}}\right)$ of the target trait for the TD to indirect selection, i.e., when selection for the target trait takes place under the non-target diet (non-TD). The $\mathrm{CR}_{\mathrm{TD}}$ expresses the expected change of the population mean for the TD, that will be observed in the next generation after selection, when selection was carried out under the non-TD.

The $\mathrm{R}_{\mathrm{TD}}$ and the $C \mathrm{R}_{\mathrm{TD}}$ were calculated as follows (Falconer \& Mackay, 1996):

$$
R_{T D}=i_{T D} \times h_{T D} \times \sigma_{A_{T D}},
$$

where $R_{T D}$ is the response of a trait to direct selection under the TD; $i_{T D}$ is the intensity of selection under the TD (assumed to be 1 in this study); $h_{T D}$ is the accuracy of selection under the TD; and $\sigma_{A_{T D}}$ is the genetic standard deviation under the TD;

$$
C R_{T D}=i_{\text {non-TD }} \times h_{\text {non-TD }} \times r_{g} \times \sigma_{A_{T D}}
$$

where $i_{\text {non-TD }}$ is the intensity of selection under the non-TD (assumed to be 1 in this study); and, $h_{n o n-T D}$ is the accuracy of selection under the non-TD.

Table 3.3 Fixed effects included in the vector $b$ of equation [3.1] for the traits ${ }^{1}$.

\begin{tabular}{ccc}
\hline Model & Dependent trait(s) & Fixed effeccts $^{2}$ \\
\hline A & ADG; LD; PD; FCR & $\mu+$ SEX $_{j}+$ CROSS $\left._{k}+\operatorname{COMP}_{(P E N}\right)_{1}+b_{1} \times$ BW $_{\text {birth }}$ \\
B & ADFI; ADEI; REI; RFI & $\mu+$ SEX $_{j}+$ CROSS $_{k}+\operatorname{COMP}(P E N)_{1}+b_{1} \times$ BW $_{\text {start }}$ \\
\hline
\end{tabular}

${ }^{1} \mathrm{ADG}$, average daily gain; LD, lipid deposition; PD, protein deposition; FCR, feed conversion rate; $A D F I$, average daily feed intake; $A D E I$, average daily energy intake; REI, residual energy intake; $\mathrm{RFI}$, residual feed intake; ${ }^{2} \mu$ is the mean of the trait; SEX, the sex of the animal; CROSS, according to the line of the dam lines used to generate the cross; COMP(PEN), pen nested within compartment; $\mathrm{BW}_{\text {birth, }}$, body weight at birth; $\mathrm{BW}_{\text {start }}$, body weight at the start of the growing-finishing period.

\subsection{Results}

\subsubsection{Variance Components}

Estimates of genetic variance $\left(\sigma_{A}^{2}\right)$ and heritability $\left(h^{2}\right)$ are presented in Table 3.4. The contribution of all random effects to the estimation of the traits, expressed as percentage of the phenotypic variance is given in Appendix. Although the standard errors of these estimates for all traits in all growth phases were high, their absolute values differed according to the diet in which the trait was measured. Heterogeneity of genetic variance indicated that GxF was present. We found lower 
Table 3.4 Estimates of genetic variance and heritability (SE) for the traits ${ }^{1}$ by feeding phase.

\begin{tabular}{|c|c|c|c|c|}
\hline & $\mathrm{CS}$ & WB & CS & WB \\
\hline Traits & \multicolumn{2}{|c|}{$\sigma_{A}^{2}$} & \multicolumn{2}{|c|}{$h^{2}$} \\
\hline \multicolumn{5}{|c|}{ Starter phase } \\
\hline ADG & 2,476 & 1,551 & $0.27(0.11)$ & $0.18(0.10)$ \\
\hline ADFI & 12,483 & 6,592 & $0.29(0.10)$ & $0.21(0.11)$ \\
\hline ADEI & 2,189 & 1,199 & $0.29(0.10)$ & $0.21(0.11)$ \\
\hline LD & 249 & 181 & $0.21(0.11)$ & $0.19(0.10)$ \\
\hline PD & 78 & 32 & $0.33(0.11)$ & $0.14(0.09)$ \\
\hline FCR & $1.11 \mathrm{E}-02$ & $1.29 \mathrm{E}-02$ & $0.27(0.09)$ & $0.35(0.10)$ \\
\hline REI & 9,171 & 8,847 & $0.26(0.10)$ & $0.31(0.10)$ \\
\hline RFI & 7,978 & 7,227 & $0.27(0.09)$ & $0.32(0.11)$ \\
\hline \multicolumn{5}{|c|}{ Grower phase } \\
\hline ADG & 2,864 & 1,837 & $0.34(0.11)$ & $0.21(0.11)$ \\
\hline ADFI & 19,164 & 15,922 & $0.26(0.11)$ & $0.23(0.11)$ \\
\hline ADEI & 3,493 & 2,764 & $0.26(0.11)$ & $0.23(0.11)$ \\
\hline LD & 607 & 346 & $0.24(0.11)$ & $0.18(0.10)$ \\
\hline PD & 78 & 51 & $0.37(0.11)$ & $0.23(0.11)$ \\
\hline FCR & 5.00E-03 & $1.16 \mathrm{E}-02$ & $0.08(0.08)$ & $0.18(0.09)$ \\
\hline REI & 3,892 & 4,070 & $0.08(0.06)$ & $0.11(0.07)$ \\
\hline RFI & 3,184 & 5,418 & $0.09(0.07)$ & $0.18(0.10)$ \\
\hline \multicolumn{5}{|c|}{ Finisher phase } \\
\hline ADG & 4,358 & 2,722 & $0.31(0.11)$ & $0.19(0.10)$ \\
\hline ADFI & 62,966 & 28,852 & $0.33(0.10)$ & $0.18(0.10)$ \\
\hline ADEI & 11,707 & 4,636 & $0.33(0.10)$ & $0.18(0.10)$ \\
\hline LD & 1,030 & 499 & $0.24(0.11)$ & $0.16(0.09)$ \\
\hline PD & 121 & 91 & $0.33(0.10)$ & $0.23(0.10)$ \\
\hline FCR & $1.31 \mathrm{E}-02$ & $1.39 \mathrm{E}-02$ & $0.17(0.07)$ & $0.20(0.10)$ \\
\hline REI & 11,388 & 10,299 & $0.14(0.05)$ & $0.18(0.09)$ \\
\hline RFI & 9,597 & 8,374 & $0.14(0.05)$ & $0.16(0.09)$ \\
\hline \multicolumn{5}{|c|}{ Overall period } \\
\hline ADG & 3,089 & 2,036 & $0.34(0.11)$ & $0.22(0.11)$ \\
\hline ADFI & 21,779 & 9,374 & $0.42(0.12)$ & $0.20(0.11)$ \\
\hline ADEI & 3,978 & 1,642 & $0.42(0.12)$ & $0.20(0.11)$ \\
\hline LD & 597 & 311 & $0.23(0.11)$ & $0.16(0.09)$ \\
\hline PD & 88 & 57 & $0.38(0.11)$ & $0.24(0.11)$ \\
\hline FCR & 5.37E-03 & $1.09 \mathrm{E}-02$ & $0.19(0.08)$ & $0.34(0.10)$ \\
\hline REI & 2,071 & 5,322 & $0.09(0.06)$ & 0.25 (0.09) \\
\hline RFI & 3,397 & 5,110 & $0.18(0.08)$ & $0.29(0.11)$ \\
\hline
\end{tabular}

$\mathrm{CS}$, diet based on corn and soybean meal; WB, diet based on wheat and barley with high addition of co-products; $\sigma_{A}^{2}$, additive genetic variance; $h^{2}$, heritability estimate. ${ }^{1)} \mathrm{ADG}$, average daily gain; $L D$, lipid deposition; $P D$, protein deposition; FCR, feed conversion rate; $A D F I$, average daily feed intake; $A D E I$, average daily energy intake; REI, residual energy intake; $\mathrm{RFI}$, residual feed intake. 
$\sigma_{A}^{2}$ and $h^{2}$ estimates under the wheat/barley/co-products diet compared to the corn/soy diet for all growth performance traits (ADG, ADFI, ADEI, LD, and PD) in all growth phases. The estimates of $\sigma_{A}^{2}$ and $h^{2}$ for the FE traits (FCR, REI and RFI) were slightly lower under the wheat/barley/co-products diet compared to the corn/soy diet during the starter and finisher phases, but they rose to 2.4 and 2.8 times the values estimated under the corn/soy diet during the grower phase and for the overall period, respectively.

\subsubsection{Genetic correlations}

The values of genetic correlation estimates $\left(r_{\mathrm{g}}\right)$ between the performances of pigs under each diet are presented in Table 3.5. All $r_{g}$ values of 0.99 and above were interpreted as unity, which indicated the absence of GxF according to this criterion. Values of $r_{g}$ between 0.80 and 0.91 were interpreted as high, which indicated the presence of low magnitude GxF. Values of $r_{g}$ between 0.41 and 0.76 were interpreted as moderate, which indicated the presence of moderate magnitude GXF. ADG, FCR, and PD presented $r_{g}$ estimates of unity in all phases; therefore, showing that these traits presented no GxF. ADFI and ADEI presented $r_{g}$ estimates of unity during the grower and finisher phase, and during the overall period; therefore, showing no GxF during these phases. However, during the starter phase, both $A D F I$ and $A D E I$ presented an $r_{g}$ estimate of 0.91 , which indicated the presence of GxF during this phase. LD presented $r_{g}$ estimates of $0.72,0.65,0.63$, and 0.62 during the starter, grower and finisher phases and overall period, respectively, which indicated the presence of a moderate magnitude GxF in all phases. In fact, LD was the only trait presenting GxF during the finisher phase. REI presented $r_{g}$ estimates of $0.81,0.41,1.00$, and 0.76 during the starter, grower and finisher phases and overall period, respectively. These values indicated a low magnitude GxF during the starter phase, a moderate magnitude GxF during the grower phase, the absence of GxF during the finisher phase, and a moderate GxF for the overall period. RFI presented $r_{\mathrm{g}}$ estimates of $0.86,0.74,0.99$, and 0.89 during the starter, grower and finisher phases and overall period, respectively, which indicated a low magnitude GxF during the starter phase, a moderate GxF during the grower phase, no GxF during the finisher phase, and a low GxF for the overall period.

\subsubsection{Responses to selection under a diet}

We calculated the trait responses to selection under the corn/soy $\left(R_{C S}\right)$ and the wheat/barley/co-products $\left(R_{\mathrm{WB}}\right)$ diets (Table 3.6). The FCR responses to selection under the two diets were similar during the starter and finisher phases, but the $R_{W B}$ was at least 2-fold higher than the $R_{\mathrm{CS}}$ during the grower phase and for the overall 
period. The REI and RFI responses to selection were similar between the two diet groups during the starter and finisher phases, but the $R_{W B}$ was 1.2- to 2.7-fold higher than the $R_{C S}$ during the grower phase and for the overall period. For the growth performance traits ( $A D G, A D F I, A D E I, L D$, and $P D$ ), the $R_{W B}$ values were always lower than the $R_{C S}$ by 0.2 - to 0.6 -fold (starter phase), 0.1 - to 0.4-fold (grower phase), 0.3 - to 0.5 -fold (finisher phase), and 0.3 - to 0.6 -fold (overall).

Table 3.5 Genetic correlations (SE) between the performances of pigs fed a diet based on corn and soybean meal and pigs fed a diet based on wheat and barley with high addition of co-products.

\begin{tabular}{lcccc}
\hline Traits & Starter phase & Grower phase & Finisher phase & Overall period \\
\hline ADG & $0.99(0.23)$ & $1.00(0.20)$ & $0.99(0.25)$ & $1.00(0.19)$ \\
ADFI & $0.91(0.16)$ & $0.99(0.17)$ & $1.00(0.23)$ & $1.00(0.22)$ \\
ADEI & $0.91(0.16)$ & $1.00(0.17)$ & $1.00(0.24)$ & $1.00(0.21)$ \\
LD & $0.72(0.21)$ & $0.65(0.22)$ & $0.63(0.23)$ & $0.62(0.23)$ \\
PD & $1.00(0.19)$ & $1.00(0.12)$ & $0.99(0.13)$ & $0.99(0.15)$ \\
FCR & $1.00(0.17)$ & $1.00(0.28)$ & $1.00(0.21)$ & $1.00(0.14)$ \\
REI & $0.81(0.17)$ & $0.41(0.36)$ & $1.00(0.27)$ & $0.76(0.23)$ \\
RFI & $0.86(0.13)$ & $0.74(0.29)$ & $0.99(0.30)$ & $0.89(0.16)$ \\
\hline ADG
\end{tabular}

ADG, average daily gain; $A D F I$, average daily feed intake; $A D E I$, average daily energy intake; LD, lipid deposition; PD, protein deposition; FCR, feed conversion rate; REI, residual energy intake; RFI, residual feed intake.

\subsubsection{Correlated responses to selection under the other diet}

The calculated correlated responses of traits for the corn/soy diet to indirect selection under the wheat/barley/co-products diet $\left(\mathrm{CR}_{\mathrm{CS}}\right)$, and for the wheat/barley/co-products diet to indirect selection under the corn/soy diet $\left(\mathrm{CR}_{\mathrm{WB}}\right)$, and the ratios between the correlated response and the response to direct selection (i.e., $C R_{C S} / R_{C S}$ and $C R_{W B} / R_{W B}$ ) are presented in Table 3.6. In all growth phases, the growth performance traits, ADG, ADFI, ADEI, and PD, presented 0.1- to 0.3-fold lower $C R_{C S}$ values than $R_{C S}$ values, and 0.1 - to 0.5 -fold higher $C R_{W B}$ values than $R_{W B}$ values. $L D$ was the only trait that $C R_{T D}$ was lower than $R_{T D}$ in both diets and in all growth phases. For this trait, the $C_{C S}$ was 0.3 - to 0.5 -fold lower than the $R_{C S}$, and the $C R_{W B}$ was 0.2- to 0.3-fold higher than $R_{W B}$, depending on the growth phase. For $F C R$, the $C R_{T D}$ and $R_{T D}$ were similar under both diets during the starter and finisher phases, but during the grower phase and for the overall period, the $\mathrm{CR}_{C S}$ was 0.3- to 0.5-fold higher than the $\mathrm{R}_{\mathrm{CS}}$, and the $\mathrm{CR}_{\mathrm{WB}}$ was 0.3-fold lower than the $R_{W B}$. For $R E I$, the $\mathrm{CR}_{C S}$ was 0.1- and 0.5-fold lower than the $R_{C S}$ during the starter 
and grower phases, respectively, but the $\mathrm{CR}_{\mathrm{CS}}$ was 0.1 - and 0.3-fold higher than the $R_{C S}$, during the finisher phase and for the overall period, respectively. For this trait, the $C_{W B}$ was 0.1- to 0.7-fold lower than the $R_{W B}$, depending on the growth phase. For RFI, the $C R_{C S}$ and $R_{C S}$ were similar in all phases, but the $C R_{W B}$ was 0.1- to 0.4-fold lower than the $R_{W B}$, depending on the growth phase.

\subsection{Discussion}

\subsubsection{Genetic correlations}

According to Falconer \& Mackay (1996), $r_{\mathrm{g}}$ values below 1 reveal the presence of a GxE. However, quantifying the GxE remains challenging. Clearly, for a given trait, the lower the $r_{g}$ value, the higher the sensitivity to the environment. However, defining boundaries to create grades of $r_{g}$ values may be confusing and imprecise. Furthermore, making decisions and inferences based solely on a defined $r_{\mathrm{g}}$ scale, without combining it with other parameters, might be misleading. Nevertheless, we defined a scale for the magnitude of $r_{g}$ to provide inferences and comparisons between the GxF detected for the different traits in the different phases of pig growth studied herein.

We found, $r_{g}$ of unity between diets for ADG, FCR, and PD in all phases, for ADFI and ADEI during the grower and finisher phases and for the overall period, and for $\mathrm{REI}$ and RFI during the finisher phase. These results showed that, according to this criterion, these traits behaved as the same trait, regardless of whether pigs were fed corn/soy or wheat/barley/co-products. Therefore, the genetic progress obtained for these traits would be fully expressed under either diet, and the expected response to selection would depend solely on the $\sigma_{A}^{2}$ and $h^{2}$ estimates under each diet. In contrast, we found low magnitude GxF for ADFI, ADEI, REI, and $\mathrm{RFI}$, during the starter phase, and for RFI for the overall period. Based on these results, we expected that, for these traits, the genetic progress observed during selection under one diet would not be fully carried over to the other diet during these phases. We observed a moderate GxF found for LD in all phases, for REI during the grower phase and for the overall period, and for RFI during the grower phase. These results suggested that, for these traits, genetic progress would be compromised after changing diets, due to a re-ranking of the genotypes.

In this study, the diets were formulated to be isoenergetic to facilitate a fair comparison. In addition, pig diets were designed to meet the requirements of net energy and essential amino acids in each growth phase, to prevent limitations on protein deposition, and thus growth. This design might explain why the $r_{g}$ of PD was 
Table 3.6 Response to direct selection and correlated response to indirect selection for the traits ${ }^{1}$ by feeding phase.

\begin{tabular}{|c|c|c|c|c|c|c|c|}
\hline Traits & $\mathrm{R}_{\mathrm{CS}}$ & $\mathrm{R}_{\mathrm{WB}}$ & $\frac{\mathrm{R}_{\mathrm{WB}}}{\mathrm{R}_{\mathrm{CS}}}$ & $\mathrm{CR}_{\mathrm{CS}}$ & $\mathrm{CR}_{\mathrm{WB}}$ & $\frac{\mathrm{CR}_{\mathrm{CS}}}{\mathrm{R}_{\mathrm{CS}}}$ & $\frac{\mathrm{CR}_{\mathrm{WB}}}{\mathrm{R}_{\mathrm{WB}}}$ \\
\hline \multicolumn{8}{|c|}{ Starter phase } \\
\hline ADG, g/d & 26 & 17 & 0.6 & 21 & 20 & 0.8 & 1.2 \\
\hline ADFI, g/d & 25 & 16 & 0.6 & 20 & 17 & 0.8 & 1.1 \\
\hline$A D E I, M J / d$ & 60 & 37 & 0.6 & 47 & 40 & 0.8 & 1.1 \\
\hline$L D, g / d$ & 7.2 & 5.9 & 0.8 & 5.0 & 4.4 & 0.7 & 0.8 \\
\hline$P D, g / d$ & 5.1 & 2.1 & 0.4 & 3.3 & 3.3 & 0.7 & 1.5 \\
\hline FCR & 0.05 & 0.07 & 1.2 & 0.06 & 0.06 & 1.1 & 0.9 \\
\hline $\mathrm{REI}, \mathrm{g} / \mathrm{d}$ & 49 & 52 & 1.1 & 43 & 39 & 0.9 & 0.7 \\
\hline $\mathrm{RFI}, \mathrm{g} / \mathrm{d}$ & 46 & 48 & 1.0 & 43 & 38 & 0.9 & 0.8 \\
\hline \multicolumn{8}{|c|}{ Grower phase } \\
\hline$A D G, g / d$ & 31 & 20 & 0.6 & 25 & 25 & 0.8 & 1.3 \\
\hline ADFI, g/d & 30 & 25 & 0.8 & 28 & 27 & 0.9 & 1.1 \\
\hline$A D E I, M J / d$ & 71 & 61 & 0.9 & 66 & 64 & 0.9 & 1.1 \\
\hline$L D, g / d$ & 12 & 7.9 & 0.7 & 6.8 & 5.9 & 0.6 & 0.8 \\
\hline$P D, g / d$ & 5.4 & 3.4 & 0.6 & 4.2 & 4.3 & 0.8 & 1.3 \\
\hline FCR & 0.02 & 0.05 & 2.3 & 0.03 & 0.03 & 1.5 & 0.7 \\
\hline $\mathrm{REI}, \mathrm{g} / \mathrm{d}$ & 18 & 21 & 1.2 & 8 & 7 & 0.5 & 0.3 \\
\hline $\mathrm{RFI}, \mathrm{g} / \mathrm{d}$ & 17 & 31 & 1.8 & 18 & 16 & 1 & 0.5 \\
\hline \multicolumn{8}{|c|}{ Finisher phase } \\
\hline$A D G, g / d$ & 37 & 23 & 0.6 & 28 & 29 & 0.8 & 1.3 \\
\hline ADFI, g/d & 62 & 29 & 0.5 & 46 & 39 & 0.7 & 1.4 \\
\hline$A D E I, M J / d$ & 144 & 72 & 0.5 & 106 & 98 & 0.7 & 1.4 \\
\hline$L D, g / d$ & 16 & 8.9 & 0.6 & 8.1 & 6.9 & 0.5 & 0.8 \\
\hline$P D, g / d$ & 6.3 & 4.6 & 0.7 & 5.3 & 5.5 & 0.8 & 1.2 \\
\hline FCR & 0.05 & 0.05 & 1.0 & 0.05 & 0.05 & 1.0 & 1.0 \\
\hline $\mathrm{REI}, \mathrm{g} / \mathrm{d}$ & 40 & 43 & 1.1 & 45 & 38 & 1.1 & 0.9 \\
\hline $\mathrm{RFI}, \mathrm{g} / \mathrm{d}$ & 37 & 37 & 1.0 & 39 & 34 & 1.1 & 0.9 \\
\hline \multicolumn{8}{|c|}{ Overall period } \\
\hline$A D G, g / d$ & 32 & 21 & 0.7 & 26 & 26 & 0.8 & 1.2 \\
\hline ADFI, g/d & 41 & 18 & 0.4 & 27 & 25 & 0.7 & 1.4 \\
\hline ADEI, MJ/d & 96 & 42 & 0.4 & 64 & 63 & 0.7 & 1.5 \\
\hline $\mathrm{LD}, \mathrm{g} / \mathrm{d}$ & 12 & 7.1 & 0.6 & 6.1 & 5.2 & 0.5 & 0.7 \\
\hline$P D, g / d$ & 5.7 & 3.7 & 0.7 & 4.5 & 4.6 & 0.8 & 1.2 \\
\hline FCR & 0.03 & 0.06 & 2.0 & 0.04 & 0.05 & 1.3 & 0.7 \\
\hline $\mathrm{REI}, \mathrm{g} / \mathrm{d}$ & 14 & 36 & 2.7 & 17 & 17 & 1.3 & 0.5 \\
\hline$R F I, g / d$ & 25 & 38 & 1.6 & 28 & 27 & 1.1 & 0.7 \\
\hline
\end{tabular}

CS, diet based on corn and soybean meal; WB, diet based on wheat and barley with high addition of co-products; $R_{C S}$, response to direct selection under the $C S ; R_{W B}$, response to direct selection under the $W B ; C R_{C S}$, correlated response for $C S$ to indirect selection under the $W B ; C R_{W B}$, correlated response for $W B$ to indirect selection under $C S ;{ }^{1} A D G$, average daily gain; ADFI, average daily feed intake; $A D E I$, average daily energy intake; LD, lipid deposition; PD, protein deposition; FCR, feed conversion rate; REI, residual energy intake; $\mathrm{RFI}$, residual feed intake. 
unity in all phases. Because both diets met the minimal requirements for crude protein, net energy, and amino acids during the entire growing-finishing periods, we hypothesized that pigs were not challenged by the environment, and hence, protein deposition was not compromised.

On the other hand, LD presented moderate GxF in all phases. When replacing corn and soybean meal by wheat and barley, starch and simple carbohydrates (highly available in the corn) and crude protein (highly available on the soybean meal) decrease. Wheat and barley are weaker in these nutrients when compared to corn and soybean meal. The addition of the protein-rich co-products offset the lack of crude protein in cereals (wheat and barley), but it increased the level of non-starch polysaccharides (fiber). To compensate for the lack of simple carbohydrates in the wheat/barley/co-products diet, animal, palm, and soybean oils were added to increase the net energy of the diet. Thus, the wheat/barley/co-products diet was richer in crude fat than the corn/soy diet. Consequently, although the two diets were isoenergetic and balanced in amino acids and crude protein, they differed in nutrient content, due to the different sources of energy. The corn/soy diet was richer in starch and poorer in fat and fiber, compared to the wheat/barley/coproducts diet. Thus, based on our results, we hypothesized that the LD, REI, and RFI traits in pigs were sensitive to changes in the source of energy nutrients in the diets.

In addition, the REI and RFI traits can capture sources of variation other than those related to production ( $A D G, L D$, and $P D)$. For example, they reflect factors related to the animal's immunity, gut function, energy required for live weight maintenance, physical activity, heat production, metabolic pathways, and others (Patience, 2012). Indeed, REI and RFI could reflect different digestion pathways that might be responsible for interactions between the genotypes and the different diets. Based on the large differences in the quantity and types of fiber in the two diets, differences in the intestinal region and the gut microbiota involved in dietary fiber digestion might give rise to variations in the capacity for nutrient utilization in pigs on different diets. In addition, the higher fiber content in the wheat/barley/coproducts diet increased its volume compared to the volume of the corn/soy diet. This difference might also explain why we found a low GxF effect on ADFI, and thus the ADEI, during the starter phase. At this young age, the pig's digestive system would not be fully developed, and high-volume feed might represent an environmental challenge that could compromise the feed intake capacity. 


\subsubsection{Direct versus indirect selection}

The heterogeneity of genetic variance observed in this study (Table 3.4 ) is important for breeding programs, because it is likely to impact the responses to selection (Table 3.6) that can be achieved by selecting under these diets. Our results suggested that the $R_{T D}$ levels that can be achieved in FE traits during most growth phases are likely to be higher under the wheat/barley/co-products than under the corn/soy diet. Conversely, growth performance traits are likely to display higher $\mathrm{R}_{\mathrm{TD}}$ levels under a corn/soy than under a wheat/barley/co-products diet.

The $\mathrm{CR}_{\mathrm{TD}}$ depended on the $\sigma_{A}^{2}$ of the TD, the $\mathrm{r}_{\mathrm{g}}$ between pig's performances under the two diets, and the intensity and accuracy of selection under the non-TD. Therefore, both sources of GxF: the heterogeneity of genetic variance and the reranking of genotypes, could impact the $\mathrm{CR}_{\mathrm{TD}}$. The benefit of indirect selection on the non-TD over direct selection on the TD was assessed with the ratio, $C R_{T D} / R_{T D}$ (Table 3.6). Assuming equal intensity of selection with both diets, this ratio can also be assessed with the formula: $h_{\text {non-TD }} \times r_{\mathrm{g}} / h_{\mathrm{TD}}$, where $h$ is the accuracy of selection (Falconer and Mackay, 1996). Thus, when the $r_{g}$ equals unity, the benefit of direct selection under the TD over indirect selection under the non-TD depends solely on

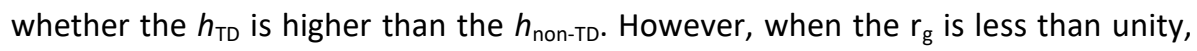
the benefit of indirect over direct selection depends on whether the $h_{\text {non-TD }} \times r_{\mathrm{g}}$ is higher than the $h_{\mathrm{TD}}$. Thus, when the $h_{\mathrm{TD}}$ is higher than the $h_{\mathrm{non}-\mathrm{TD}}$, and when the $r_{\mathrm{g}}$ is less than unity, the benefit of direct selection increases.

We found estimates of $r_{g}$ equivalent to unity for the traits ADG, ADFI, ADEI, PD, and FCR in all growth phases. This finding suggested that no re-ranking of genotypes occurred, and that all genetic progress gained in these traits under one diet would be carried over, when the pigs will be fed the other diet. However, independent of which diet the pigs are required to consume, the $R_{T D}$ and the $C R_{T D}$ values indicated that selection under the corn/soy diet would always lead to greater genetic progress in ADG, ADFI, ADEI, and PD, and selection under the wheat/barley/coproducts diet would always lead to higher genetic progress in the FCR.

We detected a GxF for LD. This effect caused re-ranking among the genotypes and heterogeneity of genetic variance. The moderate $r_{\mathrm{g}}$ values estimated for LD in all growth phases caused the $\mathrm{CR}_{\mathrm{TD}}$ to be lower than the $\mathrm{R}_{\mathrm{TD}}$ under both diets, in all growth phases. Thus, selecting pigs under a diet different from the diet pigs consume for growing-finishing performance will always compromise the genetic progress of the LD trait. Selection for LD should always be conducted under the diet pigs will be required to perform.

We detected GxF for REI and RFI. This effect caused re-ranking among genotypes and heterogeneity of genetic variance. Given the higher $h^{2}$ estimates under the 
wheat/barley/co-products diet compared to the corn/soy diet, the $\mathrm{CR}_{\mathrm{CS}}$ was consistently higher than the $R_{C S}$ in all phases for both traits, except for REI during the grower phase (in the latter case, $C R_{C S} / R_{C S}=0.5$ ). However, the $C R_{W B}$ declined to 0.7-fold lower than the $R_{W B}$, which suggested that, selecting pigs under a corn/soy diet would severely compromise genetic progress in the REI and RFI, for the wheat/barley/co-products diet. In addition, we observed $C R_{T D} / R_{T D}$ ratio values below unity with both diets during the starter phase for both REI and RFI, and a particularly low value for REI during the grower phase. These results indicated that these two traits should not be considered the same trait, when growing-finishing pigs are raised under a different diet. Selecting pigs under a diet different from the one pigs will be required to perform will always compromise genetic progress in REI and RFI. For these traits, selection should always be conducted under the same diet used in the growing-finishing period.

\subsubsection{Breeding for improved feed efficiency under lower-input diets}

Pig producers in many countries have historically benefited from access to corn and soybean grains. However, the continuous growth of the human population and increasing demand for grains from the biofuel industry have pressured animal production systems into using diet inputs in a more effective way (Neeteson-van Nieuwenhoven et al., 2013). Therefore, less use of high-input diets and inclusion of co-products is a promising alternative for reducing the pork production footprint. In addition to reducing the environmental impact of pork production, the inclusion of co-products in pig diets is a good strategy for improving economic results by reducing the price of diet inputs (Ali et al., 2017). There is a need for efficient pork production under different local circumstances; thus, breeding for efficiency should take into account differences in diets, when GxF is present.

We found that, when pigs were raised under the different diets, re-ranking of genotypes did not occur for ADG, PD, or FCR, during any growth phase, or for ADFI and ADEl during the grower and finisher phases and for the overall period. Therefore, although selection under a corn/soy diet could accelerate genetic progress in these traits, the ranking of genotypes will remain the same when pigs will be required to perform under the different diets. Thus, for these traits, changing from high-input diets (i.e., corn and soybean meal) to less valuable ingredients (wheat, barley, and co-products) would not require a change in the genetic selection process. Consequently, changing the diet from corn/soy to wheat/barley/co-products in growing-finishing pigs is advisable to reduce production costs and the environmental impact, independent of the diet used for trait selection. 
We found that GxF interfered in the ranking of genotypes and caused heterogeneity of genetic variance under both diets for lipid deposition (LD), residual energy intake (REI), and residual feed intake (RFI). Thus, selecting pigs under a diet different from the diet used for growing-finishing performance could compromise the LD in all growth phases, compromise the REI and RFI during the starter phase, and severely compromise the REI during the grower phase. Moreover, for all three FE traits, the $\mathrm{CR}_{\mathrm{WB}}$ was 0.2- to 0.7-fold lower than the $\mathrm{R}_{\mathrm{WB}}$. Consequently, when pigs selected under corn/soy, will be required to perform under wheat/barley/co-products, their efficiency will be declined. Therefore, we recommend that, when pigs are required to perform under wheat/barley/coproducts, selection for FE should be conducted under the same diet. In future, FE traits are expected to become more important as the pressure placed on animal production systems increases and as diet inputs become more expensive. Diets like the wheat/barley/co-products diet studied herein are a good alternative. Breeding for FE under lower-input diets should be considered as FE traits become more important and lower-input diets become more widespread in the near future.

\section{5 conclusions}

We found that GxF did not interfere in the ranking of genotypes under either a corn/soy or a wheat/barley/co-products diet for ADG, PD, and FCR during all growth phases, and for ADFI and ADEI during the grower and finisher phases and for the overall period. Therefore, for these traits, we recommend changing the diet of growing-finishing pigs from high-input feed (i.e., corn/soy) to feed with less valuable ingredients, as wheat/barley/co-products, to reduce production costs and the environmental impact, regardless of which diet is used in selection.

We found that GxF interfered in the ranking of genotypes and caused heterogeneity of genetic variance under both diets for LD, REI, and RFI. Thus, selecting pigs under a diet different from the diet used for growing-finishing performance could compromise the LD in all growth phases, compromise the REI and RFI during the starter phase, and severely compromise the REI during the grower phase. In particular, when pigs are required to consume a wheat/barley/coproducts diet for growing-finishing performance, pigs should be selected for FE under the same diet. Breeding pigs for FE under lower-input diets should be considered, because FE traits will become more important and lower-input diets will become more widespread in the near future. 


\subsection{References}

Ali, B. M., H. H. E. van Zanten, P. Berentsen, J. W. M. Bastiaansen, P. Bikker, and A. O. Lansink. 2017. Environmental and economic impacts of using co-products in the diets of finishing pigs in Brazil. J. Clean. Prod. 162:247-259.

Bergsma, R., P. K. Mathur, E. Kanis, M. W. A. Verstegen, E. F. Knol, and J. A. M. van Arendonk. 2013. Genetic correlations between lactation performance and growing-finishing traits in pigs. J. Anim. Sci. 91:3601-3611.

Bloemhof, S., A. Kause, E. F. Knol, J. A. M. van Arendonk, and I. Misztal. 2012. Heat stress effects on farrowing rate in sows: Genetic parameter estimation using within-line and crossbred models. J. Anim. Aci. 90:2109-2119.

Bloemhof, S., E. H. van der Waaij, J. W. M. Merks, and E. F. Knol. 2008. Sow line differences in heat stress tolerance expressed in reproductive performance traits. J. Anim. Sci. 86:3330-3337.

Cai, W., D. S. Casey, and J. C. M. Dekkers. 2008. Selection response and genetic parameters for residual feed intake in Yorkshire swine. J. Anim. Sci. 86:287-298.

CVB. 2011. Veevoedertabel. Productschap Diervoeder, Den Haag, the Netherlands.

De Greef, K. H., M. W. A. Verstegen, B. Kemp, and P. L. van der Togt. 1994. The effect of body weight and energy intake on the composition of deposited tissue in pigs. Anim. Prod. 58:263-270.

De Haer, L., L. C. M. Luiting, and H. L. M. Aarts. 1993. Relations among individual (residual) feed intake, growth performance and feed intake pattern of growing pigs in group housing. Livest. Prod. Sci. 36:223-232.

Falconer, D.S. and T. F. C. Mackay. 1996. Introduction to Quantitative Genetics. Longman, Essex, UK.

Gilbert, H., Y. Billon, L. Brossard, J. Faure, P. Gatellier, F. Gondret, E. Labussière, B. Lebret, L. Lefaucheur, N. le Floch, I. Louveau, E. Merlot, M. -C. Meunier-Salaün, L. Montagne, P. Mormede, D. Renaudeau, J. Riquet, C. Rogel-Gaillard, J. van Milgen, A. Vincent, and J. Noblet. 2017. Review: divergent selection for residual feed intake in the growing pig. Animal 1-13.

Gilmour, A. R., B. J. Gogel, B. R. Cullis, and R. Thompson. 2009. ASReml User Guide Release 3.0 VSN International Ltd, Hemel Hempstead, HP1 1ES, UK.

Herrero-Medrano J. M., P. K. Mathur, J. ten Napel, H. Rashidi, P. Alexandri, E. F. $\mathrm{Knol}$, and $\mathrm{H}$. Mulder. 2015. Estimation of genetic parameters and breeding values across challenged environments to select for robust pigs. J. Anim. Sci. 93:14941502. 
Knap, P., and L. Wang. 2012. Pig breeding for improved feed efficiency. In: J. F. Patience, Feed efficiency in swine. Wageningen Academic Publishers, Wageningen, the Netherlands. p. 167-181.

Mathur, P. K., J. M. Herrero-Medrano, P. Alexandri, E. F. Knol, J. ten Napel, H. Rashidi, and H. A. Mulder. 2014. Estimating challenge load due to disease outbreaks and other challenges using reproduction records of sows. J. Anim. Sci. 92:5374-5381.

Neeteson-van Nieuwenhoven, A.M., P. Knap, and S. Avendario. 2013. The role of sustainable commercial pig and poultry breeding for food security. Anim. Front. 3:52-57.

Patience, J. P. 2012. The influence of dietary energy on feed efficiency in growfinish swine. Pages 101-129 In: J. F. Patience, Feed efficiency in swine. Wageningen Academic Publishers, Wageningen, the Netherlands. p. 101-129.

Sevillano, C. A., C. V, Nicolaiciuc, F. Molist, J. Pijlman, and R. Bergsma. 2018. Effect of feeding cereals-alternative ingredients diets or corn-soybean meal diets on performance and carcass characteristics of growing-finishing gilts and boars. J. Anim. Sci. doi.org/10.1093/jas/sky339

Sevillano, C. A., H. A. Mulder, H. Rashidi, P. K. Mathur, and E. F. Knol. 2016. Genetic variation for farrowing rate in pigs in response to change in photoperiod and ambient temperature. J. Anim. Sci. 94:3185-3197.

Shirali, M. 2014. Improvement of energy and nitrogen utilization in pork production -genetics and growth models-. PhD Thesis, Wageningen University and Research, Wageningen, the Netherlands. 


\section{4}

\section{Genetic parameters for feed intake and growth curves of three-way crossbred pigs fed two different diets}

Rodrigo M Godinho ${ }^{1,2}$, Rob Bergsma ${ }^{3}$, Simone EF Guimarães ${ }^{1}$, Fabyano F Silva ${ }^{1}$, Egbert F Knol ${ }^{3}$, Jaap van Milgen ${ }^{4}$, Hans Komen ${ }^{2}$, John WM Bastiaansen ${ }^{2}$

${ }^{1}$ Department of Animal Science, Universidade Federal de Viçosa, 36570-900, Viçosa, Brazil; ${ }^{2}$ Wageningen University \& Research Animal Breeding and Genomics, $6700 \mathrm{AH}$, Wageningen, the Netherlands; ${ }^{3}$ Topigs Norsvin Research Center, 6640 AA Beuningen, the Netherlands; ${ }^{4}$ INRA, Agrocampus Ouest, 35590, Saint-Gilles, France 


\section{Abstract}

Improving feed efficiency (FE) of crossbred (CB) pigs in commercial environments is a priority in pig breeding programs. However, FE is affected by genotype by feed interaction (GxF) when pigs are fed different commercial diets. Feed intake (FI) curves can be fitted using non-linear models (NLMs) which are based on a reduced number of parameters that usually have biological interpretations. NLMs are implemented with functions that mimic the real behavior of the continuous trait along a dependent variable. In this sense, a Gamma function of the maintenance energy expenditure was proposed. Describing $\mathrm{FI}$ for growth and maintenance throughout the whole growing-finishing period, this curve expresses fully the pig's intake and expenditure, and thus, FE.

Using an NLM approach, breeding goals can be defined aiming to change the shape of the curves by treating the estimated parameters as phenotypic observations in genetic models. We recommend fitting curves that describe $\mathrm{FI}$ as a function of body weight (BW) given the strong interrelationship between $\mathrm{FI}$ and $\mathrm{BW}$. We also recommend selecting pigs with flatter curves, as they will have better $\mathrm{FE}$, and pigs with higher Fl precocity, i.e. higher FI in early stages of growth associated with a higher growth maturation rate and a consequent lower FI later on the finishing period. To include the NLM parameters in a breeding program, it is important to know their correlation with other traits in the breeding goal. Therefore, the current study aimed: 1 ) to fit and compare the $\mathrm{FI}$ and the growth curve of three-way $\mathrm{CB}$ pigs fed two diets; 2 ) to verify the presence of GxF for the curves' parameters; 3 ) to estimate genetic parameters for the curves' parameters; and 4) to estimate genetic correlations between the curves' parameters and both growth performance traits and residual feed intake traits.

The medium to high heritability estimates for all curves' parameters show that selection for CB pigs with better FE and higher FI precocity, and for higher mature weight and maturation rate, can be carried out with the parameters of the $\mathrm{FI}$ and the growth curves, respectively. Selection for heavier adult pigs is antagonistic to selection for higher maturation rate, better FE and higher FI precocity in CB pigs. The trajectory of $\mathrm{FI}$ along the growing-finishing period is very similar in pigs fed either a corn/soy or a wheat/barley/co-products diet. GxF was absent for these curves when pigs were fed either diets. When selecting for $\mathrm{Fl}$ and growth curves in $\mathrm{CB}$ pigs, accounting for differences in these ingredients in pig diets is unnecessary.

Key words: breeding program, feed efficiency, gamma function of maintenance energy expenditure, genotype by feed interaction, growth curves 


\subsection{Introduction}

Improving feed efficiency (FE) of crossbred (CB) pigs in commercial environments is a priority in pig breeding programs. As the purebred-crossbred correlation for feed intake (FI) and FE traits is around 0.65 (Godinho et al., 2018a), selection based on records of $\mathrm{FI}$ and $\mathrm{FE}$ of $\mathrm{CB}$ pigs is worthwhile. Both $\mathrm{FI}$ and $\mathrm{FE}$ were shown to be environmentally sensitive traits in pigs (Knap and Wang, 2012). In addition, FE was affected by genotype by feed interaction (GxF) when pigs were fed different diets (Godinho et al., 2018b). The magnitude of GxF depended on the growth phase of the pigs. However, neither FI nor growth were affected by GxF. Individual daily FI records per pigs are becoming increasingly available, thus allowing the study of each pig's FI trajectory throughout its whole growing-finishing period, the so-called FI curves. The study of FI curves under different diets can clarify the GxF for FE. These curves have been studied using random regression models (RRMs) (Schnyder et al., 2001; Chen et al., 2010; Cai et al., 2011a; Cai et al., 2011b; Wetten, et al., 2012; Coyne et al., 2017) and also using specific non-linear models (NLMs) (Kanis and Koops, 1990; Lorenzo Bermejo et al., 2003a; Lorenzo Bermejo et al., 2003b; Schinckel et al., 2009; Cai et al., 2011a; Vautier et al., 2011; Cai et al., 2012). RRMs generate genetic parameters along the whole $\mathrm{Fl}$ trajectory, but the regression coefficients from them have no biological meaning, making it impossible to make inferences on biological processes underlying the trajectory. On the other hand, NLMs are based on a reduced number of parameters that usually have biological interpretations and can be explored by pig breeding programs for the improvement of continuous traits like the FI and the growth trajectory. Using an NLM approach, breeding goals can be defined aiming to change the shape of the FI curve by treating its estimated parameters as phenotypic observations in genetic models. NLMs are implemented with functions that mimic the real behavior of the continuous trait along a dependent variable. In this sense, a Gamma function of the maintenance energy expenditure was proposed (van Milgen et al., 2008; van Milgen et al., 2015). This function allows for a reduction in $\mathrm{Fl}$ at higher body weights (BW), given that the pigs only eat for maintenance once they are mature and cease growing. Describing $\mathrm{Fl}$ for growth and maintenance throughout the whole growing-finishing period, this curve fully expresses the pig's intake and expenditure, thus, FE. To include the NLM parameters in a breeding program, it is important to know their correlation with other traits in the breeding goal. Therefore, the current study aimed: 1 ) to fit and compare the $\mathrm{FI}$ and the growth curve of three-way CB pigs fed two diets; 2) to verify the presence of GxF for the curves' parameters; 3 ) to estimate genetic parameters for the curves' parameters; 
and 4) to estimate genetic correlations between the curves' parameters and both growth performance traits and residual intake traits.

\subsection{Material and methods}

\subsubsection{Ethic statement}

Data for this study were collected at the Schothorst Feed Research B.V. farm during data recordings routinely performed in a commercial breeding program. All farm operations strictly adhered to Dutch legal regulations regarding the protection of animals (Gezondheids- en welzijnswetvoordieren).

\subsubsection{Experimental population and phenotypic data}

Phenotypic records of 2,230 three-way crossbred pigs, 1,114 boars and 1,116 gilts (offspring of $F 1$ sows, Large White $x$ Landrace, sired by a synthetic sire line) were obtained from an experiment to study GxF (Godinho et al., 2018b; Sevillano et al., 2018). In brief, the experimental design was a split-plot $2 \times 2$ with two sexes (boars and gilts), and two diets (corn/soy and wheat/barley/co-products). Details of the feeding program and the diet formulations are given in Sevillano et al. (2018). Littermates were evenly distributed over the two diets at BW of around $22 \mathrm{~kg}$ and taken off test and slaughtered around $122 \mathrm{~kg}$. The test period lasted 106 days on average. Pedigree records were available for all animals, up to a maximum of nine generations. A total of 3,991 animals were included in the pedigree with 608 different sires and 1065 different dams. BW $(\mathrm{kg})$ was recorded individually at birth, at weaning, and at the start, the middle and the end of the growing-finishing period, around day $0,27,62,117$ and 168 of life, respectively. Individual daily FI was recorded using IVOG-stations (Insentec, Marknesse, the Netherlands). To account for pigs' period of adaptation to the feeders, we discarded data from the first three days on test. As is common practice in commercial pig farms, pigs that achieved slaughter weight were removed from the pens once per week and sent to the slaughterhouse. Data of all pen mates recorded from the day just before the first pigs were removed from a pen onward were also discarded. In order to remove outliers in FI records, we defined an upper limit for $\mathrm{FI}$ equal to the median plus three median absolute deviations, $4.96 \mathrm{~kg}$, and we removed $0.24 \%$ of the records that were greater than this limit.

The analyses were conducted in two steps: firstly, individual curves were fitted using an NLM approach; secondly, curves' genetic parameters were predicted by treating the curve parameters as phenotypes in genetic models. 


\subsection{3 - 1st step: Curve fitting}

We fitted non-linear models separately for the four classes of pigs following the split-plot design of the experiment, i.e. boars or gilts fed corn/soy or wheat/barley/co-products. We implemented the approach using the maximum likelihood method in the $R(R, 2014)$ package $n$ Ime (nonlinear mixed-effects model) (Pinheiro et al., 2018). In order to use all available FI records, we firstly fitted a growth curve to have a predicted body weight for the pigs for every day on test. The Gompertz function (Gompertz, 1825) for body weight over time (Winsor, 1932) was chosen because it is one of the most widely used functions to describe animal's growth, and it allows comparison to other studies describing growth in pigs (e.g. Koivula et al., 2008; Knap, 2000; Cai et al., 2011a; Cai et al., 2012; Lázaro et al., 2017). Also, while studying several growth curves, Wellock et al. (2004) concluded that the Gompertz function happened to be the most suitable to predict the potential growth of pigs. The sigmoid shape of this function mimics the behavior of an animal's body weight over time, and thus, growth.

The following Gompertz growth model was assumed:

$$
y_{i j}=A_{i} \exp \left(-B_{i} \exp \left(-K_{i} t_{i j}\right)\right)+\varepsilon_{i j},
$$

where $y_{i j}$ is the observed BW $(\mathrm{kg})$ of individual i at age j; $A_{i}$ represents the mature body weight (adult or asymptotic weight); $B_{i}$ is a time scale parameter without direct biological interpretation; $K_{i}$ is the maturing rate (precocity measure); $t_{i j}$ is the day in which the body weight was measured; and $\varepsilon_{i j}$ is the residual term, considered as independent and identically normally distributed among individuals. On the basis of the Gamma function of maintenance energy expenditure (van Milgen et al., 2015), the following model was assumed:

$$
y_{i j}=\left(\left(a_{i}\left(b_{i} B W_{i j} \exp \left(-b_{i} B W_{i j}\right)\right)+1\right) c B W_{i j}{ }^{0.60}\right)+\varepsilon_{i j},
$$

where $y_{i j}$ is the observed daily feed intake (MJ net energy (NE)/day) of individual $i$ at BW $\mathrm{j}$ (predicted with [4.1]); $a_{i}$ is a dimensionless scale parameter; $b_{i}$ is a shape parameter; $c$ is a constant $(0.75 \mathrm{MJ} \mathrm{NE} / \mathrm{kg})$; and $\varepsilon_{i j}$ is the residual term, considered as independent and identically normally distributed among individuals. As proposed by Vautier et al. (2013), we also predicted the daily energy intake (DEI) of pigs at $50 \mathrm{~kg}\left(\mathrm{DEI}_{50}\right)$ and at $100 \mathrm{~kg}\left(\mathrm{DEI}_{100}\right)$ with [2], which were also used as phenotypes in the genetic models.

\subsection{4 - $2^{\text {nd }}$ step: Genetic parameters estimation}


Genetic parameters were estimated through a linear mixed model approach, implemented in ASReml (Gilmour et al., 2009):

$$
y=X b+Z u+W c+V g+e,
$$

where $y$ represents the vector of observations from the phenotypes (the parameters $A, B$ and $K$ in the Gompertz growth curve; the $a$ and $b$ parameters in the Gamma function, and $\mathrm{DEI}_{50}$ and $\mathrm{DEI}_{100}$ obtained with the Gamma function); $X$, $Z, W$ and $V$ are known incidence matrices; $b$ is a vector of fixed effects including the sex, diet (excluded in the GxF analyses), type of cross and pen within compartment for all traits, and the body weight at birth as a covariate of the parameters of the growth curve $(A, B$ and $K) ; u$ is the vector of random animal polygenic effects: $u \sim N\left(0, A \otimes \sum_{u}\right) ; \quad c$ is a vector of random non-genetic effects common to individuals born in the same litter: $c \sim N\left(0, I_{c} \otimes \sum_{c}\right) ; g$ is the vector of random pen effects (animals grouped together in the same pen nested within batch): $g \sim N\left(0, I_{g} \otimes \sum_{g}\right)$; $e$ is a vector of residuals: $e \sim N\left(0, I_{e} \otimes \sum_{e}\right)$; and $A$ is a matrix of additive genetic relationships among all individuals, $I_{c}, I_{g}$, and $I_{e}$ are identity matrices of the appropriate dimensions, and $\sum_{u}, \sum_{c}, \sum_{g}$, and $\sum_{e}$ are covariance matrices related to each effect.

\subsubsection{Genotype by feed interaction analyses}

We investigated the presence of GxF throughout a bivariate linear mixed model approach considering each curve parameter $(p)$ as a different phenotype when observed on pigs fed corn/soy (CS) or wheat/barley/co-products (WB). For these analyses, the model [3] can be rewritten as:

$$
\begin{gathered}
{\left[\begin{array}{c}
y_{p_{C S}} \\
y_{p_{W B}}
\end{array}\right]=} \\
{\left[\begin{array}{cc}
X_{p_{C S}} & 0 \\
0 & X_{p_{W B}}
\end{array}\right]\left[\begin{array}{l}
b_{p_{C S}} \\
b_{p_{W B}}
\end{array}\right]+\left[\begin{array}{cc}
Z_{p_{C S}} & 0 \\
0 & Z_{p_{W B}}
\end{array}\right]\left[\begin{array}{c}
u_{p_{C S}} \\
u_{p_{W B}}
\end{array}\right]+\left[\begin{array}{cc}
W_{p_{C S}} & 0 \\
0 & W_{p_{W B}}
\end{array}\right]\left[\begin{array}{c}
c_{p_{C S}} \\
c_{p_{W B}}
\end{array}\right]+} \\
{\left[\begin{array}{cc}
V_{p_{C S}} & 0 \\
0 & V_{p_{W B}}
\end{array}\right]\left[\begin{array}{l}
g_{p_{C S}} \\
g_{p_{W B}}
\end{array}\right]+\left[\begin{array}{c}
e_{p_{C S}} \\
e_{p_{W B}}
\end{array}\right]}
\end{gathered}
$$

with covariance symmetric matrices given by:

$$
\begin{aligned}
& \sum_{p_{u}}=\left[\begin{array}{cc}
\sigma_{p_{u_{C S}}}^{2} & \sigma_{p_{u_{C S}} p_{u_{W B}}} \\
& \sigma_{p_{u_{W B}}}^{2}
\end{array}\right] ; \quad \sum_{p_{c}}=\left[\begin{array}{cc}
\sigma_{p_{c_{C S}}}^{2} & \sigma_{p_{c_{C S}} p_{c_{W B}}} \\
& \sigma_{p_{c_{W B}}}^{2}
\end{array}\right] ; \\
& \sum_{p_{g}}=\left[\begin{array}{cc}
\sigma_{p_{g_{C S}}}^{2} & 0 \\
& \sigma_{p_{g_{W B}}}^{2}
\end{array}\right] ; \quad \sum_{p_{e}}=\left[\begin{array}{cc}
\sigma_{p_{e_{C S}}}^{2} & 0 \\
& \sigma_{p_{e_{W B}}}^{2}
\end{array}\right] \text {. }
\end{aligned}
$$


A genetic correlation lower than 1 (Falconer \& Mackay, 1996) would indicate the presence of GxF:

$$
r_{g_{C S W B}}=\frac{\sigma_{p_{u_{C S}}} p_{u_{W B}}}{\sqrt{\sigma_{p_{u_{C S}}^{2}}^{2} \sigma_{p_{u_{W B}}^{2}}^{2}}} .
$$

\subsubsection{Curves' parameters estimation}

To estimate genetic values for curve parameters, we implemented a multi-trait linear mixed model in ASReml (Gilmour et al., 2009) taking the curve parameters estimates as phenotypes.

In the case of the growth curve, the model [4.3] can be rewritten as:

$$
\begin{gathered}
{\left[\begin{array}{l}
y_{A} \\
y_{B} \\
y_{K}
\end{array}\right]=\left[\begin{array}{ccc}
X_{A} & 0 & 0 \\
0 & X_{B} & 0 \\
0 & 0 & X_{K}
\end{array}\right]\left[\begin{array}{l}
b_{A} \\
b_{B} \\
b_{K}
\end{array}\right]+\left[\begin{array}{ccc}
Z_{A} & 0 & 0 \\
0 & Z_{B} & 0 \\
0 & 0 & Z_{K}
\end{array}\right]\left[\begin{array}{l}
u_{A} \\
u_{B} \\
u_{K}
\end{array}\right]+} \\
{\left[\begin{array}{ccc}
W_{A} & 0 & 0 \\
0 & W_{B} & 0 \\
0 & 0 & W_{K}
\end{array}\right]\left[\begin{array}{l}
c_{A} \\
c_{B} \\
c_{K}
\end{array}\right]+\left[\begin{array}{ccc}
V_{A} & 0 & 0 \\
0 & V_{B} & 0 \\
0 & 0 & V_{K}
\end{array}\right]\left[\begin{array}{l}
g_{A} \\
g_{B} \\
g_{K}
\end{array}\right]+\left[\begin{array}{l}
e_{A} \\
e_{B} \\
e_{K}
\end{array}\right]}
\end{gathered}
$$

with covariance symmetric matrices given by:

$$
\begin{aligned}
\sum_{u}=\left[\begin{array}{ccc}
\sigma_{A_{u}}^{2} & \sigma_{A_{u} B_{u}} & \sigma_{A_{u} K_{u}} \\
& \sigma_{B_{u}}^{2} & \sigma_{B_{u} K_{u}} \\
& & \sigma_{K_{u}}^{2}
\end{array}\right] ; & \sum_{c}=\left[\begin{array}{ccc}
\sigma_{A_{c}}^{2} & \sigma_{A_{c} B_{c}} & \sigma_{A_{c} K_{c}} \\
& \sigma_{B_{c}}^{2} & \sigma_{B_{c} K_{c}} \\
& & \sigma_{K_{c}}^{2}
\end{array}\right] ; \\
\sum_{g}=\left[\begin{array}{ccc}
\sigma_{A_{g}}^{2} & \sigma_{A_{g} B_{g}} & \sigma_{A_{g} K_{g}} \\
& \sigma_{B_{g}}^{2} & \sigma_{B_{g} K_{g}} \\
& & \sigma_{K_{g}}^{2}
\end{array}\right] ; & \sum_{e}=\left[\begin{array}{ccc}
\sigma_{A_{e}}^{2} & \sigma_{A_{e} B_{e}} & \sigma_{A_{e} K_{e}} \\
& \sigma_{B_{e}}^{2} & \sigma_{B_{e} K_{e}} \\
& & \sigma_{K_{e}}^{2}
\end{array}\right] .
\end{aligned}
$$

In the case of the FI curve, the model [3] can be rewritten as:

$$
\begin{gathered}
{\left[\begin{array}{l}
y_{a} \\
y_{b}
\end{array}\right]=\left[\begin{array}{cc}
X_{a} & 0 \\
0 & X_{b}
\end{array}\right]\left[\begin{array}{l}
b_{a} \\
b_{b}
\end{array}\right]+\left[\begin{array}{cc}
Z_{a} & 0 \\
0 & Z_{b}
\end{array}\right]\left[\begin{array}{l}
u_{a} \\
u_{b}
\end{array}\right]+\left[\begin{array}{cc}
W_{a} & 0 \\
0 & W_{b}
\end{array}\right]\left[\begin{array}{l}
c_{a} \\
c_{b}
\end{array}\right]+\left[\begin{array}{cc}
V_{a} & 0 \\
0 & V_{b}
\end{array}\right]\left[\begin{array}{l}
g_{a} \\
g_{b}
\end{array}\right]+\left[\begin{array}{l}
e_{a} \\
e_{b}
\end{array}\right] ;} \\
{\left[\begin{array}{c}
y_{D E I_{50}} \\
y_{D E I_{100}}
\end{array}\right]=\left[\begin{array}{cc}
X_{D E I_{50}} & 0 \\
0 & X_{D E I_{100}}
\end{array}\right]\left[\begin{array}{c}
b_{D E I_{50}} \\
b_{D E I_{100}}
\end{array}\right]+\left[\begin{array}{cc}
Z_{D E I_{50}} & 0 \\
0 & Z_{D E I_{100}}
\end{array}\right]\left[\begin{array}{c}
u_{D E I_{50}} \\
u_{D E I_{100}}
\end{array}\right]+} \\
0 \\
{\left[\begin{array}{cc}
W_{D E I_{50}} & 0 \\
0 & W_{D E I_{100}}
\end{array}\right]\left[\begin{array}{c}
c_{D E I_{50}} \\
c_{D E I_{100}}
\end{array}\right]+\left[\begin{array}{cc}
V_{D E I_{50}} & 0 \\
0 & V_{D E I_{100}}
\end{array}\right]\left[\begin{array}{c}
g_{D E I_{50}} \\
g_{D E I_{100}}
\end{array}\right]+\left[\begin{array}{c}
e_{D E I_{50}} \\
e_{D E I_{100}}
\end{array}\right] ;}
\end{gathered}
$$

with covariance symmetric matrices given by:

$$
\sum_{u}=\left[\begin{array}{cc}
\sigma_{a_{u}}^{2} & \sigma_{a_{u} b_{u}} \\
& \sigma_{b_{u}}^{2}
\end{array}\right] ; \quad \sum_{c}=\left[\begin{array}{cc}
\sigma_{a_{c}}^{2} & \sigma_{a_{c} b_{c}} \\
& \sigma_{b_{c}}^{2}
\end{array}\right] ;
$$




$$
\begin{array}{cc}
\sum_{g}=\left[\begin{array}{cc}
\sigma_{a_{g}}^{2} & \sigma_{a_{g} b_{g}} \\
& \sigma_{b_{g}}^{2}
\end{array}\right] ; & \sum_{e}=\left[\begin{array}{cc}
\sigma_{a_{e}}^{2} & \sigma_{a_{e} b_{e}} \\
& \sigma_{b_{e}}^{2}
\end{array}\right] ; \\
\sum_{u}=\left[\begin{array}{cc}
\sigma_{D E I_{50 u}}^{2} & \sigma_{D E I_{50 u} D E I_{100 u}} \\
\sigma_{D E I_{100 u}}^{2}
\end{array}\right] ; & \sum_{c}=\left[\begin{array}{cc}
\sigma_{D E I_{50} 0_{c}}^{2} & \sigma_{D E I_{50} D E I_{100} c} \\
\sigma_{D E I_{100_{c}}}^{2}
\end{array}\right] ; \\
\sum_{g}=\left[\begin{array}{cc}
\sigma_{D E I_{50 g}}^{2} & \sigma_{D E I_{50 g} D E I_{100} g} \\
\sigma_{D E I_{100 g}}^{2}
\end{array}\right] ; & \sum_{e}=\left[\begin{array}{cc}
\sigma_{D E I_{50} 0_{e}}^{2} & \sigma_{D E I_{50} e_{e E I_{100}}} \\
& \sigma_{D E I_{100 e}}^{2}
\end{array}\right] .
\end{array}
$$

\subsubsection{Genetic and phenotypic correlations estimation between the feed intake and growth curves, and growth performance and residual intake traits}

A similar multi-trait linear mixed model approach was implemented to assess the genetic and phenotypic correlations between the parameters from the $\mathrm{FI}$ and growth curves, and also, between the parameters of both curves and growth performance traits and residual intake traits. The growth performance traits included were: average daily gain on test (ADG, g/d), average daily energy intake $(A D E I, M J / d)$, lipid deposition (LD, g/d) and protein deposition (PD, g/d). The residual intake traits included were: residual energy intake $(\mathrm{REI}, \mathrm{g} / \mathrm{d})$ and residual feed intake (RFI, g/d). The details on the calculation of these traits, and their phenotypic and genetic parameters are presented by Godinho et al. (2018b).

\subsection{Results}

\subsubsection{Growth and feed intake curves}

The estimated parameters of the growth and FI curves are presented in Table 4.1. The growth curves differed between boars fed either diet. Boars fed the wheat/barley/co-products diet had lower estimates for A-mature-weight and higher $K$-maturation-rate than boars fed the corn/soy diet. In gilts, the growth curves did not differ.

The opposite was observed for the FI curve, which did not differ for boars fed either diet, but in gilts, the $b$-shape parameter was higher with the wheat/barley/co-products diet than with the corn/soy diet, while the a-scale parameter did not differ. While the $\mathrm{DEI}_{100}$ of boars or gilts fed either diets did not differ, the $\mathrm{DEI}_{50}$ was higher when boars or gilts were fed the wheat/barley/coproducts diet. Most parameters significantly differed when comparing boars and gilts. 
Regarding the growth curve, boars had higher A-mature-weight and lower $K$ maturation-rate than gilts. Regarding the $\mathrm{FI}$ curve, boars presented a lower a-scale parameter and lower predicted energy intake at 50 and $100 \mathrm{~kg}\left(\mathrm{DEI}_{50}\right.$ and $\left.\mathrm{DEI}_{100}\right)$ than gilts. The $b$-shape parameter of the FI curve in gilts fed the wheat/barley/coproducts diet was higher in comparison with boars, while this parameter did not differ in boars and gilts fed the corn/soy diet.

Table 4.1 Mean (standard deviation) for curve parameters ${ }^{1}$.

\begin{tabular}{|c|c|c|c|c|}
\hline \multirow[b]{2}{*}{$\begin{array}{c}\text { Curve } \\
\text { Parameters }\end{array}$} & \multicolumn{2}{|c|}{ Boars } & \multicolumn{2}{|c|}{ Gilts } \\
\hline & $\operatorname{CS}(n=547)$ & WB $(n=567)$ & $\mathrm{CS}(n=558)$ & WB $(n=558)$ \\
\hline & \multicolumn{4}{|c|}{ Growth } \\
\hline A & $262.6^{\mathrm{a}}(63.8)$ & $252.5^{b}(60.3)$ & $238.4^{c}(44.7)$ & $236.0^{c}(40.5)$ \\
\hline B & $5.01^{\mathrm{a}}(0.21)$ & $4.99^{\mathrm{a}}(0.22)$ & $4.96^{\mathrm{b}}(0.23)$ & $4.93^{c}(0.20)$ \\
\hline \multirow[t]{2}{*}{ K } & $\begin{array}{c}1.16 \mathrm{E}-02^{\mathrm{a}} \\
(1.81 \mathrm{E}-03)\end{array}$ & $\begin{array}{c}1.19 \mathrm{E}-02^{\mathrm{b}} \\
(1.81 \mathrm{E}-03)\end{array}$ & $\begin{array}{l}1.20 \mathrm{E}-02^{\mathrm{bc}} \\
(1.45 \mathrm{E}-03)\end{array}$ & $\begin{array}{c}1.21 \mathrm{E}-02^{\mathrm{C}} \\
(1.39 \mathrm{E}-03)\end{array}$ \\
\hline & \multicolumn{4}{|c|}{ Feed intake } \\
\hline a & $4.16^{\mathrm{a}}(0.64)$ & $4.13^{\mathrm{a}}(0.57)$ & $4.34^{b}(0.65)$ & $4.31^{b}(0.59)$ \\
\hline b & $\begin{array}{c}1.37 \mathrm{E}-02^{\mathrm{a}} \\
(4.64 \mathrm{E}-03)\end{array}$ & $\begin{array}{c}1.40 \mathrm{E}-02^{\mathrm{a}} \\
(4.07 \mathrm{E}-03)\end{array}$ & $\begin{array}{l}1.41 \mathrm{E}-02^{\mathrm{a}} \\
(4.52 \mathrm{E}-03)\end{array}$ & $\begin{array}{l}1.50 \mathrm{E}-02^{\mathrm{b}} \\
(3.96 \mathrm{E}-03)\end{array}$ \\
\hline $\mathrm{DEI}_{50}$ & $18.5^{\mathrm{a}}(1.38)$ & $18.7^{\mathrm{b}}(1.35)$ & $19.1^{\mathrm{c}}(1.54)$ & $19.5^{d}(1.60)$ \\
\hline $\mathrm{DEI}_{100}$ & $28.4^{\mathrm{a}}(3.60)$ & $28.4^{\mathrm{a}}(3.32)$ & $28.9^{b}(3.56)$ & $28.8^{\mathrm{b}}(3.29)$ \\
\hline
\end{tabular}

A, mature weight; B, time scale parameter (no direct biological interpretation); and $\mathrm{K}$, maturation rate; parameters of the Gompertz growth curve; $a$, scale; and $b$, shape parameter of the Gamma function of the maintenance energy expenditure; $\mathrm{DEl}_{50}$, predicted energy intake at $50 \mathrm{~kg}$, and, $\mathrm{DEI}_{100}$, predicted energy intake at $100 \mathrm{~kg}$; CS, diet based on corn and soybean meal; WB, diet based on wheat and barley with high amounts of added proteinrich co-products. Means followed by different letters differ according to T-test $(\mathrm{P}<0.05)$.

\subsubsection{Genotype by feed interaction analyses}

The values of genetic correlation estimates $\left(r_{\mathrm{g}}\right)$ between the performances of pigs under each diet are presented in Table 4.2. All $r_{\mathrm{g}}$ values were between 0.95 and unity, which indicated the absence of GxF for these parameters, thus the absence of GxF for growth and FI curves.

\subsubsection{Curves and Genetic Parameters Estimation}

After concluding that GxF was absent, we decided to continue the estimation of genetic parameters using only a common curve corrected for the fixed effect of diet. Also, as the $B$ parameter of the Gompertz curve is an integration parameter 
that has no direct biological interpretation, we decided not to show genetic parameters for it.

Table 4.2 Genetic correlations (SE) between the curve parameters ${ }^{1)}$ of pigs fed a diet based on corn and soybean meal and pigs fed a diet based on wheat and barley with high amounts of added protein-rich co-products.

\begin{tabular}{|c|c|c|c|c|c|c|c|}
\hline \multirow{2}{*}{ Curve parameters } & \multicolumn{3}{|c|}{ Growth } & \multicolumn{4}{|c|}{ Feed Intake } \\
\hline & $\mathrm{A}$ & B & $\mathrm{K}$ & $\mathrm{a}$ & $\mathrm{b}$ & $\mathrm{DEI}_{50}$ & $\mathrm{DEI}_{100}$ \\
\hline$r_{g_{C S W B}}$ & $\begin{array}{c}1.00 \\
(0.31)\end{array}$ & $\begin{array}{c}1.00 \\
(0.19)\end{array}$ & $\begin{array}{c}1.00 \\
(0.42)\end{array}$ & $\begin{array}{c}0.95 \\
(0.22)\end{array}$ & $\begin{array}{c}0.98 \\
(0.39)\end{array}$ & $\begin{array}{c}0.99 \\
(0.15)\end{array}$ & $\begin{array}{c}1.00 \\
(0.37)\end{array}$ \\
\hline
\end{tabular}

${ }^{1} \mathrm{~A}=$ mature weight , $\mathrm{B}=$ time scale parameter (no direct biological interpretation), and $\mathrm{K}=$ maturation rate, parameters of the Gompertz growth curve; $a=$ scale, and, $b=$ shape parameter of the Gamma function of the maintenance energy expenditure, $\mathrm{DEI}_{50}=$ predicted energy intake at $50 \mathrm{~kg}$, and, $\mathrm{DEI}_{100}=$ predicted energy intake at $100 \mathrm{~kg} ; \mathrm{CS}=$ diet based on corn and soybean meal, WB = diet based on wheat and barley with high amounts of added protein-rich co-products. 1.00 = value higher than 0.995 .

Table 4.3 Contribution (SE) of different random effects ${ }^{1}$ to the estimation of the curve parameters ${ }^{2}$.

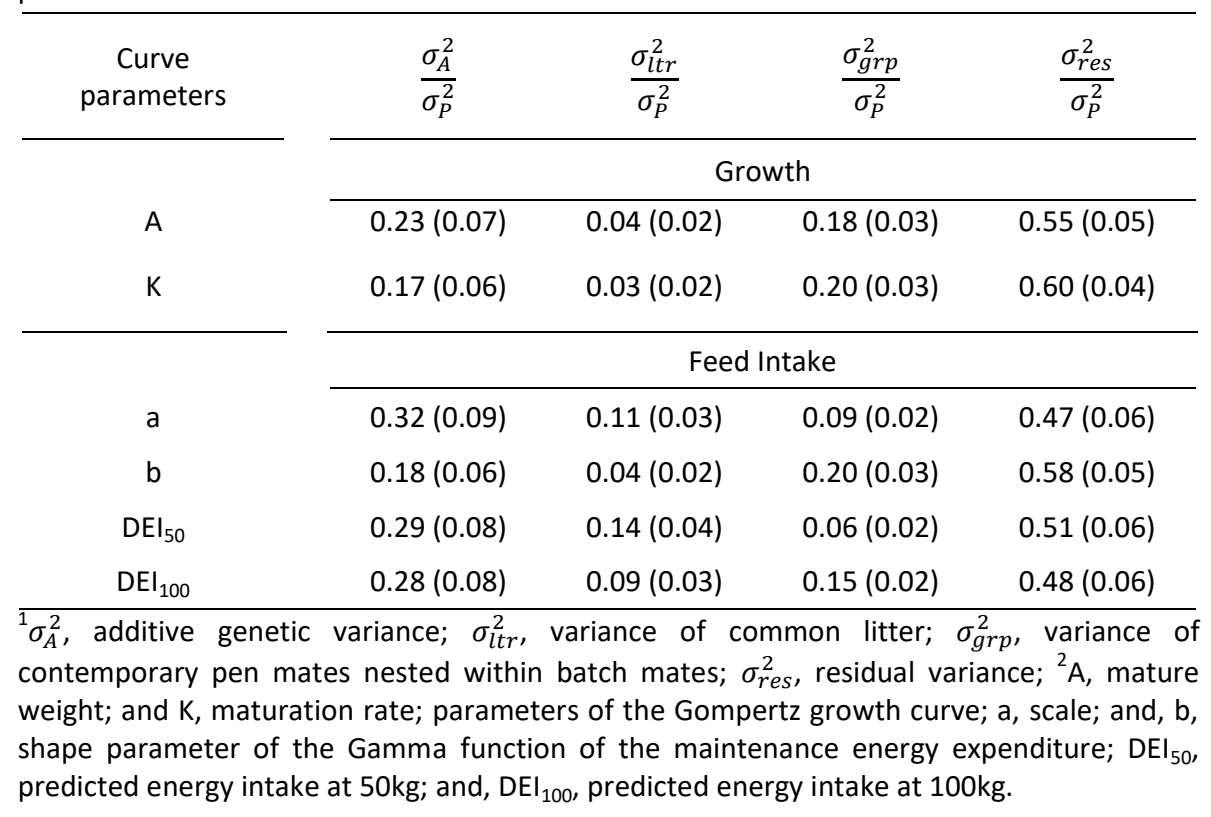

The contributions of all random effects to the estimation of the curve parameters, expressed as a percentage of the phenotypic variance, are presented in Table 4.3. All curve parameters presented medium to high heritability estimates. 
The genetic and phenotypic correlations between parameters of the same curves are presented in Table 4.4. A-mature-weight and K-maturation-rate were strongly negatively correlated, meaning that pigs with higher precocity would achieve a lower BW at maturity. The $a$-scale and $b$-shape parameter of the FI curve were also strongly negatively correlated. The genetic correlation between $\mathrm{DEI}_{50}$ and $\mathrm{DEI}_{100}$ was high, but lower than 1.0, meaning that $\mathrm{Fl}$ in the beginning and at the end of the growing-finishing period do not behave completely as the same trait. $\mathrm{DEI}_{50}$ and $\mathrm{DEI}_{100}$ both presented high genetic correlations with the a-scale parameter of the $\mathrm{FI}$ curve. $\mathrm{DEI}_{100}$ was strongly negatively correlated with the $b$-shape parameter of the Fl curve, meaning that pigs with higher value for $b$-shape eat less in the end of the growing-finishing period.

Table 4.4 Genetic and phenotypic correlations ${ }^{1}$ (SEs) between the curve parameters ${ }^{2}$.

\begin{tabular}{|c|c|c|c|c|}
\hline \multirow[t]{2}{*}{$\begin{array}{c}\text { Curve } \\
\text { parameters }\end{array}$} & & \multicolumn{2}{|c|}{ Growth } & \\
\hline & & A & $\mathrm{K}$ & \\
\hline A & & & $-0.87(0.01)$ & \\
\hline \multirow[t]{3}{*}{ K } & & $-0.93(0.05)$ & & \\
\hline & \multicolumn{4}{|c|}{ Feed Intake } \\
\hline & $a$ & $b$ & $\mathrm{DEI}_{50}$ & $\mathrm{DEl}_{100}$ \\
\hline a & & $-0.47(0.02)$ & $0.69(0.01)$ & $0.86(0.01)$ \\
\hline b & $-0.61(0.16)$ & & $0.14(0.03)$ & $-0.80(0.01)$ \\
\hline $\mathrm{DEI}_{50}$ & $0.85(0.07)$ & $-0.17(0.24)$ & & $0.45(0.02)$ \\
\hline $\mathrm{DEI}_{100}$ & $0.95(0.03)$ & $-0.79(0.09)$ & $0.71(0.12)$ & \\
\hline
\end{tabular}

\subsubsection{Genetic and phenotypic correlations between curve parameters, growth performance, and residual intake traits}

The genetic and phenotypic correlations between the parameters of the growth curve and the parameters of the $\mathrm{Fl}$ curve are presented in Table 4.5. A-matureweight was strongly positively correlated with both the a-scale parameter of the $\mathrm{FI}$ curve and $\mathrm{DEI}_{100}$, was moderately positively correlated with $\mathrm{DEI}_{50}$, and strongly negatively correlated with the $b$-shape parameter of the Fl curve. K-maturationrate was strongly positively correlated with the $b$-shape parameter of the $\mathrm{Fl}$ curve, and moderately negatively correlated with both the a-scale parameter of the $\mathrm{FI}$ curve and $\mathrm{DEI}_{100}$.

The genetic and phenotypic correlations between the parameters of the growth and $\mathrm{FI}$ curves, and the growth performance and residual intake traits are presented 
in Table 4.6 and Table 4.7, respectively. Genetic correlations between A-matureweight and ADG, ADEI and PD, were high and positive. This parameter presented unfavorable genetic correlations with REI and RFI. Genetic correlations with $K$ maturation-rate were moderate and negative with ADG, ADEI and PD. This parameter presented favorable genetic correlations with REI and RFI, and unfavorable with BF and LD. The a-scale parameter presented high and positive genetic correlations with most of the traits. On the other hand, the b-shape parameter presented negative genetic correlations with most of the traits. $\mathrm{DEI}_{50}$ and $\mathrm{DEI}_{100}$ presented positive genetic correlations with all traits, being high with $A D G, A D E I, L D, P D$, and RFI, and moderate with BF, PD and REI.

\subsection{Discussion}

\subsubsection{Genotype by feed interaction for feed efficiency}

One of the aims of the current study was to fit and compare the FI (Gamma function) and growth curves of crossbred pigs fed a corn/soy or a wheat/barley/coproducts diet, and investigate GxF for the parameters of the curves.

The most meaningful differences found in the curves of pigs fed different diets (Table 4.1) were the difference in the growth curves parameters in boars, and the higher $b$-shape parameter of the FI curve in gilts fed the wheat/barley/co-products diet. The pattern found in boars fed the wheat/barley/co-products diet (lower $A$ mature-weight and higher $K$-maturation-rate) seems to be preferred since the higher A-mature-weight of boars fed the corn/soy diet is not going to be advantageous as growing-finishing pigs are slaughtered at about half their mature weight. Nevertheless, this parameter gives the scale of the growth curve and is correlated with the BW of the pig at any given age, which means that high $A$ mature-weight is desired. The $K$-maturation-rate is an important parameter as it is related to the rate of growth of the pigs, thus, a pig that grows faster is preferred.

Regarding the $\mathrm{Fl}$ curve, the meaningful difference between diets is the $b$-shape parameter in gilts. Gilts fed the wheat/barley/co-products diet presented higher $b$ shape than gilts fed the corn/soy diet. The differences between diets in the $A$ mature-weight, $K$-maturation-rate, and b-shape parameter were only present in one of the sexes. Moreover, when comparing the whole picture of the FI curves (Table 4.1), we conclude that the trajectory of $\mathrm{Fl}$ along the growing-finishing period is very similar regardless of whether the pigs were fed a corn/soy or a wheat/barley/co-products diet. 
Table 4.5 Genetic and phenotypic correlations (SE) between the feed intake and the growth curve parameters ${ }^{1}$.

\begin{tabular}{|c|c|c|c|}
\hline & Curve & & \\
\hline & & A & $\mathrm{K}$ \\
\hline & Feed Intake & & \\
\hline$r_{g}$ & & $0.63(0.14)$ & $-0.37(0.20)$ \\
\hline$r_{p}$ & $d$ & $0.48(0.02)$ & $-0.22(0.03)$ \\
\hline$r_{g}$ & $h_{-}$ & $-0.85(0.10)$ & $0.78(0.13)$ \\
\hline$r_{p}$ & D & $-0.63(0.02)$ & $0.58(0.02)$ \\
\hline$r_{g}$ & $\mathrm{DEI}$ & $0.35(0.20)$ & $0.09(0.22)$ \\
\hline$\underline{r_{p}}$ & LLI50 & $0.12(0.03)$ & $0.13(0.03)$ \\
\hline$\overline{r_{g}}$ & DFI & $0.80(0.09)$ & $-0.57(0.17)$ \\
\hline$r_{p}$ & LL'100 & $0.64(0.02)$ & $-0.44(0.02)$ \\
\hline
\end{tabular}

${ }^{1} \mathrm{~A}$, mature weight; and $\mathrm{K}$, maturation rate; parameters of the Gompertz curve describing pigs' growth; a, scale; and, $b$, shape parameter of the Gamma function of the maintenance energy expenditure; $\mathrm{DEI}_{50}$, predicted energy intake at $50 \mathrm{~kg}$; and, $\mathrm{DEI}_{100}$, predicted energy intake at $100 \mathrm{~kg}$.

GxF was absent for the FI and growth curves when pigs were fed the two trial diets. For both the $\mathrm{FI}$ and growth curves, the genetic correlations between the parameters when pigs were fed the different diets were either very high or unity (Table 4.2). This means that when selecting for $\mathrm{FI}$ and growth curves in crossbred pigs, accounting for these differences in diets is not necessary, as no re-ranking of the best genotypes would be expected. Godinho et al. (2018b) investigated GxF when the same crossbred pigs were fed those two diets. They found that GxF was absent for growth (ADG) and for FI. GxF was present for FE when considering the residual energy intake (REI) and residual feed intake (RFI), but it was absent when FE was calculated as feed conversion rate. Furthermore, GxF was higher for REI, and was found to be dependent on the growth stage of the pigs (i.e. low, moderate and absent, during the starter, grower, and finisher phases, respectively). There was a question mark over whether the trajectories of the $\mathrm{FI}$ and growth curves would be affected by GxF, and whether this could explain why GxF was only observed for FE, but not for FI and ADG. The current results show that this was not the case.

\subsubsection{Improving the feed intake and growth curves}

Under an NLM approach, breeding goals can be defined aiming to change the shape of a curve such as the growth curve or FI curve of growing-finishing pigs. The shape can be changed by treating its estimated parameters as phenotypic 
observations in genetic models and giving weights to them in the selection index. This means that once we have estimated the breeding values for a small set of curve parameters for each animal, decisions can then be taken to increase or decrease the values of these parameters over subsequent generations, and consequently changing the mean shape of the growth or FI trajectory in a group of animals.

In the case of the growth curve, the Gompertz function has two parameters with a well-understood biological interpretation. As the curve describes body weight over time, $A$ will give the plateau of the curve, meaning the time when growth ceases and weight stays constant. It represents the mature or adult weight of the animal. The $K$ parameter gives the slope of this curve, measuring how quickly the plateau will be reached. It represents the maturation rate. Selection for higher A-matureweight leads to heavier animals at maturity, while selection for higher $K$ maturation-rate leads to animals that grow faster and mature precociously.

Several functions have been used to describe $\mathrm{Fl}$ as a function of pig's age or as function of pig's BW (Kanis and Koops, 1990; Lorenzo Bermejo et al., 2003a; Lorenzo Bermejo et al., 2003b; Schinckel et al., 2009; Cai et al., 2011a; Vautier et al., 2011; Cai et al., 2012). As NLMs are implemented with functions that mimic the real behaviour of the continuous trait along a dependent variable, we believe that functions that describe $\mathrm{FI}$ as a function of BW should be preferred given the strong interrelation between $\mathrm{FI}$ and growth (Emmans, 1997; Strathe, 2009; van Milgen, 2015). Whether animals grow as a consequence of FI (push effect) or they eat to meet the requirements of growth (pull effect), the interrelation is strong. Animals' FI will depend more on their BW than on their age. Besides being less empirical, functions that describe $\mathrm{FI}$ as a function of BW present a measure of $\mathrm{FE}$ throughout the growing-finishing period.

Here we use the Gamma function of the maintenance energy expenditure that is measuring the total $\mathrm{FI}$ as multiples of the $\mathrm{FI}$ required for the maintenance at the current BW. Therefore, it describes the level of FI for growth and maintenance over the BW of the pig. The dimensionless a-scale parameter is related to amount of feed that is used for growth, and the $b$-shape parameter is related to the relative changes of the curve in both axes, $\mathrm{FI}$ and BW. In contrast to the parameters of the growth curve, it is not immediately clear in which direction the parameters of the FI curve should be changed. To show the impact of the parameters $a$-scale and $b$ shape of this curve, we use the average, minimum, and maximum values predicted for individual pigs in the study. The different combinations of average, minimum, and maximum parameter values are combined to plot the FI curves of 'average' and 'extreme' pigs (Figure 1). 
$\mathrm{NE}$ intake $=$ Multiples of maintenance $\mathbf{x} \mathrm{NE}$ intake for maintenance

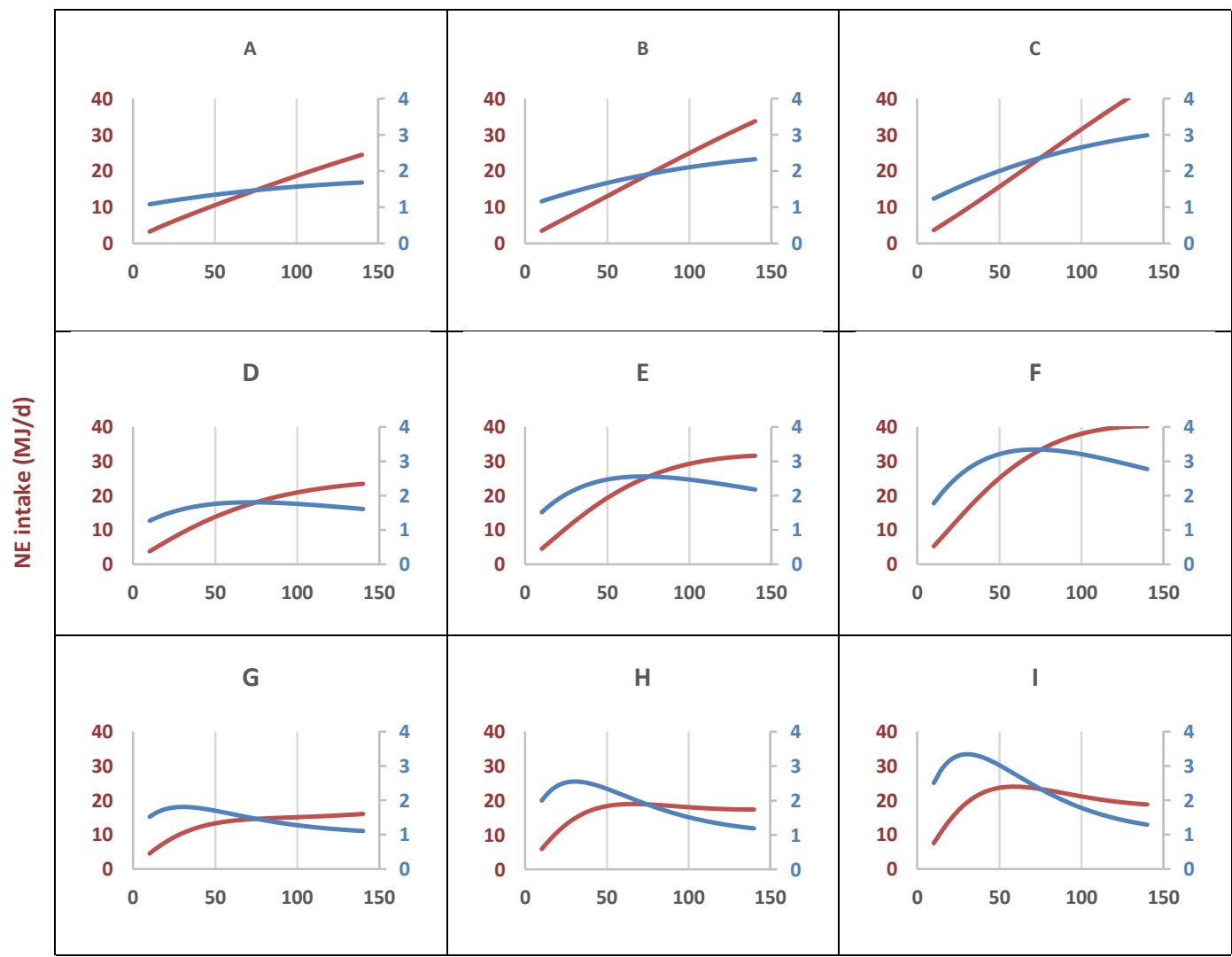

Body weight (kg)

\begin{tabular}{|c|c|c|c|c|c|c|c|c|c|}
\hline Parameters $^{1}$ & A & B & C & D & E & $\mathbf{F}$ & G & H & 1 \\
\hline$a$ & 2.19 & 4.23 & 6.36 & 2.19 & 4.23 & 6.36 & 2.19 & 4.23 & 6.36 \\
\hline $\boldsymbol{b}$ & $\begin{array}{c}3.81 \mathrm{E}- \\
03\end{array}$ & $\begin{array}{c}3.81 \mathrm{E}- \\
03\end{array}$ & $\begin{array}{c}3.81 \mathrm{E}- \\
03\end{array}$ & $\begin{array}{c}1.39 \mathrm{E}- \\
02\end{array}$ & $\begin{array}{c}1.39 \mathrm{E}- \\
02\end{array}$ & $\begin{array}{c}1.39 \mathrm{E}- \\
02\end{array}$ & $\begin{array}{c}3.29 \mathrm{E}- \\
02\end{array}$ & $\begin{array}{c}3.29 \mathrm{E}- \\
02\end{array}$ & $\begin{array}{c}3.29 \mathrm{E}- \\
02\end{array}$ \\
\hline $\mathrm{DEI}_{50}$ & 10.5 & 13.1 & 15.7 & 13.8 & 19.3 & 25.1 & 13.3 & 18.4 & 23.7 \\
\hline $\mathrm{DEI}_{100}$ & 18.7 & 25.0 & 31.6 & 20.9 & 29.3 & 38.1 & 15.1 & 18.0 & 21.1 \\
\hline
\end{tabular}

Figure 4.1 Feed intake curves fitted with the Gamma function of maintenance energy expenditure using the average, minimum, and maximum predicted values for parameters $a$ scale-FE and b-shape-precocity. The left (A, D, and $\mathrm{G})$, middle (B, E, and $\mathrm{H})$ and right (C, F, and I) columns correspond to low, minimum and maximum values for a-scale-FE, respectively. The top ( $A, B$ and $C$ ), middle $(D, E$, and $F$ ) and bottom $(G, H$, and $I)$ rows correspond to low, minimum and maximum values for $b$-shape-precocity, respectively. ${ }^{1} a$, scale; and, $b$, shape parameter of the Gamma function of the maintenance energy expenditure; DEI50, predicted energy intake at $50 \mathrm{~kg}$; and, DEI100, predicted energy intake at $100 \mathrm{~kg}$ 
The red curves represent the predicted $\mathrm{Fl}$ curves in net energy basis (left-hand scale), obtained by multiplying the first part of the equation in Figure 1 , the blue curves, by the $\mathrm{FI}$ required for the maintenance at a given $\mathrm{BW}\left(0.75 \mathrm{BW}^{0.60}\right)$ (righthand scale). Going from the left column to the right column in Figure 1 shows the effect of changing the a-scale parameter from low to high. Going from the top row to the bottom row shows the effect of changing the $b$-shape parameter from low to high. As the middle column and middle row are based on average parameters, the average curve of the pigs in the current study is shown in the middle of this graph. From the analysis of Figure 1, we conclude that the dimensionless a-scale parameter represents pigs' $\mathrm{FE}$, and we therefore propose to call this parameter $a$ scale-FE. It gives the slope of the curve. Curves on the left side of the figure (panels $A, D$ and $G$ ) are flatter, and these pigs will have lower $D E I_{50}$ and $D E I_{100}$. This means that they eat less at the same stage of growth than pigs with steeper curves at the right side of the figure ( $\mathrm{C}, \mathrm{F}$ and $\mathrm{I})$. Therefore, selection for lower a-scale-FE will improve pigs $\mathrm{FE}$. Also, from this analysis, we conclude that the $b$-shape parameter represents pigs' precocity concerning $\mathrm{Fl}$; therefore we propose to call this parameter $b$-shape-precocity. Pigs with the straight curves on the top of Figure 1 (panels A, B and C), have a constant rate of increase in intake through the growingfinishing period which means that pigs with those curves have low $\mathrm{DEI}_{50}$ and high $\mathrm{DEI}_{100}$. The increase in the value of the $b$-shape-precocity parameter bulges the curve up and to the left. Changing $b$ from low to average levels increases both $\mathrm{DEI}_{50}$ and $\mathrm{DEI}_{100}$ which can be seen from comparing the top $(\mathrm{A}, \mathrm{B}$, and $\mathrm{C})$ to the middle row ( $D, E$, and $F)$. When $b$ values are changed from average to higher values, the $D I_{100}$ is decreased considerably, while $D E I_{50}$ is increased (G, H, and I). Therefore, selection for higher $b$-shape-precocity will increase pigs' precocity for FI. In brief this means that selecting pigs for higher $b$ results in increased $\mathrm{Fl}$ in the start of the growing-finishing period and decreased Fl later in the growing-finishing period. The decreased Fl later on the growing-finishing period may be due to a compensation mechanism (i.e. precocious pigs, with a higher early intake, have consequently a lower need for FI later on). This high intake early and low intake later is a desired profile in pork production and the parameter $b$-shape-precocity now provides an opportunity to select for this.

Even though selection for pigs with lower $\mathrm{FI}$ is intuitively attractive, selection for high $\mathrm{Fl}$ capacity has been advocated. The reason is that selection for leaner pigs with low feed conversion ratio may lead to reduced $\mathrm{Fl}$ capacity and thus less potential to grow (Kanis, 1988; de Vries and Kanis, 1992; Webb, 1998; Eissen, 2000). Moreover, it has been proposed that selection should be conducted to increase FI in early stage of growth (Eissen, 2000; Schulze et al., 2001; Lorenzo 
Bermejo et al., 2003a), while Fl at the end of the growing-finishing period should be reduced because at this stage pigs feed conversion is lower and high FI will result in high lipid deposition. Lorenzo Bermejo et al. (2003a, 2003b) studied 15 functions describing $\mathrm{Fl}$ over age of crossbred pigs and suggested that selection for early $\mathrm{FI}$ may be conducted by the age of the pig at which FI plateau is reached in a linearsegmented function, or by the age of the pig corresponding to maximum increment in $\mathrm{FI}$ per day in a logistic function. These strategies aim to improve the pigs' $\mathrm{FI}$ precocity. Given the properties of the Gamma function of the maintenance energy expenditure, we believe that the use of the parameters of this curve to improve FE and $\mathrm{FI}$ precocity is a better strategy for a pig breeding program because it allows breeders to define an optimal FI profile and apply selection on the curve parameters to move toward this optimum

\subsubsection{Genetic Parameters for the feed intake and growth curves}

The medium to high heritability estimates for all curves' parameters (Table 4.3), indicate that these traits are a feasible alternative for pig breeding programs aiming to change the shape of the $\mathrm{Fl}$ and the growth curves in crossbred pigs.

Table 4.6 Genetic correlations (SE) between the feed intake and the growth curves parameters ${ }^{1)}$ and the growth performance and residual intake traits.

\begin{tabular}{lccccccc}
\hline $\begin{array}{l}\text { Curve } \\
\text { parameters }\end{array}$ & ADG & BF & ADEI & LD & PD & REI & RFI \\
\hline Growth curve & & & & & & & \\
& & & & & & & \\
$\mathrm{A}$ & 0.80 & -0.34 & 0.60 & 0.10 & 0.84 & 0.34 & 0.30 \\
& $(0.10)$ & $(0.23)$ & $(0.15)$ & $(0.25)$ & $(0.09)$ & $(0.21)$ & $(0.18)$ \\
& -0.46 & 0.49 & -0.31 & 0.18 & -0.58 & -0.21 & -0.11 \\
$\mathrm{~K}$ & $(0.21)$ & $(0.21)$ & $(0.23)$ & $(0.26)$ & $(0.18)$ & $(0.23)$ & $(0.21)$ \\
\hline Gamma function & & & & & & & \\
& 0.79 & 0.38 & 0.94 & 0.68 & 0.62 & 0.66 & 0.86 \\
a & $(0.09)$ & $(0.18)$ & $(0.03)$ & $(0.13)$ & $(0.13)$ & $(0.17)$ & $(0.08)$ \\
& -0.52 & -0.04 & -0.45 & -0.33 & -0.50 & -0.23 & -0.32 \\
b & $(0.18)$ & $(0.25)$ & $(0.19)$ & $(0.25)$ & $(0.18)$ & $(0.26)$ & $(0.22)$ \\
& 0.68 & 0.49 & 0.91 & 0.73 & 0.45 & 0.57 & 0.78 \\
DEI $_{50}$ & $(0.12)$ & $(0.19)$ & $(0.05)$ & $(0.14)$ & $(0.16)$ & $(0.18)$ & $(0.09)$ \\
& 0.79 & 0.32 & 0.90 & 0.70 & 0.60 & 0.52 & 0.71 \\
$\mathrm{DEI}_{100}$ & $(0.08)$ & $(0.20)$ & $(0.05)$ & $(0.14)$ & $(0.13)$ & $(0.20)$ & $(0.12)$ \\
\hline
\end{tabular}

\footnotetext{
${ }^{1} \mathrm{~A}$, mature weight; and $\mathrm{K}$, maturation rate, parameters of the Gompertz curve describing Animals' growth; a, scale; and, b, shape parameter of the Gamma function of the maintenance energy expenditure; $\mathrm{DEl}_{50}$, predicted energy intake at $50 \mathrm{~kg}$; and, $\mathrm{DEl}_{100}$, predicted energy intake at $100 \mathrm{~kg}$.
} 
Regarding the growth curve, selection should be conducted optimally to increase both A-mature-weight and $K$-maturation-rate. However, these parameters are genetically strongly negatively correlated (Table 4.4), meaning that selection for pigs that grow faster is antagonistic to selection for pigs that achieve a higher adult BW.

Regarding the $\mathrm{FI}$ curve, we concluded previously that selection should be conducted to lower $a$-scale-FE and increase $b$-shape-precocity, thus, increasing FE and precocity, respectively. Both parameters were favorably genetically correlated. These parameters presented favorable genetic correlations with the $K$-maturationrate but unfavorable with A-mature-weight. Selection for a-scale-FE, b-shapeprecocity and $K$-maturation-rate will decrease $A$-mature-weight, but this will not be a problem given the big difference between mature weight and slaughter weight.

Table 4.7 Phenotypic correlations (SE) between the feed intake and the growth curves parameters ${ }^{1}$ and the growth performance and residual intake traits.

\begin{tabular}{lccccccc}
\hline $\begin{array}{l}\text { Curve } \\
\text { parameters }\end{array}$ & ADG & BF & DEI & LD & PD & REI & RFI \\
\hline Growth curve & & & & & & & \\
& & & & & & & \\
A & 0.60 & 0.25 & 0.38 & 0.41 & 0.53 & -0.24 & -0.08 \\
& $(0.02)$ & $(0.03)$ & $(0.02)$ & $(0.02)$ & $(0.02)$ & $(0.03)$ & $(0.03)$ \\
& & & & & & & \\
K & -0.25 & -0.10 & -0.07 & -0.15 & -0.23 & 0.22 & 0.14 \\
& $(0.03)$ & $(0.03)$ & $(0.03)$ & $(0.03)$ & $(0.03)$ & $(0.03)$ & $(0.03)$ \\
\hline Gamma function & & & & & & & \\
& 0.60 & 0.45 & 0.82 & 0.58 & 0.42 & 0.30 & 0.59 \\
a & $(0.02)$ & $(0.02)$ & $(0.01)$ & $(0.02)$ & $(0.02)$ & $(0.02)$ & $(0.02)$ \\
& -0.42 & -0.25 & -0.35 & -0.35 & -0.33 & 0.10 & -0.04 \\
b & $(0.02)$ & $(0.03)$ & $(0.02)$ & $(0.02)$ & $(0.02)$ & $(0.03)$ & $(0.03)$ \\
& 0.49 & 0.35 & 0.74 & 0.47 & 0.34 & 0.38 & 0.65 \\
DEI ${ }_{50}$ & $(0.02)$ & $(0.02)$ & $(0.01)$ & $(0.02)$ & $(0.03)$ & $(0.02)$ & $(0.02)$ \\
\multirow{2}{*}{ DEI $_{100}$} & 0.66 & 0.44 & 0.77 & 0.60 & 0.49 & 0.15 & 0.45 \\
& $(0.02)$ & $(0.02)$ & $(0.01)$ & $(0.02)$ & $(0.02)$ & $(0.03)$ & $(0.02)$ \\
\hline
\end{tabular}

${ }^{1} \mathrm{~A}$, mature weight; and $\mathrm{K}$, maturation rate, parameters of the Gompertz growth curve; $\mathrm{a}$, scale; and, b, shape parameter of the Gamma function of the maintenance energy expenditure; $\mathrm{DEI}_{50}$, predicted energy intake at $50 \mathrm{~kg}$; and, $\mathrm{DEI} \mathrm{I}_{100}$, predicted energy intake at $100 \mathrm{~kg}$.

The negative genetic relationship between mature weight and maturation rate predicted with different growth curves has been pointed out by Fitzhugh (1976) as general in several species, following that the increase of maturation rate is a strategy to increase efficiency and one of the main reasons for altering the shape of a growth curve. This high negative correlation has been reported in purebred 
(Koivula et al., 2008) and crossbred pigs (Silva et al., 2013), who also suggested increasing maturation rate and decreasing mature weight as an appealing strategy for a pig breeding program. In beef cattle, Crispim et al. (2015) suggested selection to decrease mature weight and increase maturation rate as a strategy to select for faster early growth rate animals with lower mature weight, as they require less energy for maintenance and reach puberty earlier in life.

The different profiles of genetic correlations of the curves parameters both with growth performance traits and residual intake traits (Table 4.6) is important for a breeding program aiming to change the shape of these curves. Although the standard errors of some of these estimates were high, a pattern is clear. The genetic correlations of $K$-maturation-rate, $a$-scale- $F E$, and $b$-shape-precocity were favorable with residual intake traits (REI and RFI), but unfavorable with ADG and PD. The opposite happened with A-mature-weight that was unfavorably genetically correlated with REI and RFI, but these correlations were favorable with ADG and PD. In addition, the a-scale-FE and b-shape-precocity were also favorably genetically correlated with BF and LD, which is expected as pigs with higher FI precocity and FE should deposit less fat. It is indicated that selection for heavier pigs is antagonistic to selection for better FE and high precocity in crossbred pigs. As mentioned before, as the common slaughter weight in pork production systems is around half the mature weight herein predicted, selection for maturation rate, $\mathrm{FI}$ precocity and better FE might be advantageous.

\section{5 conclusions}

The medium to high heritability estimates for all curves' parameters, indicate that these traits are a feasible alternative for pig breeding programs aiming to change the shape of the $\mathrm{FI}$ and the growth curves in crossbred pigs. Selection for crossbred pigs with better FE and higher FI precocity, and for higher mature weight and maturation rate, can be carried out with the parameters of the Gamma function of maintenance energy expenditure, and the Gompertz growth curve, respectively. Applying these functions indicate that selection for heavier pigs is antagonistic to selection for higher maturation rate, better FE and higher FI precocity in crossbred pigs.

The trajectory of $\mathrm{FI}$ along the growing-finishing period is very similar in pigs fed either a corn/soy or a wheat/barley/co-products diet. GxF was absent for these curves when pigs were fed either diets. When selecting for $\mathrm{Fl}$ and growth curves in crossbred pigs, accounting for differences in these ingredients in swine diets is not necessary. 


\subsection{References}

Cai, W., H. Wu, and J. C. M. Dekkers. 2011a. Longitudinal analysis of body weight and feed intake in selection lines for residual feed intake in pigs. Asian-australas. J. Anim. Sci. 24:17-27.

Cai, W., M. S. Kaiser, and J. C. M. Dekkers. 2011b. Genetic analysis of longitudinal measurements of performance traits in selection lines for residual feed intake in Yorkshire swine. J. Anim. Sci. 89:1270-1280.

Cai, W., M. S. Kaiser, and J. C. M. Dekkers. 2012. Bayesian analysis of the effect of selection for residual feed intake on growth and feed intake curves in Yorkshire swine. J. Anim. Sci. 90:127-141.

Chen, C. Y., I. Misztal, S. Tsuruta, B. Zumbach, W. O. Herring, J. Holl, and M. Culbertson. 2010. Estimation of genetic parameters of feed intake and daily gain in Durocs using data from electronic swine feeders. J. Anim. Breed. Genet. 127:230-234.

Coyne, J. M., D. P. Berry, K. Matilainen, M.-L. Sevon-Aimonen, E. A. Mantysaari, J. Juga, T. Serenius, and N. McHugh. 2017. Genetic co-variance functions for live weight, feed intake, and efficiency measures in growing pigs. J. Anim. Sci. 95:3822-3832.

Crispim, A. C., M. J. Kelly, S. E. F. Guimarães, F. F. e Silva, M. R. S. Fortes, R. R. Wenceslau, and S. Moore. 2015. Multi-trait GWAS and new candidate genes annotation for growth curve parameters in Brahman cattle. Plos One. 10(10):e0139906.

de Vries, A. G., and E. Kanis. 1992. A growth model to estimate economic values for food intake capacity in pigs. Anim. Prod. 55:241-246.

Eissen, J. 2000. Breeding for feed intake capacity in pigs. PhD Thesis. Wageningen Agricultural University, the Netherlands.

Emmans, G. C. 1997. A method to predict the food intake of domestic animals from birth to maturity as a function of time. J. Theor. Biol. 186:189-200.

Fitzhugh, H. A. J. 1976. Analysis of growth curves and strategies for altering their shape. J. Anim. Sci. 42:1036-1051.

Gilmour, A. R., B. J. Gogel, B. R. Cullis, and R. Thompson. 2009. ASReml User Guide Release 3.0 VSN International Ltd, Hemel Hempstead, HP1 1ES, UK.

Godinho, R. M., R. Bergsma, F. F. Silva, C. A. Sevillano, E. F. Knol, M. S. Lopes, P. S. Lopes, J. W. M. Bastiaansen, and S. E. F. Guimarães. 2018a. Genetic correlations between feed efficiency traits, and growth performance and carcass traits in purebred and crossbred pigs. J. Anim. Sci. 96:817-829. 
Godinho, R. M., J. W. M. Bastiaansen, C. A. Sevillano, F. F. Silva, S. E. F. Guimarães, and R. Bergsma. 2018b. Genotype by feed interaction for feed efficiency and growth performance traits in pigs. J. Anim. Sci. doi.org/10.1093/jas/sky304

Gompertz, B. 1825. On the nature and the function expressive of the law of human mortality and a new method of determining the value of life contingencies. Philos. Trans. R. Soc., 115:513-585.

Kanis, E. 1988. Food intake capacity in relation to breeding and feeding of growing pigs. PhD Thesis. Wageningen Agricultural University, the Netherlands.

Kanis, E., and W. J. Koops. 1990. Daily gain, food intake and food efficiency in pigs during the growing period. Anim. Sci. 50:353-364.

Knap, P.W. 2000. Time trends of Gompertz growth parameters in 'meat-type' pigs. Anim. Sci. 70:39-49.

Knap, P. W., and L. Wang. 2012. Pig breeding for improved feed efficiency. In: J. F. Patience, Feed efficiency in swine. Wageningen Academic Publishers, Wageningen, the Netherlands. p. 167-181.

Koivula, M., M. -L. Sevón-Aimonen, I. Strandén, K. Matilainen, T. Serenius, K. J. Stalder, and E. A. Mäntysaari. 2008. Genetic (co)variances and breeding value estimation of Gompertz growth curve parameters in Finnish Yorkshire boars, gilts and barrows. J. Anim. Breed. Genet. 125:168-175.

Lázaro, S. F., N. Ibáñez-Escriche, L. Varona, F. F. e Silva, L. C. Brito, S. E. F. Guimarães, P. S. Lopes. 2017. Bayesian analysis of pig growth curves combining pedigree and genomic information. Livest. Sci. 201:34-40.

Lorenzo Bermejo, J., R. Roehe, G. Rave, E. Kalm. 2003a. Comparison of linear and nonlinear functions and covariance structures to estimate feed intake pattern in growing pigs. Liv. Produc. Sci. 82:15-26.

Lorenzo Bermejo, J., R. Roehe, V. Schulze, H. Looft, E. Kalm. 2003b. Genetic change of feed intake curves in growing pigs using non-linear two-stage genetic analysis and linear random regression models. J. Anim. Breed. Genet. 120:217-227.

Pinheiro, J., D. Bates, S. DebRoy, D. Sarkar and R Core Team. 2018. Nlme: Linear and Nonlinear Mixed Effects Models. R package version 3.1-137, https://CRAN.Rproject.org/package=nlme.

Schinckel, A. P., M. E. Einstein, S. Jungst, C. Booher, and S. Newman. 2009. Evaluation of different mixed model nonlinear functions to describe the feed intakes of pigs of different sire and dam lines. The professional animal scientist 25:345-359.

Schnyder, U., A. Hofer, F. Labroue, and N. Künzi. 2001. Genetic parameters of a random regression model for daily feed intake of performance tested French Landrace and Large White growing pigs. Genet. Sel. Evol. 33:635-658. 
Schulze, V., R. Roehe, H. Looft, and E., Kalm. 2001. Genetische Analyse des individuellen Wachstums-und Futteraufnahmeverlaufs von Jungebern während der Eigenleistungsgruppenprüfung. Arch. Anim. Breed. 44: 139-156.

Sevillano, C. A., C. V, Nicolaiciuc, F. Molist, J. Pijlman, and R. Bergsma. 2018. Effect of feeding cereals-alternative ingredients diets or corn-soybean meal diets on performance and carcass characteristics of growing-finishing gilts and boars. J. Anim. Sci. doi.org/10.1093/jas/sky339

Silva, F. F., M. D. V., Resende, G. S. Rocha, D. A. S. Duarte, P. S. Lopes, O. J. B. Brustolini, S. Thus, J. M. S. Viana, and S. E. F. Guimaraes. 2013 Genomic growth curves of an outbred pig population. Gen. Mol. Bio. 36: 520-527.

Strathe, A. B., H. Sørensen, and A. Danfaer. 2009. A new mathematical model for combining growth and energy intake in animals: The case of the growing pig. J. Theor. Biol. 261:165-175.

van Milgen, J., Valancogne, A., Dubois, S., Dourmad, J. Y., Seve, B. \& Noblet, J. 2008. InraPorc: A model and decision support tool for the nutrition of growing pigs. Animal Feed Science and Technology, 143, 387-405.

van Milgen, J., J. Y. Dourmad, J. Noblet, E. Labussière, F. Garcia-Launay, S. Dubois, A. Valancogne, and L. Brossard, 2015. InraPorc: Where do we come from and where do we want to go? In: N. K. Sakomura, R. Gous, I Kyriazakis., and L Hauschild, eds. Nutritional modeling for pigs and poultry. CABI ed. 318p.

Vautier, B., N. Quiniou, J. van Milgen, L. Brossard. 2013. Accounting for variability among individual pigs in deterministic growth models. Animal. 7:8, 1265-1273.

Vautier, B., N. Quiniou, J. van Milgen, L. Brossard. 2011. Modelling the dynamics of feed intake in growing pigs; interest for modeling populations of pigs. In: 62th Annual Meeting of the European Association for Animal Production . In: Book of abstracts of the 62nd annual meeting of the European federation of animal science (Stavanger, Norway). p.105-110. Wageningen Academic Publishers, Wageningen, the Netherlands.

Webb, A. J. 1998. Objectives and strategies in pig improvement: an applied perspective. J. Dairy Sci. 81: 36-46.

Wellock, I. J., G. C. Emmans, and I. Kyriazakis. 2004. Describing and predicting potential growth in the pig. Anim. Sci. 78:379-388.

Wetten, M., J. Ødegård, O. Vangen, and T. H. E. Meuwissen. 2012. Simultaneous estimation of daily weight and feed intake curves for growing pigs by random regression. Animal 6:433-439.

Winsor, C. P. 1932. The Gompertz curve as a growth curve. Proc. Natl. Acad. Sci. USA 18:1-8. 


\section{Genetic correlations between growth performance and carcass traits of purebred and crossbred pigs raised in tropical and temperate climates}

Rodrigo M Godinho ${ }^{1,2}$, Rob Bergsma ${ }^{3}$, Fabyano $\mathrm{F} \mathrm{Silva}^{1}$, Claudia A Sevillano ${ }^{2,3}$, Egbert F Knol ${ }^{3}$, Hans Komen ${ }^{2}$, Simone EF Guimarães ${ }^{1}$, Marcos S Lopes ${ }^{3,4}$, John WM Bastiaansen²

${ }^{1}$ Department of Animal Science, Universidade Federal de Viçosa, 36570-900, Viçosa, Brazil; ${ }^{2}$ Wageningen University \& Research Animal Breeding and Genomics, $6700 \mathrm{AH}$, Wageningen, the Netherlands; ${ }^{3}$ Topigs Norsvin Research Center, 6640 AA, Beuningen, the Netherlands; ${ }^{4}$ Topigs Norsvin, 80420-210, Curitiba, Paraná, Brazil. 


\begin{abstract}
In pig breeding, selection commonly takes place in purebred (PB) pigs raised mainly in temperate climates (TEMP) under optimal environmental conditions in nucleus farms. However, pork production typically makes use of crossbred (CB) animals raised in non-standardised commercial farms, which are located in TEMP but also in tropical and subtropical regions (TROP). Besides the differences in the genetic background of $P B$ and $C B$, differences in climate conditions, and differences between nucleus and commercial farms, can lower the genetic correlation between the performance of PB in the TEMP ( $P B_{\text {TEMP }}$ ) and $C B$ in the TROP ( $\left.C B_{\text {TROP }}\right)$. Genetic correlations $\left(r_{\mathrm{g}}\right)$ between the performance of $\mathrm{PB}$ and $\mathrm{CB}$ growing-finishing pigs in TROP and TEMP environments have not been reported yet, due to the scarcity of data in both CB and TROP. Therefore, the current study aimed: 1) to verify the presence of genotype by environment interaction (GxE), and 2) to estimate the purebred-crossbred correlation $\left(r_{p c}\right)$ for carcass and growth performance traits when $\mathrm{PB}$ and three-way $\mathrm{CB}$ pigs are raised in two different climatic environments (TROP and TEMP). Phenotypic records of 217,332 PB and 195,978 CB, representing two climatic environments: TROP (Brazil) and TEMP (Canada, France, and the Netherlands) were available for this study. The PB population consisted of two sire lines, and the $C B$ population consisted of terminal three-way cross progeny generated by crossing sires from one of the PB sire lines with commercially available two-way maternal sow crosses. GxE appears to be present for average daily gain, protein deposition and muscle depth $\left(r_{g}=0.64-0.79\right)$. With the presence of GxE, phenotypes should be collected in TROP when the objective is to improve the performance of $\mathrm{CB}$ for those traits in the TROP. Also, based on the basis of the estimates of $r_{\mathrm{pc}}$ for $\mathrm{PB}_{\mathrm{TEMP}}$ and $\mathrm{CB}_{\text {TROP }}(0.22-0.25)$ ), and on the expected responses to selection, selecting based only on the performance of $\mathrm{PB}_{\text {TEMP }}$ would give limited genetic progress in the $\mathrm{CB}_{\text {TROP }}$. The $r_{p c}$ estimates in the TROP are high (0.80-0.99), suggesting that combined crossbred-purebred selection schemes (CCPS) would probably not be necessary to increase genetic progress in $\mathrm{CB}_{\text {TROP }}$. However, the calculated responses to selection shows that when the objective is the improvement of $\mathrm{CB}_{\mathrm{TROP}}$, direct selection based on the performance of $\mathrm{CB}_{\mathrm{TROP}}$ has the potential to lead to the higher genetic progress compared to indirect selection on the performance of $\mathrm{PB}_{\text {TROP. }}$.
\end{abstract}

Key words: genotype by environment interactions, breeding program, correlated response, crossbred pigs, growing-finishing pigs 


\subsection{Introduction}

In pig breeding, consolidation has resulted in a reduced number of global breeding programs where selection takes place in purebred pigs (PB) raised mainly in temperate climates (TEMP) under optimal environmental conditions (Knap, 2005). However, pork production typically makes use of crossbred (CB) animals raised in non-standardised commercial farms all over the world. Around $50 \%$ of the commercial farms are in tropical and subtropical regions (TROP; Rosé, 2017).

As the final product of pig breeding is mostly a crossbred animal (Hidalgo et al., 2015), the genetic correlation between the performance of $P B$ and $C B\left(r_{p c}\right)$ is an important parameter to be considered by pig breeding companies applying crossbreeding schemes. Combined crossbred purebred selection (CCPS) is recommended for traits presenting $r_{p c}$ estimates lower than 0.8 (Wei and van der Werf, 1994), which is the case for pigs, as the average of the reported $r_{p c}$ estimates is 0.63 (Wientjes and Calus, 2017). Other than a genotype by genotype interaction (GXG) (caused by differences in the genetic background of $P B$ and $C B$ ), a genotype by environment interaction (GXE) (caused by differences between nucleus and commercial farms) may also lower the $r_{p c}$ (Bijma and van Arendonk, 1998; Zumbach et al., 2007; Tussel et al., 2016; Wientjes and Calus, 2017; Godinho et al., 2018). Robertson (1959) suggested that GxE is important when genetic correlations $\left(r_{g}\right)$ are below 0.80 , and this suggestion is widely accepted in animal breeding.

In addition to the variable sensitivity of genotypes to changes from nucleus to commercial farming systems, differences in sensitivity to climate conditions can also lower the $r_{p c}$ when PB and CB are kept in different climates. Sensitivity to ambient temperature and humidity (heat stress) has been described in growingfinishing pigs (Zumbach, et al., 2008a, 2008b; Fragomeni et al., 2016; Rosé et al., 2017). In an international context, the sensitivity to heat stress becomes especially important because pork production is spread between TROP and TEMP. Nevertheless, to the best of our knowledge, $r_{g}$ between the performance of PB in TEMP and $C B$ growing-finishing pigs in TROP environments have not been reported yet. This is probably due to the scarcity of data in both CB and TROP. Therefore, the current study aimed: 1) to verify the presence of GxE, and 2) to estimate the $r_{p c}$ for carcass and growth performance traits when $\mathrm{PB}$ and three-way $\mathrm{CB}$ pigs are raised in both TEMP and TROP climates.

\subsection{Material and methods}

\subsubsection{Ethic statement}


Data for this study was collected as part of routine data recording in a commercial breeding program. Observations from 19 farms located in four different countries (Brazil, Canada, France and the Netherlands) were used in this study. All these farms are operating in line with the regulations on protection of animals of their countries.

\subsubsection{Dataset}

To verify the presence of GxE for different climates, phenotypic records were available on 217,332 PB pigs and 195,978 CB pigs (Table 5.1), across two climatic environments, TROP (Brazil) and TEMP (Canada, France and the Netherlands). The PB population consisted of two sire lines, which were located in 12 farms. The CB population consisted of terminal three-way crossbred progeny generated by crossing sires from one of the PB sire lines with commercially available two-way maternal sow crosses, which were located in eight farms. Pedigree records were available for all animals, up to a maximum of 17 generations. A total of 535,272 pigs were included in the pedigree file with 6,229 different sires and 30,800 different dams.

Table 5.1 Number of pigs with phenotypes of each line (sire or three-way-cross) by country.

\begin{tabular}{|c|c|c|c|c|c|c|c|}
\hline \multirow[b]{2}{*}{ Country } & \multicolumn{2}{|l|}{ PB } & \multicolumn{3}{|c|}{ CB } & \multirow[b]{2}{*}{ CB 2} & \multirow[b]{2}{*}{ Total } \\
\hline & Farms & Sire 1 & Sire 2 & Farms & CB 1 & & \\
\hline Brazil & 4 & 7,223 & 13,451 & 2 & 975 & 4,785 & 26,434 \\
\hline Canada & 3 & 46,598 & 14,989 & 1 & 9045 & - & 70,632 \\
\hline France & 1 & 29,345 & 24,196 & - & - & - & 53,541 \\
\hline $\begin{array}{l}\text { The } \\
\text { Netherlands }\end{array}$ & 4 & 39,134 & 42,396 & 5 & 80,044 & 101,129 & 262,703 \\
\hline Total & 12 & 122,300 & 95,032 & 8 & 90,064 & 105,914 & 413,310 \\
\hline
\end{tabular}

$\mathrm{PB}$, purebred; $\mathrm{CB}$, Three-way-cross between the numbered sire line and a crossbred female (Large White $\mathrm{x}$ Landrace)

\subsubsection{Traits}

Each growth performance trait (average daily gain, ADG; lipid deposition, LD; and protein deposition, PD) and carcass trait (back fat thickness, BF; and muscle depth, $M D$ ) were considered as a different trait depending on the group of pigs in which it was measured (i.e. the four groups $\mathrm{PB}_{\text {TROP }}, \mathrm{CB}_{\text {TROP }}, \mathrm{PB}_{\text {TEMP }}$, and $\mathrm{CB}_{\text {TEMP }}$ ) (Table 5.2). All animals were weighed individually at the start of the growing-finishing period ('ontest'). All PB, and all CB in Canada, had their body weight (BW, kg) recorded, and back fat thickness (BF, $\mathrm{mm}$ ) and muscle depth (MD, $\mathrm{mm}$ ) ultrasonically measured at the end of the growing-finishing period ('offtest'). In Brazil, most of CB 
had their BW recorded, and BF ultrasonically measured at offtest. A small number, 250 , of CB pigs in one farm in Brazil, had their hot carcass weight (HCW) recorded at slaughter. All CB animals in the Netherlands had their HCW recorded along with BF and MD using the Hennessy Grading Probe (Hennessy Grading Systems, Auckland, New Zealand) or the Capteur Gras Maigre (CGM, Sydel, France) at slaughter. For the pigs with $\mathrm{BW}$ recorded offtest $\left(\mathrm{BW}_{\text {offtest }}\right)$, average daily gain ontest ( $A D G, g / d)$ was obtained as the difference between $B W_{\text {offest }}$ and $B W_{\text {ontest }}$ divided by the length of the test period. For the pigs with $\mathrm{HCW}$ recorded at

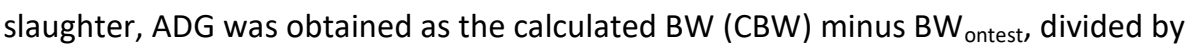
the length of the growing-finishing period. The formula used to obtain the CBW based on the HCW (Handboek varkenshouderij, 2004) was the following:

$$
C B W=1.3 \times H C W-0.0025 \times H C W^{2}+0.2075 \times H C W .
$$

Lipid deposition (LD, g/d) and protein deposition (PD, g/d) were estimated as the increment in lipid and protein mass content during the growing-finishing period based on BW and back fat measurements (de Greef et al., 1994):

$$
\begin{aligned}
& \% \text { fat }_{\text {offtest }}=\frac{B F, m m-1.87}{53.3}, \\
& \% \text { fat }_{\text {ontest }}=\% \text { fat }_{\text {offtest }} \times \frac{-0.000005\left(B W_{\text {ontest }}\right)^{2}+0.0019\left(B W_{\text {ontest }}\right)+0.0665}{-0.000005\left(B W_{\text {offtest }}\right)^{2}+0.0019\left(B W_{\text {offtest }}\right)+0.0665^{\prime}}, \\
& \text { Protein water ratio }=5.39(B W \times 0.14)^{-0.145}, \\
& \text { Ash }=0.03 \times B W, \\
& \text { Lipid mass }(L M)=\% \text { fat } \times 0.95 \times B W, \\
& \text { Protein mass }(P M)=\frac{0.95 \times B W-L M-\text { Ash }}{\text { Protein water ratio }+1^{\prime}} \\
& \text { LD }=\frac{\left(L M_{\text {offtest }}-\text { LM } M_{\text {ontest }}\right) \times 1000}{\text { Test length }, d}, \\
& P D=\frac{\left(P M_{\text {offtest }}-\text { PM } M_{\text {ontest }}\right) \times 1000}{\text { Test length }, d}
\end{aligned}
$$

\subsubsection{Genetic parameters estimation}

Univariate analyses were performed to estimate the variance components and heritabilities for all traits. Genetic correlations were estimated using bivariate analyses. A linear mixed model implemented in ASReml (Gilmour et al., 2009) was used for the analyses as follows:

$$
y=X b+Z a+W c+V g+U f+e
$$


Table 5.2 Number of observations (No.), mean ( $\mu$ ), standard deviation (SD), minimum (Min) and maximum (Max) for covariates ${ }^{1}$ and traits $^{2}$ used to estimate variance components and genetic correlations.

\begin{tabular}{|c|c|c|c|c|c|c|c|c|c|c|}
\hline \multirow[b]{2}{*}{ Traits } & \multicolumn{5}{|c|}{ TROP } & \multicolumn{5}{|c|}{ TEMP } \\
\hline & No. & $\mu$ & SD & Min & Max & No. & $\mu$ & SD & Min & Max \\
\hline \multicolumn{11}{|l|}{ Purebreds } \\
\hline BWbirth, g & & 1,658 & 331.5 & 660.0 & 2,670 & & - & - & - & - \\
\hline BWontest, kg & & 29.6 & 5.6 & 10.0 & 57.0 & & 32.1 & 8.4 & 9.0 & 59.0 \\
\hline BWofftest, kg & & 102.9 & 11.4 & 73.9 & 152.7 & & 125.9 & 10.0 & 94.3 & 155.1 \\
\hline$A D G, g / d$ & 20,344 & 934.5 & 128.1 & 543.0 & 1,464 & 192,767 & 1,001 & 138.6 & 540.0 & 1,474 \\
\hline$L D, g / d$ & 19,987 & 145.9 & 45.3 & 29.1 & 376.6 & 188,250 & 162.9 & 53.8 & 21.3 & 450.1 \\
\hline$P D, g / d$ & 19,987 & 160.6 & 21.0 & 85.5 & 248.4 & 188,250 & 172.1 & 24.3 & 78.9 & 272.5 \\
\hline $\mathrm{BF}, \mathrm{mm}$ & 20,746 & 10.1 & 1.7 & 4.3 & 17.4 & 195,394 & 9.6 & 1.9 & 3.3 & 18.6 \\
\hline $\mathrm{MD}, \mathrm{mm}$ & 13,979 & 58.3 & 5.9 & 38.6 & 80.3 & 193,856 & 59.0 & 5.9 & 37.5 & 81.4 \\
\hline \multicolumn{11}{|l|}{ Crossbreds } \\
\hline BWbirth, g & & 1,445 & 325.7 & 450.0 & 2,350 & & 1,375 & 312.4 & 440.0 & 2,350 \\
\hline BWontest, kg & & 24.4 & 4.8 & 10.5 & 40.4 & & 25.7 & 4.7 & 10.2 & 40.8 \\
\hline BWofftest, kg & & 104.8 & 10.9 & 78.4 & 151.8 & & 118.6 & 9.0 & 79.0 & 150.0 \\
\hline $\mathrm{HCW}, \mathrm{kg}$ & & 93.1 & 7.9 & 68.0 & 113.9 & & 92.9 & 6.6 & 72.2 & 114.0 \\
\hline CBW, $\mathrm{kg}$ & & 118.5 & 8.3 & 90.9 & 139.2 & & 118.4 & 6.8 & 95.8 & 139.4 \\
\hline$A D G, g / d$ & 5,756 & 936.3 & 104.1 & 507.0 & 1,336 & 47,945 & 869.2 & 93.7 & 562.0 & 1,156 \\
\hline LD, g/d & 5,227 & 212.3 & 57.6 & 69.3 & 459.2 & 21,205 & 219.8 & 58.8 & 53.7 & 490.0 \\
\hline$P D, g / d$ & 5,227 & 144.1 & 13.8 & 92.0 & 200.4 & 21,205 & 138.9 & 19.2 & 64.7 & 211.7 \\
\hline $\mathrm{BF}, \mathrm{mm}$ & 5,577 & 13.1 & 2.3 & 6.1 & 20.3 & 190,064 & 13.6 & 2.6 & 5.5 & 24.1 \\
\hline $\mathrm{MD}, \mathrm{mm}$ & - & - & - & - & - & 190,563 & 62.4 & 6.5 & 39.7 & 86.6 \\
\hline
\end{tabular}

in which $y$ is the vector of observations; $X, Z, W, V$ and $U$ are known incidence matrices; $b$ is a vector of fixed effects (Table 5.3); $a$ is a vector of random additive genetic effects (breeding values), $a \sim N\left(0, A \otimes \sum_{a}\right) ; c$ is a vector of random nongenetic effects common to individuals born in the same litter, $c \sim N\left(0, I_{c} \otimes \sum_{c}\right) ; g$ is the vector of random pen effects (individuals grouped together in the same 
pen) $g \sim N\left(0, I_{g} \otimes \sum_{g}\right) ; f$ is the vector of random effects common to individuals performance-tested in the same compartment of the barn within the same contemporary group, $f \sim N\left(0, I_{f} \otimes \sum_{f}\right)$; and $e$ is a vector of residuals, $e \sim N\left(0, I_{e} \otimes\right.$ $\left.\sum_{e}\right)$. A is a matrix of average additive genetic relationships among all individuals, $I_{c}$, $I_{g}, I_{f}$ and $I_{e}$ are identity matrices of the appropriate dimensions and $\sum_{a}, \sum_{c}$, $\sum_{g}, \sum_{f}$ and $\sum_{e}$ are covariance matrices related to each effect. In the case of univariate analyses, the covariance matrix $\sum_{i}$ is a scalar with the variance component, $\sigma_{i}$, associated with the respective effect. In the case of bivariate analyses, the covariance matrices for $\mathrm{PB}_{\mathrm{TROP}}$ and $\mathrm{CB}_{\mathrm{TROP}}$ are given by:

$$
\begin{gathered}
\sum_{a}=\left[\begin{array}{cc}
\sigma_{a_{-} P B_{T R O P}}^{2} & \sigma_{a_{-} P B_{T R O P} C B_{T R O P}} \\
s y m & \sigma_{a_{-} C B_{T R O P}}^{2}
\end{array}\right] ; \sum_{c}=\left[\begin{array}{cc}
\sigma_{C_{-} P B_{T R O P}}^{2} & 0 \\
0 & \sigma_{C_{-} C B_{T R O P}}^{2}
\end{array}\right] ; \\
\sum_{g}=\left[\begin{array}{cc}
\sigma_{g_{-} P B_{T R O P}}^{2} & 0 \\
0 & \sigma_{g_{-} C B_{T R O P}}^{2}
\end{array}\right] ; \sum_{f}=\left[\begin{array}{cc}
\sigma_{f_{-} P B_{T R O P}}^{2} & 0 \\
0 & \sigma_{f_{-} C B_{T R O P}}^{2}
\end{array}\right] ; \\
\sum_{e}=\left[\begin{array}{cc}
\sigma_{e_{-} P B_{T R O P}}^{2} & 0 \\
0 & \sigma_{e_{-} C B_{T R O P}}^{2}
\end{array}\right] .
\end{gathered}
$$

Table 5.3 Fixed effects included in the vector $b$ of equation [5.1] for the traits ${ }^{1}$.

\begin{tabular}{ccc}
\hline Model & Dependent trait(s) & Fixed effects $^{2}$ \\
\hline A & ADG; LD; PD & $\mu+\mathrm{SEX}_{\mathrm{j}}+\mathrm{LINE}_{\mathrm{k}}+\mathrm{HYS}_{\mathrm{I}}+\mathrm{COMP}_{\mathrm{m}}+b_{1} \mathrm{BW}_{\text {birth }}$ \\
$\mathrm{B}$ & $\mathrm{BF}$ and MD offtest & $\mu+\mathrm{SEX}_{\mathrm{j}}+\mathrm{LINE}_{\mathrm{k}}+\mathrm{HYS}_{\mathrm{I}}+\mathrm{COMP}_{\mathrm{m}}+b_{1} \mathrm{BW}_{\text {offest }}$ \\
$\mathrm{C}$ & $\mathrm{BF}$ and MD at slaughter & $\mu+\mathrm{SEX}_{\mathrm{j}}+\mathrm{LINE}_{\mathrm{k}}+\mathrm{HYS}_{\mathrm{I}}+\mathrm{COMP}_{\mathrm{m}}+b_{1} \mathrm{HCW}$ \\
\hline
\end{tabular}

${ }^{1} A D G$, average daily gain; $L D$, lipid deposition; $P D$, protein deposition; $B F$, back fat thickness; $M D$, muscle depth. ${ }^{2}$ SEX, the sex of the pig; LINE, the line of the pig; HYS, Herd-Year-Season = farm $x$ year $x$ month of birth; COMP, compartment within barn $x$ farm; BW $_{\text {birth, body weight }}$ at birth; $\mathrm{BW}_{\text {offest, }}$ body weight offtest; $\mathrm{HCW}$, hot carcass weight (BF and MD were preadjusted for the covariate weight prior to the analysis).

For the bivariate analysis of the other combinations of groups $\mathrm{PB}_{\mathrm{TROP}}, \mathrm{CB}_{\mathrm{TROP}}$, $\mathrm{PB}_{\mathrm{TEMP}}$, and $\mathrm{CB}_{\mathrm{TEMP}}$, the covariance matrices are set up in the same manner. The $\mathrm{r}_{\mathrm{pc}}$ estimates in the TROP $\left(r_{p c_{T R O P}}\right)$ and in the TEMP $\left(r_{p c_{T E M P}}\right)$, the $r_{\mathrm{g}}$ between the performance of $\mathrm{PB}$ in both climates $\left(r_{g_{P B}}\right)$, the genetic correlation between the performance of $\mathrm{PB}_{\mathrm{TROP}}$ and $\mathrm{CB}_{\mathrm{TEMP}}\left(r_{p c_{T R O P-T E M P}}\right)$, and the genetic correlation between the performance of $\mathrm{PB}_{\mathrm{TEMP}}$ and $\mathrm{CB}_{\mathrm{TROP}}\left(r_{p c_{T E M P-T R O P}}\right)$ were estimated by:

$$
r_{p c_{T R O P}}=\frac{\sigma_{a_{-} P B_{T R O P} C B_{T R O P}}}{\sqrt{\sigma_{a_{-} P B_{T R O P}}^{2} \sigma_{a_{-} C B_{T R O P}}^{2}}} ; r_{p c_{T E M P}}=\frac{\sigma_{a_{-} P B_{T E M P} C B_{T E M P}}}{\sqrt{\sigma_{a_{-} P B_{T E M P}}^{2} \sigma_{a_{-} C B_{T E M P}}^{2}}} ;
$$




$$
\begin{gathered}
r_{g_{P B}}=\frac{\sigma_{a_{-} P B_{T R O P} P B_{T E M P}}}{\sqrt{\sigma_{a_{-} P B_{T R O P}}^{2} \sigma_{a_{-} P B_{T E M P}}^{2}}} ; r_{p c_{T R O P-T E M P}}=\frac{\sigma_{a_{-} C B_{T E M P} P B_{T R O P}}}{\sqrt{\sigma_{a_{-} C B_{T E M P}}^{2} \sigma_{a_{-} P B_{T R O P}}^{2}}} ; \\
r_{p c_{T E M P-T R O P}}=\frac{\sigma_{a_{-} C B_{T R O P} P B_{T E M P}}}{\sqrt{\sigma_{a_{-} C B_{T R O P}}^{2} \sigma_{a_{-} P B_{T E M P}}^{2}}} .
\end{gathered}
$$

\subsubsection{Responses to selection}

To assess the genetic progress a breeding program can achieve for $\mathrm{CB}_{\text {TROP }}$ performance for the traits studied here, we use the breeders' equation to calculate the responses to selection. Phenotypes measured in PB or CB and in TROP or TEMP were considered as four different traits, similar to Wientjes and Calus (2017). Three different responses to selection were calculated: 1 ) the response for the $\mathrm{CB}_{\text {TROP }}$ trait to direct selection based on $\mathrm{CB}_{\mathrm{TROP}}$ performance $\left.\left(R_{C B_{T R O P}\left(C B_{T R O P}\right)}\right) ; 2\right)$ the correlated response for the $\mathrm{CB}_{\text {TROP }}$ trait to indirect selection based on $\mathrm{PB}_{\mathrm{TROP}}$ performance $C R_{C B_{T R O P}\left(P B_{T R O P}\right)}$; and 3) the correlated response for the $\mathrm{CB}_{\mathrm{TROP}}$ trait to indirect selection based on $\mathrm{PB}_{\mathrm{TEMP}}$ performance $C R_{C B_{T R O P}\left(P B_{T E M P}\right)}$.

These three responses were calculated as follows (Falconer \& Mackay, 1996):

$$
R_{C B_{T R O P}\left(C B_{T R O P}\right)}=i_{C B_{T R O P}} x h_{C B_{T R O P}} x \sigma_{a_{-} C B_{T R O P}}
$$

in which $i_{C B_{T R O P}}$ is the intensity of selection on $C B_{T R O P}$ (assumed to be 1 in this study), $h_{C B_{T R O P}}$ is the square root of the heritability of the trait $C B_{T R O P}$, and $\sigma_{a_{-} C B_{T R O P}}$ is the genetic standard deviation of the trait $C B_{T R O P}$.

$$
C R_{C B_{\text {TROP }}\left(P B_{T R O P}\right)}=i_{P B_{T R O P}} x h_{P B_{T R O P}} x r_{p C_{T R O P}} x \sigma_{a_{-} C B_{T R O P}}
$$

in which $i_{P B_{T R O P}}$ is the intensity of selection on $P B_{T R O P}$ (assumed to be 1 in this study), $h_{P B_{T R O P}}$ is the square root of the heritability of the trait $P B_{T R O P}, r_{p C_{T R O P}}$ is the genetic correlation between the performance of $P B_{T R O P}$ and $C B_{T R O P}$, and $\sigma_{a_{-} C B_{T R O P}}$ is the genetic standard deviation of the trait $C B_{T R O P}$.

$$
C R_{C B_{T R O P}\left(P B_{T E M P}\right)}=i_{P B_{T E M P}} x h_{P B_{T E M P}} x r_{p c_{T E M P-T R O P}} x \sigma_{a_{-} C B_{T R O P}}
$$

in which $i_{P B_{T E M P}}$ is the intensity of selection on $P B_{T E M P}$ (assumed to be 1 in this study), $h_{P B_{T E M P}}$ is the square root of the heritability of the trait $P B_{T E M P}$, $r_{P c_{T E M P-T R O P}}$ is the genetic correlation between the performance of $P B_{T E M P}$ and $C B_{T R O P}$, and $\sigma_{a_{-} C B_{T R O P}}$ is the genetic standard deviation of the trait $C B_{T R O P}$. 
Table 5.4 Additive genetic, and phenotypic, variances, and contribution (SE) of different random effects ${ }^{1}$ to the estimation of the traits ${ }^{2}$ expressed as percentage of the phenotypic variance.

\begin{tabular}{|c|c|c|c|c|c|c|c|}
\hline Traits & $\sigma_{A}^{2}$ & $\sigma_{P}^{2}$ & $h^{2}$ & $\frac{\sigma_{l t r}^{2}}{\sigma_{P}^{2}}$ & $\frac{\sigma_{\text {pen }}^{2}}{\sigma_{P}^{2}}$ & $\frac{\sigma_{c o}^{2}}{\sigma_{P}^{2}}$ & $\frac{\sigma_{\text {res }}^{2}}{\sigma_{P}^{2}}$ \\
\hline & \multicolumn{7}{|c|}{ TROP } \\
\hline \multicolumn{8}{|c|}{ Purebreds } \\
\hline ADG & 2,680 & 14,890 & $0.18(0.02)$ & $0.06(0.01)$ & $0.17(0.01)$ & $0.12(0.02)$ & $0.48(0.02)$ \\
\hline LD & 492 & 1,822 & $0.27(0.02)$ & $0.06(0.01)$ & $0.12(0.01)$ & $0.08(0.01)$ & $0.48(0.02)$ \\
\hline PD & 62.9 & 392.9 & $0.16(0.02)$ & $0.05(0.01)$ & $0.19(0.01)$ & $0.12(0.02)$ & $0.48(0.02)$ \\
\hline $\mathrm{BF}$ & 0.7 & 2.3 & $0.29(0.02)$ & $0.05(0.01)$ & $0.13(0.01)$ & $0.05(0.01)$ & $0.48(0.02)$ \\
\hline MD & 6.2 & 17.7 & $0.35(0.03)$ & $0.03(0.01)$ & $0.08(0.01)$ & $0.04(0.01)$ & $0.49(0.02)$ \\
\hline \multicolumn{8}{|c|}{ Crossbreds } \\
\hline ADG & 3,788 & 9,238 & $0.41(0.06)$ & $0.05(0.01)$ & $0.06(0.01)$ & $0.03(0.02)$ & $0.45(0.05)$ \\
\hline LD & 1,146 & 3,015 & $0.38(0.06)$ & $0.04(0.01)$ & $0.09(0.01)$ & $0.02(0.02)$ & $0.47(0.05)$ \\
\hline PD & 89.9 & 199.7 & $0.45(0.06)$ & $0.03(0.01)$ & $0.06(0.01)$ & $0.05(0.02)$ & $0.40(0.05)$ \\
\hline $\mathrm{BF}$ & 1.8 & 4.5 & $0.39(0.06)$ & $0.03(0.01)$ & $0.07(0.01)$ & $0.02(0.01)$ & $0.49(0.05)$ \\
\hline $\mathrm{MD}$ & - & - & - & - & - & - & - \\
\hline & \multicolumn{7}{|c|}{ TEMP } \\
\hline
\end{tabular}

Purebreds

$\begin{array}{llllllll}\text { ADG } & 2,810 & 13,381 & 0.21(0.01) & 0.07(0.00) & 0.12(0.00) & 0.07(0.00) & 0.53(0.01) \\ \text { LD } & 862 & 2,462 & 0.35(0.01) & 0.06(0.00) & 0.09(0.00) & 0.05(0.00) & 0.45(0.01) \\ \text { PD } & 80.5 & 366.0 & 0.22(0.01) & 0.06(0.00) & 0.11(0.00) & 0.06(0.00) & 0.54(0.01) \\ \text { BF } & 1.3 & 2.7 & 0.46(0.01) & 0.04(0.00) & 0.06(0.00) & 0.03(0.00) & 0.40(0.01) \\ \text { MD } & 7.7 & 18.8 & 0.41(0.01) & 0.03(0.00) & 0.06(0.00) & 0.05(0.00) & 0.44(0.01)\end{array}$

Crossbreds

\begin{tabular}{llllllll} 
ADG & 1,739 & 7,563 & $0.23(0.01)$ & $0.05(0.00)$ & $0.07(0.00)$ & $0.06(0.01)$ & $0.58(0.01)$ \\
LD & 1,014 & 3,170 & $0.32(0.02)$ & $0.04(0.01)$ & $0.04(0.00)$ & $0.04(0.01)$ & $0.56(0.02)$ \\
PD & 59.3 & 219.6 & $0.27(0.02)$ & $0.06(0.01)$ & $0.07(0.01)$ & $0.05(0.01)$ & $0.55(0.02)$ \\
BF & 2.3 & 6.0 & $0.38(0.01)$ & $0.03(0.00)$ & $0.03(0.00)$ & $0.02(0.00)$ & $0.54(0.01)$ \\
MD & 6.1 & 35.8 & $0.17(0.01)$ & $0.02(0.00)$ & $0.02(0.00)$ & $0.01(0.00)$ & $0.77(0.01)$ \\
\hline
\end{tabular}

${ }^{1} \sigma_{A}^{2}$, additive genetic variance; $\sigma_{P}^{2}$, phenotypic variance; $\mathrm{h}^{2}$, heritability; $\sigma_{l t r}^{2}$, variance of common litter; $\sigma_{p e n}^{2}$, variance of contemporary pen; $\sigma_{c o}^{2}$, variance of contemporary compartment; $\sigma_{\text {res }}^{2}$, residual variance; ${ }^{2} \mathrm{ADG}$, average daily gain; $L D$, lipid deposition; $\mathrm{PD}$, protein deposition; $\mathrm{BF}$, back fat thickness; MD, muscle depth; TROP, tropical climate; TEMP, temperate climate. 0.00 , value lower than 0.005 . 


\subsubsection{Genetic distances}

To evaluate the genetic distance between the PB and CB located at both TROP and TEMP environments, a distance plot was produced by applying Principal Coordinates Analysis to the additive relationship matrix using the function cmdscale in R. From each combination of population and environment, five hundred animals were selected at random to be included in the distance plot.

\subsection{Results}

\subsubsection{Variance components}

Estimates of variance components are presented in Table 5.4. As expected, all traits presented medium to high heritability estimates, with the larger values for $\mathrm{CB}_{\text {TROP }}$ for growth performance traits $(0.38-0.45)$ and for $\mathrm{PB}_{\text {TEMP }}$ for carcass traits $(0.41$ 0.46). In the TROP, all traits in $C B$ presented larger values for heritability estimates, while in the TEMP, PB presented larger heritability estimates for LD, BF and MD, and $\mathrm{CB}$ presented larger estimates for ADG and PD. The phenotypic variance explained by the common environment among litter mates was similar in the four groups, being larger for growth performance traits (3-7\%) than for carcass traits (2$5 \%)$. The phenotypic variance explained by the contemporary pen effect was larger for growth performance traits (4-19\%) than for carcass traits $(3-13 \%)$, with the larger values (0.08-0.19) for PB_TROP and the lower values (0.02-0.09) for CB_TEMP. The phenotypic variance explained by the contemporary compartment effect was larger for growth performance traits (2-12\%) than for carcass traits (1$5 \%)$, with the larger values (0.04-0.12) for PB_TROP, and the lower values (0.010.06) for $C B$ in both climates.

\subsubsection{Genetic correlations}

Estimates of genetic correlations between climates and between PB and CB are presented in Table 5.5. Some estimates could only be obtained with restrained components, in all cases these estimates included data from $\mathrm{PB}_{\text {TROP }}$, and should be treated with caution. Estimates of $r_{p c_{T R O P}}(0.80$ to 0.99$)$ were higher than $r_{p c_{T E M P}}$ (0.71 to 0.81). GxE appears to be present for ADG, PD and MD $\left(r_{g_{P B}}=0.64-0.75\right)$ and absent for BF and LD $\left(r_{g_{P B}}=0.97-0.98\right)$. The $r_{p c}$ estimates of $\mathrm{PB}_{\mathrm{TROP}}$ and $\mathrm{CB}_{\mathrm{TEMP}}$ were mostly moderate and $r_{p c}$ estimates between $\mathrm{PB}_{\mathrm{TEMP}}$ and $\mathrm{CB}_{\mathrm{TROP}}$ were low (0.22-0.25) and had relatively high standard errors. 
Table 5.5 Genetic correlations (SE).

\begin{tabular}{|c|c|c|c|c|c|}
\hline Traits & $\mathrm{r}_{\mathrm{pc}_{\mathrm{TROP}}}$ & $\mathrm{r}_{\mathrm{pc}_{\mathrm{TEMP}}}$ & $r_{g_{P B}}$ & $\mathrm{r}_{\mathrm{pc}_{\mathrm{TROP}-T E M P}}$ & $\mathrm{r}_{\mathrm{pc}} \mathrm{TEMP-TROP}_{\mathrm{TEM}}$ \\
\hline ADG & $0.88(0.14)$ & $0.73(0.04)$ & $0.64 *(0.25)$ & $0.45(0.40)$ & $0.22(0.58)$ \\
\hline LD & $0.97 *(0.08)$ & $0.78(0.04)$ & $0.97 *(0.10)$ & $0.87(0.31)$ & $0.24(0.77)$ \\
\hline PD & $0.80(0.16)$ & $0.79(0.05)$ & $0.73 *(0.23)$ & $0.68(0.37)$ & $\mathrm{nc}$ \\
\hline $\mathrm{BF}$ & $0.99 *(0.10)$ & $0.81(0.02)$ & $0.98 *(0.08)$ & $0.97 *(0.11)$ & $0.25(0.52)$ \\
\hline $\mathrm{MD}$ & - & $0.71(0.02)$ & $0.75(0.17)$ & $0.88(0.17)$ & - \\
\hline \multicolumn{6}{|c|}{ 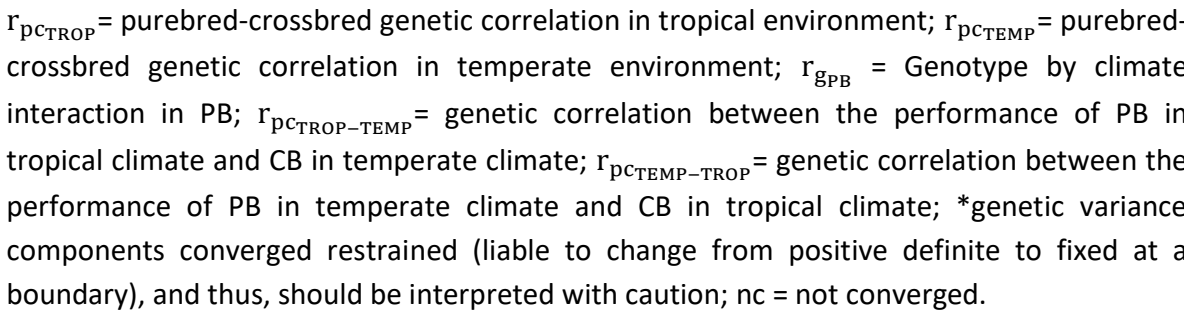 } \\
\hline
\end{tabular}

\subsubsection{Responses to selection}

The calculated responses to selection are presented in Table 5.6. Direct selection for $\mathrm{CB}_{\text {TROP }}$ leads to higher responses than indirect selection on either $\mathrm{PB}_{\mathrm{TROP}}$ or $\mathrm{PB}_{\text {TEMP. }}$. Across the different traits, the direct response $\mathrm{R}_{\mathrm{CB}_{\mathrm{TROP}}\left(\mathrm{CB}_{\mathrm{TROP}}\right)}$ was

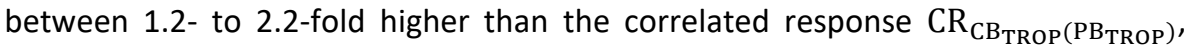
and between 3.7- to 6.4-fold higher than $\mathrm{CR}_{\mathrm{CB}_{\mathrm{TROP}}\left(\mathrm{PB}_{\mathrm{TEMP}}\right)}$.

\subsubsection{Genetic distances}

$\mathrm{PB}_{\mathrm{TEMP}}$ and $\mathrm{CB}_{\mathrm{TEMP}}$ are found close together on the distance plot (Figure 1), as expected based on the small standard errors that are observed for $r_{p c_{T E M P}}$ in Table 5.5. For both lines 1 and 2, the average distance between points for $\mathrm{PB}_{\text {TEMP }}$ and

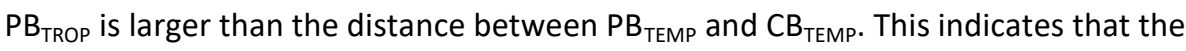
pedigree relationships contributing to $r_{g_{P B}}$ are on average smaller than the pedigree relationships for $r_{p c_{T E M P}}$. CB pigs in TROP show different patterns for CB1 and CB2.

For sire line 1 , some $C B_{\text {TROP }}$ are found close to $\mathrm{PB}_{\text {TROP }}$, some are close to $P B_{\text {TEMP, }}$ while others are at some distance from all other groups. For sire line $2, \mathrm{CB}_{\mathrm{TROP}}$ are separated from the other groups, but closest to PB TEMP. $_{\text {. }}$ 
Table 5.6 Response to direct selection on $\mathrm{CB}_{\mathrm{TROP}}$ and correlated response for indirect selection based on $\mathrm{PB}_{\text {TROP }}$ or $\mathrm{PB}_{\text {TEMP. }}$.

\begin{tabular}{|c|c|c|c|c|}
\hline Response & $A D G, g / d$ & $\mathrm{LD}, \mathrm{g} / \mathrm{d}$ & $\mathrm{PD}, \mathrm{g} / \mathrm{d}$ & $\mathrm{BF}, \mathrm{mm}$ \\
\hline $\mathrm{R}_{\mathrm{CB}_{\mathrm{TROP}}\left(\mathrm{CB}_{\mathrm{TROP}}\right)}$ & 39.4 & 20.9 & 6.36 & 0.84 \\
\hline $\mathrm{CR}_{\mathrm{CB}_{\mathrm{TROP}}\left(\mathrm{PB}_{\mathrm{TROP}}\right)}$ & 23 & 16.2 & 2.92 & 0.72 \\
\hline $\mathrm{CR}_{\mathrm{CB}_{\text {TROP }}\left(\mathrm{PB}_{\text {TEMP }}\right)}$ & 6.2 & 4.8 & 1.02 & 0.23 \\
\hline $\mathrm{R}_{\mathrm{CB}_{\text {TROP }}\left(\mathrm{CB}_{\text {TROP }}\right)} / \mathrm{CR}_{\mathrm{CB}_{\text {TROP }}\left(\mathrm{PB}_{\text {TROP }}\right)}$ & 1.7 & 1.3 & 2.2 & 1.2 \\
\hline $\mathrm{R}_{\mathrm{CB}_{\text {TROP }}\left(\mathrm{CB}_{\text {TROP }}\right)} / \mathrm{CR}_{\mathrm{CB}_{\mathrm{TROP}}\left(\mathrm{PB}_{\mathrm{TEMP}}\right)}$ & 6.4 & 4.3 & 6.2 & 3.7 \\
\hline
\end{tabular}

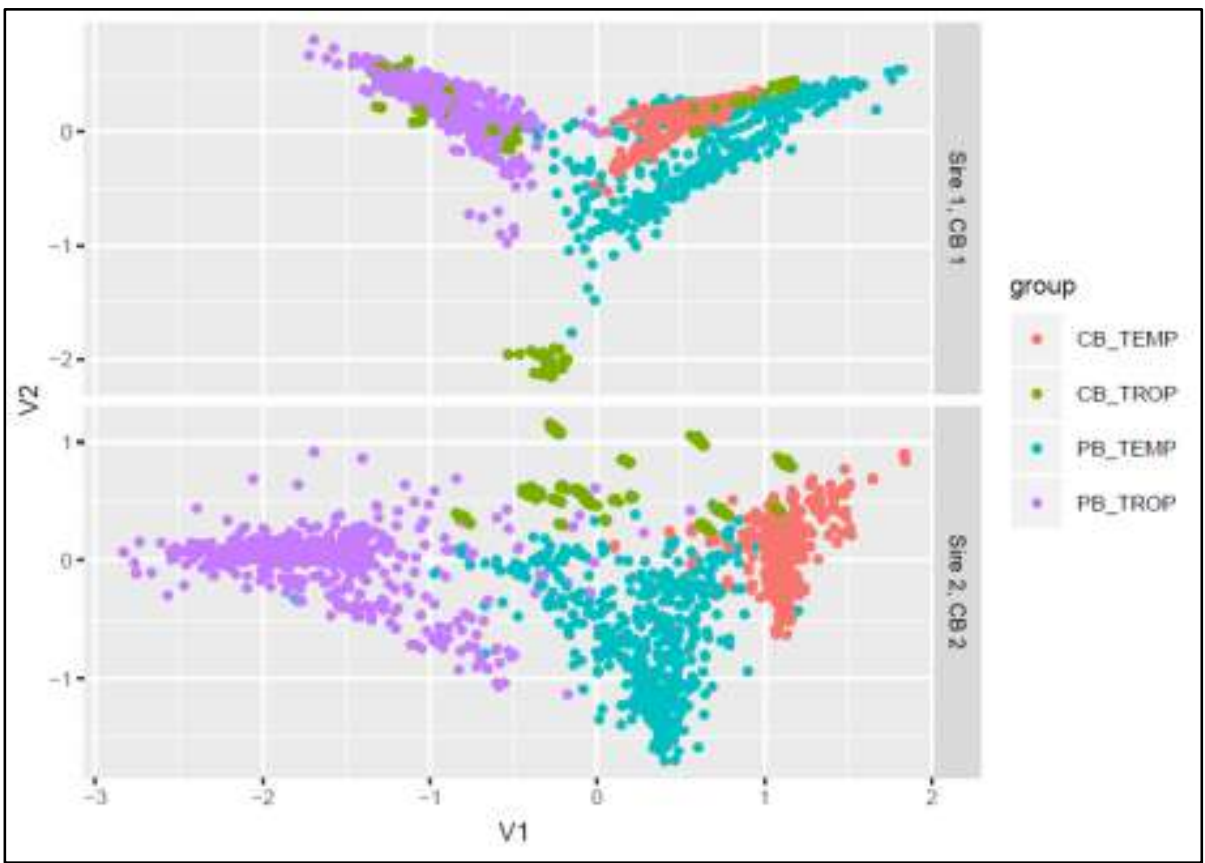

Figure 5.1 Distance plot based on the 1st (V1) and 2nd (V2) principal components of the additive relationship matrix between purebred (PB) and crossbred (CB) pigs located in both tropical (TROP) and temperate (TEMP) environment for sire lines 1 and 2.

\subsection{Discussion}

The performance of CB pigs is typically improved by applying selection in purebred lines. In recent years the use of data on crossbred offspring has come into play as 
well as the collection of performance data in the commercial environment. With this, the need for estimation of GxE and $r_{p c}$ has increased. Estimates of $r_{p c}$ in pigs were recently reviewed by Wientjes and Calus (2017) who reported a $r_{p c}$ average of 0.63. The $r_{p c}$ can, in theory, be decomposed into GxE due to interaction with the environment, and GxG due to interaction of genes with the differences in genetic background of $\mathrm{PB}$ and $\mathrm{CB}$. Here we aimed to separate these two components by estimating $r_{p c}$ of the same $P B$ and their $C B$ in two environments, as well as estimating the PB genetic correlation between these two environments.

\subsubsection{Data}

Even though the data used herein contained records on over 400,000 pigs, it did not yield reliable estimates for some of the correlations of interest. Some estimates of $r_{\mathrm{pc}_{\mathrm{TROP}}}$ and $\mathrm{r}_{\mathrm{gPB}}$ and also the $r_{\mathrm{pc}}$ estimates of $\mathrm{PB}_{\mathrm{TROP}}$ and $\mathrm{CB}_{\mathrm{TEMP}}$ for $\mathrm{BF}$ were obtained with components restrained. The data on $\mathrm{PB}_{\text {TROP }}$ is common to all these estimates.

Clearly, many records alone are not sufficient for accurate estimation of genetic correlations. In addition, the records obtained in the two environments should be on pigs that are closely related. Typically, the relationships are closest between PB and $\mathrm{CB}$ in the same environment. Relationships between $\mathrm{PB}$ in different environments are lower and finally the relationship between $C B$ in different environments is smallest because the pedigree connection would mostly be through relationships between PB in the two environments. A small subset of 250 $\mathrm{CB}$ pigs in TROP were produced as part of an experiment where semen was collected from PB sires in TEMP and exported to Brazil to produce CB in TROP. In this experiment the relationships from $\mathrm{PB}_{\text {TEMP }}$ to $\mathrm{CB}_{\text {TROP }}$ are good but the number of sires involved was too small to estimate genetic correlations based on this experiment alone. Because importing semen is both difficult and costly, due to legislation and veterinary requirements, this is not a routine practice for production of $C B$ in TROP.

An alternative to importing semen to TROP may be the use of genomic data to more accurately measure relationships between $\mathrm{PB}_{\text {TEMP }}$ and $\mathrm{CB}_{\text {TROP }}$. The benefits of genomic, rather than pedigree, relationships for estimation of genetic correlations are unknown. For the estimation of breeding values with genomic relationships, it is still important to have close relatives in the training dataset if a high accuracy is required (Pszczola et al., 2012). To estimate a genetic correlation with small standard error may therefore still require close relatives to be present in both $\mathrm{PB}_{\mathrm{TEMP}}$ and $\mathrm{CB}_{\mathrm{TROP}}$, even when using a genomic relationship matrix. 


\subsubsection{Environments}

Estimates below 0.8 for ADG, PD and MD indicate GxE for these traits. GxE may be due to the climatic differences since sensitivity to heat stress has been described in pigs (Zumbach, et al., 2008; Fragomeni et al., 2016; Rosé et al., 2017). There may also be differences in the farms for PB in TROP and TEMP that could contribute to GxE. Firstly, PB in TROP were kept in open or semi-open barns. Secondly, the farm environments in different climates were also different in health status and management practices. Differences in health status of farms have been shown to cause GxE in pigs (Rashidi et al., 2014; Herrero-Medrano et al., 2015; Mathur, 2018).

The nucleus farms for the $\mathrm{PB}_{\text {TEMP }}$ probably provide the least, and $\mathrm{CB}_{\text {TROP }}$ the most, challenging environment, while $\mathrm{PB}_{\text {TROP }}$ and $\mathrm{CB}_{\text {TEMP }}$ are in intermediate environments. The environment of $\mathrm{PB}_{\text {TROP }}$ is better controlled than commercial Brazilian farms but considerably less well controlled than the environment provided by genetic nucleus farms in TEMP. Therefore, differences between the environment of $\mathrm{PB}_{\mathrm{TROP}}$ and $\mathrm{CB}_{\text {TEMP }}$ are probably smaller than the differences between the environment of $\mathrm{PB}_{\text {TEMP }}$ and $\mathrm{CB}_{\mathrm{TROP}}$, as $\mathrm{PB}_{\mathrm{TEMP}}$ are in the better controlled environment and $\mathrm{CB}_{\mathrm{TROP}}$ are in the less well-controlled environment.

\subsubsection{Estimates of $r_{p c}$ within environment}

The estimates of $r_{\mathrm{pc}}$ within environments $\left(\mathrm{r}_{\mathrm{pc}_{\mathrm{TROP}}}\right.$ and $\left.\mathrm{r}_{\mathrm{pc}_{\mathrm{TEMP}}}\right)$ were in the range of the literature (Wientjes and Calus, 2017), with higher values in TROP than in TEMP. The $\mathrm{r}_{\mathrm{pc}_{\mathrm{TROP}}}$ for ADG and PD were estimated without model constraints and are in

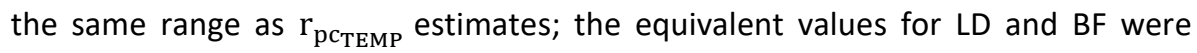
close to 1.0 but estimated with components restrained, so differences with the corresponding $\mathrm{r}_{\mathrm{pc}}$ TEMP are uncertain. Standard errors of $\mathrm{r}_{\mathrm{pc}_{\mathrm{TROP}}}$ were higher, which is expected given the reduced number of records in TROP. For BF, the higher

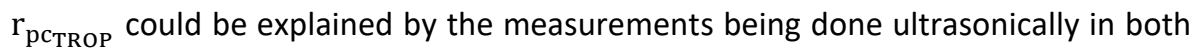
$P B$ and $C B$ in the TROP, while in the TEMP the vast majority of $C B$ had $B F$ recorded with a probe in the carcass at slaughter.

The environment of PB in TROP is more challenging than for PB in TEMP, which could make the difference between $\mathrm{PB}$ and $\mathrm{CB}$ environments smaller in TROP than in TEMP. This may have resulted in the higher $\mathrm{r}_{\mathrm{pc}_{\mathrm{TROP}}}$ than $\mathrm{r}_{\mathrm{pc}_{\mathrm{TEMP}}}$. Moreover, selection under improved conditions has been shown to increase sensitivity (van der Waaij, 2004). Therefore, the reverse may be true in TROP whereby the challenging environment for PB may have resulted in selection for more robust 
$\mathrm{PB}_{\text {TROP. }}$. This increased robustness could contribute to the higher $\mathrm{r}_{\mathrm{pc}_{\mathrm{TROP}}}$ when transmitted to the CB in TROP.

CCPS is recommended when the $r_{p c}$ is lower than 0.8; the values of the $r_{p c}$ estimates in this study are mostly around this value. With higher values of $r_{\mathrm{pc}_{\mathrm{TROP}}}$ compared to $r_{\text {pc }}$ TEMP we should expect less benefit of having data recorded on CB in TROP than in TEMP.

\subsubsection{Purebred-crossbred correlations between environments}

The typical situation in pig production is that genetic progress is created by selection of PB in TEMP. The performance of CB in TROP would therefore depend on the genetics of $\mathrm{PB}$ in TEMP. When $\mathrm{PB}$ and $\mathrm{CB}$ were in different climates, the $\mathrm{r}_{\text {pс }}$ TEMP-TROP was low (0.22-0.25). Besides the $\mathrm{GxG}$, these estimates are also lowered by GxE given the climate differences; the differences in the health status and farm management between the TROP and the TEMP, as discussed above, also contribute. The $r_{p c}$ between climates was higher when the PB were in the TROP with $r_{\text {pc }_{\text {TROP-TEMP }}}$ between 0.45-0.97. We speculate that an increased robustness of $\mathrm{PB}_{\text {TROP }}$ would also be reflected in the higher $\mathrm{r}_{\text {рс }_{\text {TROP-TEMP }}}$ compared to the $r_{\text {pс }}$ TEMP-TROP . This could indicate a benefit for overall efficiency by selecting records on $\mathrm{PB}_{\text {TROP }}$ when the objective is to improve the performance of $\mathrm{CB}$ in both TEMP and TROP. However, most of the pigs' nucleus farms are in the TEMP.

\subsubsection{Genetic distances}

Figure 1 shows data on the same number of pigs for all 4 groups. However, the points for $\mathrm{CB}_{\text {TROP }}$ are much more clustered than for the other 3 groups. This is due to the smaller number of families that are present in $\mathrm{CB}_{\mathrm{TROP}}$. The standard errors of $\mathrm{r}_{\text {pc }}$ TEMP $_{\text {are the smallest (Table 5.5), which is to be expected given that PB }}$ TEMP and $\mathrm{CB}_{\mathrm{TEMP}}$ are found closest together on the distance plots, and the largest number of records contribute to these estimates. The large pedigree distances perhaps contribute to the size of standard errors of $\mathrm{r}_{\mathrm{pc}_{\mathrm{TROP}}}$, but these are probably more down to the smaller number records in $\mathrm{CB}_{\text {TROP }}$. Given the smaller distance of $\mathrm{CB}_{\mathrm{TROP}}$ to $\mathrm{PB}_{\text {TEMP }}$, a smaller standard error would be expected for $\mathrm{r}_{\text {pс }_{\text {TEMP_TROP }}}$ than for $r_{\text {pc }}$ TROP but the opposite is observed. The estimated values for $r_{\text {pc }_{\text {TEMP_TROP }}}$ are however much closer to 0 than for $r_{p c_{T R O P}}$ which increases the expected standard error of the estimates (Bijma and Bastiaansen, 2014). Smaller, though still rather large, values are seen for the standard erros of $r_{\text {pc }}$ TROP_TEMP $_{\text {compared to the }}$ standard errors of $r_{\text {p }_{\text {TEMP_TROP }}}$, which is not supported by the distances in Figure 1. Especially in the lower panel for sire line 2, a large distance is seen between PB ${ }_{\text {TROP }}$ 
and $\mathrm{CB}_{\text {TEMP. The }}$ much larger dataset for $\mathrm{CB}_{\text {TEMP }}$ will probably have contributed to this smaller standard error.

\subsection{Conclusions}

The current dataset collected from a breeding and genetic dissemination program makes it difficult to obtain accurate estimates of genetic correlations between performance in temperate and tropical climates, especially when the aim is to estimate $r_{p c}$ between PB in one climate and CB in the other climate because pigs in both climates are only distantly related. GxE between the temperate and tropical environment appears to be present for ADG, PD and MD. In addition, $r_{p c}$ within TEMP and within TROP are smaller than 1 for most traits. Collection of phenotypes in the TROP should be included when the objective of selection is the performance of $\mathrm{CB}_{\text {TROP. }}$. On the basis of $r_{P c_{T E M P-T R O P}}$ and the expected responses to selection, selection for $\mathrm{CB}_{\text {TROP }}$ based on the performance of $\mathrm{PB}_{\text {TEMP }}$ would compromise the genetic progress for the traits being studied. Based solely on the $r_{p c_{T R O P}}$ estimates, CCPS would not be necessary to increase genetic progress in $\mathrm{CB}_{\mathrm{TROP}}$. However, based on the calculated responses to selection, when the objective is the improvement of $\mathrm{CB}_{T R O P}$, direct selection based on the performance of $\mathrm{CB}_{\mathrm{TROP}}$ has the potential to lead to the higher genetic progress for growth performance and carcass traits.

\section{References}

Bijma, P., and J. W. M. Bastiaansen. 2014. Standard error of the genetic correlation: how much data do we need to estimate a purebred-crossbred genetic correlation? Gen. Selec. Evo. 46:79.

Bijma, P., and J. A. van Arendonk. 1998. Maximizing genetic gain for the sire line of a crossbreeding scheme utilizing both purebred and crossbred information. J. Anim. Sci. 66:529-542.

de Greef, K. H., M. W. A. Verstegen, B. Kemp, and P. L. van der Togt. 1994. The effect of body weight and energy intake on the composition of deposited tissue in pigs. Anim. Prod. 58:263-270.

Falconer, D.S. and T.F.C. Mackay. 1996. Introduction to Quantitative Genetics. Longman, Essex, UK.

Fragomeni, B. O., D. A. L. Lourenco, S.Tsuruta, K. Gray, Y. Huang, and I. Misztal. 2016. Modeling response to heat stress in pigs from nucleus and commercial farms in different locations. J. Anim. Sci. 94:4789-4798. 
Gilmour, A. R., B. J. Gogel, B. R. Cullis, and R. Thompson. 2009. ASReml User Guide Release 3.0 VSN International Ltd, Hemel Hempstead, HP1 1ES, UK.

Godinho, R. M., R. Bergsma, F. F. Silva, C. A. Sevillano, E. F. Knol, M. S. Lopes, P. S. Lopes, J. W. M. Bastiaansen, and S. E. F. Guimarães. 2018. Genetic correlations between feed efficiency traits, and growth performance and carcass traits in purebred and crossbred pigs. J. Anim. Sci. 96:817-829.

Handboek varkenshouderij. 2004. ISSN 1570-8632. p. 312.

Herrero-Medrano J. M., P. K. Mathur, J. ten Napel, H. Rashidi, P. Alexandri, E. F. $\mathrm{Knol}$, and $\mathrm{H}$. Mulder. 2015. Estimation of genetic parameters and breeding values across challenged environments to select for robust pigs. J. Anim. Sci. 93:14941502.

Hidalgo, A. M., J. W. M. Bastiaansen, M. S. Lopes, B. Harlizius, M. A. M. Groenen, and D.-J. de Koning. 2015a. Accuracy of predicted genomic breeding values in purebred and crossbred pigs. G3: Genes/ Genomes/ Genetics 5:1575-1583.

Knap, P. W. 2005. Breeding robust pigs. Austral. J. Exp. Agric. 45:763-773.

Mathur, P. K. 2018. Genotype-environment interactions in pig breeding. In: Proceedings of $11^{\circ}$ World Congress on Genetics Applied to Livestock Production. Proceedings, Auckland, New Zealand, 668.

Pszczola, M., T. Strabel, H. A. Mulder, and M.P.L. Calus. 2012. Reliability of direct genomic values for animals with different relationships within and to the reference population. J Dairy Sci. 95:389-400.

Robertson, A. 1959. The sampling variance of the genetic correlation coefficient. Biometrics. 15:469-485.

Rosé, R., H. Gilbert, T. Loyau, M. Giorgi, Y. Billon, J. Riquet, D. Renaudeau, J.-L. Gourdine. Interactions between sire family and production environment (temperate vs. tropical) on performance and thermoregulation responses in growing pigs. J. Anim. Sci. 95:4738-4751.

Tusell, L., H. Gilbert, J. Riquet, M. J. Mercat, A. Legarra, and C. Larzul. 2016. Pedigree and genomic evaluation of pigs using a terminal-cross model. Genet. Sel. Evol. 48:32.

Van der Waaij, E.H. 2004. A resource allocation model describing consequences of artificial selection under metabolic stress. J. Anim. Sci. 82: 973-981.

Wei, M., and J. H. J. van der Werf. 1994. Maximizing genetic response in crossbreds using both purebred and crossbred information. Anim. Produc. 59:401-413.

Wientjes, Y. C. J., and M. P. L. Calus. 2017. Board invited review: The purebredcrossbred correlation in pigs: A review of theory, estimates, and implications. J. Anim. Sci. 95:3467-3478. 
Zumbach, B., I. Misztal, S. Tsuruta, J. P. Sanchez, M. Azain, W. Herring, J. Holl, T. Long, and M. Culbertson. 2008b. Genetic components of heat stress in finishing pigs: Parameter estimation. J. Anim. Sci. 86:2076-2081. 


\section{6}

General discussion 



\subsection{Introduction}

The majority of the cost of pork production comes from feeding crossbred (CB) growing-finishing pigs. Therefore, increasing attention is given to selection for feed efficiency and to include in the genetic evaluations the performance records of $C B$ pigs in commercial production circumstances. In addition, sustainability should be at the top of the agenda for all livestock production systems, and thus, improving the feed efficiency of CB pigs farmed around the globe is necessary. Modern pig breeding should have, as one of its main goals, the improved feed efficiency of $C B$ pigs across a range of diverse and challenging environments in commercial farms.

In this thesis, I showed that the collection of feed intake data on CB at commercial farms is worthwhile to increase genetic progress in $C B$ feed efficiency and that residual energy intake (REI) is an attractive trait for pig breeding programs (Chapter 2). Depending on the definition of feed efficiency, this trait is variably sensitive to changes in the ingredients of the two most common pig commercial rations (corn/soy or wheat/barley/co-products). Breeding for feed efficiency under lowerinput diets, such as wheat/barley/co-products, should be considered (Chapter 3). Feed efficiency can be improved by changing the trajectory of feed intake as a function of body weight, i.e., the feed intake curves. A flatter feed intake curve, and high feed intake precocity (higher feed intake in early stages of growth associated with a higher growth maturation rate and a consequent lower feed intake later on the finishing period) is a desired profile in pig breeding (Chapter 4). Collection of production data in a tropical climate is worthwhile, and feed efficiency is expected to be sensitive to climate (Chapter $\mathbf{5}$ ).

In this general discussion, I place my work in a broader context, discuss the implications and formulate recommendations for future breeding for feed efficiency in growing-finishing pigs, with special attention to feed efficiency in the tropics, and recommend future research.

\subsection{Future Breeding for Feed Efficiency}

The demand for food, including animal protein, will further increase with more than 9 billion people on the globe by 2050 (FAO, 2012). The actual reduction in meat consumption in the Northern Hemisphere is not expected to decrease the demand for animal protein because the increase in the standard of life in developing countries will inevitably be followed by an increase in the consumption of animal products. Apart from the increasing demand for grains for human consumption and by the biofuel industry, a third of the grains produced in the world are used to feed livestock (FAO, 2012). Therefore, livestock production 
systems need to increase productivity and reduce environmental load (Neetesonvan Nieuwenhoven et al., 2013), and they will face increasing pressure from society to do so. Breeding for livestock feed efficiency and feeding alternative diets are important strategies to improve the sustainability of livestock production.

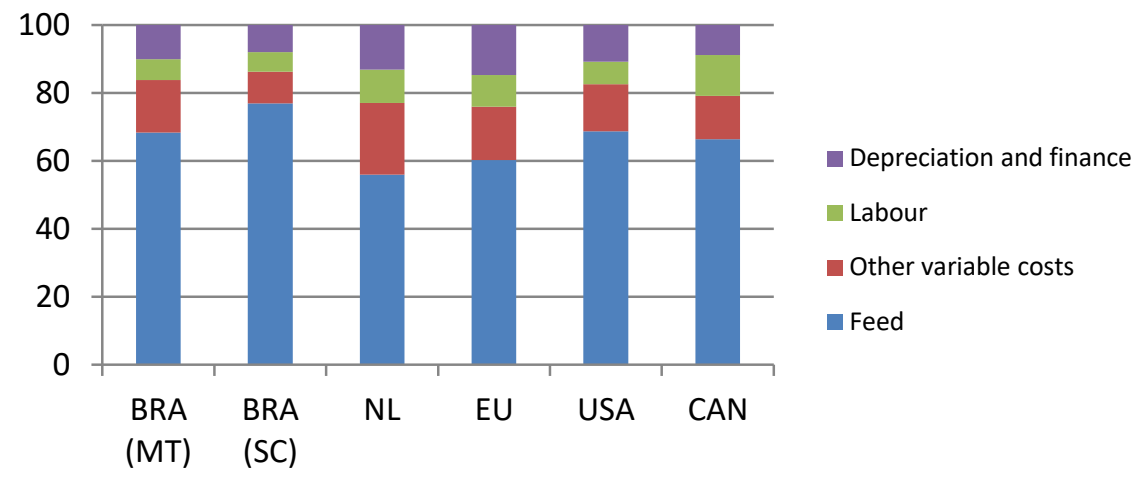

Figure 6.1 Average (2014-2016) cost of pig production expressed in percentage of total cost by category (ADBH, 2017). BRA, Brazil; MT, Mato Grosso (Central-West); SC, Santa Catarina (South); NL, The Netherlands; EU, European Union; USA, United States of America; CAN, Canada.

The future of pork production is centered on pigs that efficiently convert feed into lean meat. Feed is responsible for the majority of the cost of pig production according to the InterPig inventories in selected countries (AHDB, 2017), as shown in Figure 6.1 and Table 6.1.

Table 6.1 Average (2014-2016) cost of pig production (ADBH, 2017).

\begin{tabular}{lcccccc}
\hline & $\begin{array}{c}\text { BRA } \\
(\mathrm{MT})\end{array}$ & $\begin{array}{c}\text { BRA } \\
(\mathrm{SC})\end{array}$ & NL & EU & USA & CAN \\
\cline { 2 - 7 } Average Cost Activity (€/kg) & 1.05 & 1.29 & 1.62 & 1.62 & 1.05 & 1.24 \\
Feed (\%) & 68 & 77 & 56 & 60 & 69 & 66 \\
Other variable costs (\%) & 16 & 10 & 20 & 16 & 15 & 13 \\
Total variable costs (\%) & 84 & 86 & 78 & 76 & 82 & 79 \\
Labor (\%) & 6 & 6 & 10 & 9 & 7 & 12 \\
Depreciation and finance (\%) & 10 & 8 & 13 & 15 & 11 & 9 \\
Total fixed costs (\%) & 16 & 14 & 23 & 24 & 18 & 21 \\
\hline
\end{tabular}

BRA = Brazil; MT = Mato Grosso (Central-West region); SC=Santa Catarina (South region); NL $=$ The Netherlands; $\mathrm{EU}=$ European Union; USA = United States of America; CAN = Canada. 
Only a few economies account for the majority (84\%) of global pork production. The top four producers are China, the European Union, the United States, and Brazil, respectively; and the top four pork exporters are the United States, the European Union, Canada, and Brazil, respectively (USITC, 2014). Cost of pig production in China is not reported in the inventories. Brazil is represented by two regions given the large differences in the cost of pig production. While, Santa Catarina (SC) represents one state of the Brazilian South region, the later accounting for $70 \%$ of the country's pig production; Mato Grosso (MT) represents one state of the Brazilian Central-West region, the later accounting for $14 \%$ of the country's pig production.

SC (the biggest producer [38\%, ABPA, 2017] and the biggest exporter of Brazilian pork) has the highest percentage feed cost compared to all the economies in the inventories, i.e. $77 \%$ of the cost of pig production in the region is accounted for by feed. SC has a lower cost of production compared to the Netherlands and the European Union (Table 1), but the cost is higher than in North America. MT, together with the United States, has the lowest cost of pig production in the inventories. However, MT has higher costs of transportation of pigs to slaughterhouses and of pork to ports (USITC, 2014). Another big concern of pork production in MT is pigs' heat load due to climatic conditions.

\subsubsection{Breeding for novel feed efficiency traits}

Since the introduction of electronic feeders in pig husbandry, new venues have opened up for pig breeding. Great improvements have been made in feed conversion rate (FCR). However, it is evident and widely accepted in pig breeding that the majority of the genetic progress made in FCR is a consequence of the selection for leaner pigs. FCR is not ideal because it does not account for variations in size, growth rate, and body composition of animals (Young and Dekkers, 2012; Knap and Wang, 2012). Additionally, selection for feed efficiency should be centered on feed intake and not in FCR to allow the control of possible side effects (Knap and Wang, 2012), e.g., on sow appetite, body composition, and reproduction (Gilbert et al., 2012).

Residual feed intake (RFI, Koch et al., 1963), defined as the difference between the observed feed intake and the expected feed intake based on the expected requirements for production and maintenance, gained considerable attention in pig breeding in the last two decades as a powerful alternative to FCR (Dekkers and Gilbert, 2010; Young and Dekkers, 2012; Gilbert et al., 2017). RFI is obtained by adjusting the observed feed intake for the growth and body composition of the animal. Because RFI is independent from production at the phenotypic level, most 
of its variation is due to the basal metabolic state of animals, physical activity, maintenance requirements, digestion, energy efficiency, tissue turnover rates, and immune response (Young and Dekkers, 2012). Selection for low RFI in growingfinishing pigs as a measure of net feed efficiency is feasible, with high response in FCR and limited impacts on other production traits and no marked reduction of the pig's ability to face challenges, including lactation (Gilbert et al., 2017).

However, some aspects of RFI remain unexplored. Genotype by environment interaction (GXE) for this trait has not been widely investigated. This trait is expected to be environmentally sensitive because it is dependent on several body maintenance processes (Knap and Wang, 2012). GxE for feed efficiency also becomes important when selection for feed efficiency is combined with the use of alternative diet ingredients. In Chapter 3, I found that RFI and REI are sensitive to changes in the ingredients of the two most common pig commercial rations, i.e., diets based on corn/soy and wheat/barley/co-products. This sensitivity is dependent on the phase of the pigs' growth, with pigs being sensitive in the starting and growing phase, but not in the finishing phase. Rosé et al. (2017) investigated GxE when half-sibs CB pigs were generated by a backcross design and raised in two different climatic conditions, temperate and tropical. GxE was present for the average daily gain, average daily feed intake, and FCR, but was absent for RFI. When considering the vast diversity in environments $C B$ pigs may face in commercial farms, further studying GxE for feed efficiency traits is necessary.

Although individual daily feed intake records per pig are becoming increasingly available, the longitudinal property of these data has been less explored. These data usually generate an average daily feed intake measure for the growingfinishing period as a whole, and the RFI or FCR is calculated for the whole period. It is likely that different body processes requiring energy expenditure will vary according to the growth phase of the pig, and the RFI at the start and end of the growing-finishing period are consequently different traits. It is widely known that the nutritional requirements of pigs change during the growing-finishing period, so different diets are designed to meet the requirements of pigs in each growth phase. A first approach, although not a very refined one, is to consider different periods of changing feeding strategies and accounting for the individual feed intake data in those periods. Shirali et al. (2014) studied the REI for each phase of a threephase feeding strategy for growing-finishing pigs and obtained moderate genetic correlations $(0.28-0.58)$ and low-to-moderate phenotypic correlations $(0.17-0.31)$ between phases, showing that the trait largely behaves as different traits depending on the phase of pigs' growth. In Chapter 3, I calculated FCR, REI, and RFI for each phase of a three-phase feeding strategy in growing-finishing pigs and 
found that variance components and heritabilities largely differed depending on the phase of growth, reinforcing the notion that feed efficiency does not behave like the same trait throughout the growing-finishing period. Further studies may clarify the different aspects of feed efficiency in different stages of growth.

Individual daily feed intake records also allow us to study the trajectories of pigs' feed intake throughout the whole growing-finishing period; the feed intake curves. As discussed in detail in Chapter 4, selection should be conducted to increase feed intake in the early stage of growth, whereas feed intake at the end of the growingfinishing period should be reduced because in this stage, pigs' feed conversion is lower, and high feed intake will result in high lipid deposition. This selection can be conducted using the parameters of the Gamma function of the energy maintenance expenditure (Chapter 4).

\subsubsection{Data collection on CB pigs is necessary}

Selection for feed efficiency, like for other traits, traditionally takes place based on purebred (PB) performance at the nucleus level, and the success of this selection, therefore, depends on the genetic correlation between the performance of PB and CB pigs $\left(r_{p c}\right)$. However, little is known about $r_{p c}$ for feed efficiency in pigs because the literature on the topic is scarce. There are only 5 studies reporting $r_{p c}$ for FCR or gain-to-feed ratio (Wong et al., 1971; Nakavisut et al., 2005; Habier et al., 2007; Tusell et al., 2016; Chapter 2). In Chapter 2, the $r_{p c}$ for REI and RFI were estimated for the first time. There are a limited number of studies because records on $C B$ are not broadly available. This is because CB pigs are located on commercial farms and feed intake, and thus feed efficiency, is expensive to measure. In particular, the availability of feed intake data on CB pigs in the commercial environment is very low.

Disentangling the effect of each component of the $r_{p c}$ (i.e., a genotype by genotype interaction $[G \times G]$ given the differences in the genetic background of $P B$ and $C B$ pigs, a GXE given the differences in the environment of nucleus and commercial farms, and differences in $\mathrm{PB}$ and $\mathrm{CB}$ trait measures) is not possible without an appropriate design (Wientjes and Calus, 2017). Studies with a design to disentangle the effect of each component are not available in the literature.

The effect of GxG is considerably high (Wientjes and Calus, 2017). Therefore, inclusion of data recorded on CB pigs, even though they are kept in high standard conditions, and the use of combined CB-PB selection schemes (CCPS; Wei and van der Werf, 1994) is necessary. A lot of attention has been given lately to methodologies to include $C B$ records in selection schemes for $C B$ performance (e.g., Hidalgo et al., 2015a; Hidalgo et al., 2015b; Lopes et al., 2015; Tusell et al., 
2016; Xiang et al., 2016a; Xiang et al., 2016b; Sevillano et al., 2017). However, designs for detection of GxE lowering the $r_{p c}$ have not been made.

Drawing conclusions on the extent of GxE due to differences between nucleus and commercial environments based on the existent literature on $r_{p c}$ estimates seems to me to be misleading and not meaningful. The designs of most of these studies were intended to detect GxG rather than GxE. In several of these studies, the differences between nucleus and commercial farms were minimized by keeping both $\mathrm{PB}$ and $\mathrm{CB}$ populations in experimental farms or governmental breeding stations. Because the differences in the environments are minimal, detection of GxE is naturally not likely to happen. These experimental environments probably represent neither the nucleus environment nor the commercial environment. This is the case for all previous studies involving $r_{p c}$ estimates for feed efficiency as FCR or gain-to-feed ratio (Wong et al., 1971; Nakavisut et al., 2005; Habier et al., 2007; Tusell et al., 2016).

In Chapter 2, I analyzed data of PB pigs kept in 23 nucleus farms and CB pigs kept in 3 commercial farms where research was conducted under a near-commercial environment. It may be argued that these commercial farms can be grouped together with experimental farms. However, they can definitely not be grouped together with nucleus farms. The situation in Chapter 2 is closer to reality compared to the situations in other studies. The $r_{p c}$ estimate for feed efficiency traits in this thesis was around 0.65, and it included three factors lowering $r_{p c}$ ( $G x G$, $\mathrm{GxE}$, and differences in trait measures). In this study, the management and sanitary status of those CB farms were better than that of the average commercial farm, as would be expected from a farm where individual feeding recording stations are installed. This 0.65 estimate would have been higher if $\mathrm{PB}$ and $\mathrm{CB}$ pigs were both kept in experimental farms, and if they were kept in the same single farm, because the differences between the large number of farms also gave rise to GxE. Tussel et al. (2016) reported $r_{p c}$ between 0.89 and 0.91 for FCR when PB and CB pigs were raised in the same single experimental farm, but not at the same time. Additionally, this 0.65 estimate would certainly have been lower if the CB pigs had been kept in low-hygiene, low management, and adverse physiological comfort conditions because feed intake and feed efficiency are dependent on several body maintenance processes and thus are expected to be environmentally sensitive (Knap and Wang, 2012).

The results of this thesis and the literature show that the range of $r_{p c}$ estimates indicate that the inclusion of phenotypes recorded on CB pigs in commercial farms in the prediction of breeding values for $\mathrm{PB}$ to successfully breed for $\mathrm{CB}$ performance is necessary. The benefit of this inclusion is expected to be higher for 
feed efficiency traits. GxE is likely to be underestimated given the lack of designs for the detection of its effect in lowering the $r_{p c}$. However, the effect of GxG is considerably important. Data collection in CB pigs is thus necessary.

\subsubsection{Improved feed efficiency in commercial environments}

It has been pointed out that feed intake, as recorded in nucleus conditions, is not very useful for breeding value estimation in a system that aims to produce commercially viable end products (Knap and Wang, 2012). These authors presented correlations between univariate estimated EBVs based on PB pigs housed in a nucleus environment and CB pigs, half-sibs of the PB candidates, housed in a commercial environment. These correlations were reasonable high, around 0.8 , for average daily gain and back fat thickness, but feed intake was clearly much more environmentally sensitive, with correlations around 0.5 , and RFI was even more so, with a correlation of $0.00 \pm 0.06$. A drawback of this approach is that these estimates are affected by EBVs' accuracies. Additionally, no details about the commercial conditions are given. Nevertheless, the conclusion holds: there is a strong effect of the different environments of nucleus and commercial farms that gives rise to GxE in feed intake and feed efficiency.

The first complication in the search for recording data that reflect the environment that commercial CB pigs are reared in is that the environment is not standardized. Several decisions related to running a profitable pig operation can contribute to variation in this environment. CCPS schemes should deal with the collection of data on $C B$ pigs instead of reliance on PB data alone, and it is also important that these pigs will be in an environment that is representative of commercial farms. However, with the environment of the commercial farms being highly variable, robust pigs are necessary. A robust pig not only deals well with the challenging environment of commercial farms but also stays high in feed efficiency and production levels across a range of diverse environments in commercial farms. Breeding for robustness can be implemented by conducting reaction norms analysis, but another complication emerges because considerable amounts of data on different levels of the environment are necessary. To improve feed efficiency at the commercial level, both the trait level as well as the sensitivity to the environment needs to be improved.

One can argue that with the increasing trend towards large and highly technological farms, there is no need to consider GxE because the environmental conditions in such farms will be better than in traditional farms (Mathur, 2018). However, it is not likely that this technological improvement will occur at a fast pace, especially in developing or tropical countries, where some commercial farms 
have very low hygiene status, common incidences of diseases, and low levels of management, and workers may have limited time and training to deal with the pigs. All these aspects are likely to affect feed efficiency, so the improvement of this trait across a range of diverse and challenging environments calls for data collection on the environments.

\subsection{Breeding for Conditions in the Tropics}

Tropical and subtropical regions of the globe will gain increasing attention from agricultural businesses, including breeding companies, because these are the regions where the highest increase in agricultural output is expected to take place (FAO, 2012). Half of the current pork production occurs in temperate climates such as Europe, North America, North China, and Russia, whereas the other half occurs in tropical climates such as Brazil, Mexico, South China, and Vietnam (Rosé et al., 2017).

\subsubsection{Environmental Variation is Inevitable}

Genetic progress in pigs is achieved mostly with a correlate response in CB pigs to indirect selection based on PB performance recorded at nucleus farms in temperate climates under highly controlled environmental conditions. These controlled conditions include closed barns where the temperature and humidity are set to ensure the physiological comfort of the pigs, and the highest levels of sanitary control, health status, and management are applied. However, pork is produced mostly from CB pigs raised in non-standardized commercial farms all over the world. The consequences of this consolidation and selection scheme are that: 1) $P B$ and $C B$ are farmed in environments that are inevitably different; and 2) the environments in which $\mathrm{PB}$, and especially the environments in which $\mathrm{CB}$ are farmed, may be drastically different when comparing, for instance, pig farms in tropical developing countries and in temperate developed countries. These differences may be due to different sources of environmental variation such as health and hygiene status, level of management, climatic conditions, feed ingredients and nutritional plane, and a combination of these.

This environmental variation gives rise to GxE, which is present and important for pig breeding (Mathur, 2018). In pigs, GxE has been described due to heat stress (Zumbach et al., 2008; Bloemhof et al., 2008; Bergsma and Hermesch, 2012; Fragomeni et al., 2017); due to differences in tropical and temperate climates (Chapter 5; Rosé et al., 2017); due to seasonality (Sevillano et al., 2016); due to disease outbreak (Mathur et al., 2014; Rashidi et al., 2014); due to disease challenge load (Herrero-Medrano et al., 2015); due to the combined environmental 
variation in contemporary groups (HYS, Knap and Su, 2008; Silva et al. 2014); due to changes in the diet ingredients (Chapter 3); and due to differences between nucleus and commercial farms (Chapter 2; Zumbach et al., 2007).

The GxE in growing-finishing pigs due to heat stress has been describe affecting the carcass weight of CB pigs (Zumbach et al., 2008) with no genetic association $\left(r_{g}=\right.$ 0.02 ) between carcass weights in the most extremely different temperaturehumidity-index months. When comparing $\mathrm{PB}$ and $\mathrm{CB}$ pigs with this approach, the live body weight of PB pigs is less sensitive than the carcass weight of $C B$ pigs (Fragomeni et al., 2016). On-farm cooling systems might be better in the nucleus environment, resulting in the larger effect of heat stress in CB pigs on commercial farms.

Several of the studies on GxE in pigs used reproduction data collected from F1 sows. Very few studies before this thesis examined GxE in growing-finishing pigs' traits. The difficulty with growing-finishing traits is that they involve a more complicated collection of data because $C B$ pigs are in commercial farms and, as mentioned before, under non-standardized environmental conditions.

\subsubsection{Breeding for Brazilian pork producers}

Even with its high cost of feeding (Table 1), Brazilian pork production is a market undergoing fast expansion. The country increased its pork production from around 3 to 3.75 million tons over the last ten years (ABPA, 2017). Historically, Brazilian pig producers benefited from access to corn and soy grains because both crops and pig farmers were closely located in the south and southeast regions of Brazil. These are highly populated areas that contain more than half of the population of the country. Competition has put pressure on both crops (to a large extent) and livestock production to migrate to the Central-West region of the country, a phenomenon that has intensified from the end of the 1900s to modern times. Grain production also faced an increasing demand in the global market as input for renewable fuels and for human consumption, and international fluctuations of the prices of these commodities became a threat to pig farmers.

Moving the majority of the Brazilian pig production to $\mathrm{MT}$, where the cost of production is much lower (Table 1), may seem like an easy solution. However, this area is not densely populated, so most of the internal market for pork is found elsewhere. Further, MT is not easily connected to the harbors of the country, through which it could reach the export market. This is due to the absence of a hydrographical basin or railway system connecting the Central-West to the coast, which would have allowed large-scale transport of goods and commodities at low cost. The production of pigs in this area is driven by the low financial cost, but it 
incurs an environmental load from the long transportation routes taken by trucks via poorly structured highways. Finally, given the climatic conditions, heat stress is of major concern for pig farming in the Central-West region.

Table 6.2 Average (2014-2016) herds' physical performance (ADBH, 2017).

\begin{tabular}{|c|c|c|c|c|c|}
\hline & $\begin{array}{l}\text { BRA } \\
\text { (MT) }\end{array}$ & $\begin{array}{l}\text { BRA } \\
\text { (SC) }\end{array}$ & NL & EU & USA \\
\hline \multicolumn{6}{|l|}{ Physical performance } \\
\hline Finishing daily live weight gain (g/day) & 831 & 820 & 804 & 814 & 821 \\
\hline Standardized finishing daily live weight gain $(\mathrm{g} / \mathrm{day})^{1}$ & 821 & 809 & 830 & - & 826 \\
\hline Finishing feed conversion ratio & 2.60 & 2.60 & 2.59 & 2.83 & 2.74 \\
\hline Standardized finishing feed conversion ratio ${ }^{1}$ & 2.78 & 2.78 & 2.60 & - & 2.99 \\
\hline Average live weight at slaughter (kg) & 122 & 120 & 119 & 120 & 128 \\
\hline Average carcasses weight-cold (kg) & 91.1 & 89.6 & 92.6 & 92.4 & 94.6 \\
\hline Average dressing percentage ${ }^{2}$ & 74.7 & 74.7 & 77.8 & 77.0 & 73.9 \\
\hline Carcasses meat production/sow/year (kg) & 2279 & 2289 & 2601 & 2336 & 2172 \\
\hline Rearing mortality (\%) & 2.0 & 2.0 & 2.5 & 2.7 & 4.4 \\
\hline Finishing mortality (\%) & 2.2 & 2.2 & 2.3 & 2.6 & 5.0 \\
\hline Pigs weaned/sow/year & 26.1 & 26.7 & 29.5 & 26.8 & 25.3 \\
\hline Pigs reared/sow/year & 25.6 & 26.1 & 28.8 & 26.1 & 24.2 \\
\hline Pigs sold/sow/year & 25.0 & 25.6 & 28.1 & 25.4 & 23.0 \\
\hline Litter/sow/year & 2.41 & 2.30 & 2.36 & 2.30 & 2.41 \\
\hline \multicolumn{6}{|c|}{$\begin{array}{l}\text { BRA = Brazil; MT = Mato Grosso (Central-West region); SC=Santa Catarina (South region); NL } \\
=\text { The Netherlands; EU = European Union; USA = United States of America; CAN = Canada; } \\
\text { 'Standardised to three weights: Transfer from breeding unit to rearing unit = } 8 \mathrm{~kg} \text {; transfer } \\
\text { from rearing unit to finishing unit = } 30 \mathrm{~kg} \text {; live weight at slaughter }=120 \mathrm{~kg} ;{ }^{2} \text { calculated as } \\
\text { average carcass weight/average live weight at slaughter } \mathrm{x} 100 .\end{array}$} \\
\hline
\end{tabular}

The physical performance of pig production in Brazil (Table 2) is comparable to that in other economies. The standardized average lifetime daily gain is lower, but the standardized feed conversion ratio is higher compared to that in North America. In the Netherlands, the extensive use of non-castrated males leads to an advantage in the standardized feed conversion ratio. I speculate that even though the FCR of growing-finishing pigs in Brazil is among the best compared to other countries, the lower standardized average lifetime daily gain could indicate a lower potential for pigs to grow. As discussed in Chapter 4, selection for leaner pigs with low FCR may lead to reduced feed intake capacity and thus less potential to grow. For Brazilian pork producers, it is extra important that genetic supplies, as recommended by 
Knap and Wang (2012), center their breeding goals around feed intake and not around FCR and that breeding values are predicted based on feed intake in Brazilian commercial conditions. For breeders to implement this recommendation, the collection of individual daily feed intake in CB pigs at commercial farms in Brazil for the improvement of REl, RFI, and feed intake curves is recommended. This would allow the FCR to be kept low while not limiting the pigs' potential to grow.

\subsubsection{Optimizing data collection schemes}

One challenge of current pig breeding programs is the collection of phenotypes at the commercial level. Collection of phenotypes is time, human-capacity, and money consuming, so it has to be worthwhile. This commercial-level data collection should be both of high quality and routine, but at the same time, the management of the farm needs to remain the same as on a commercial farm. There is a risk, for instance, that when installing individual feeding recording stations in a commercial farm and setting up experiments for data collection, all the routines and operations of the farm will change to highly sanitized and controlled environmental conditions. It has to be ensured that the hygiene status and management do not increase substantially towards the nucleus farm environment; otherwise, the extra cost of phenotyping pigs in this environment would not be worthwhile.

Even with the required investment, the collection of the individual daily feed intake of $C B$ pigs in the commercial environment seems necessary. This will involve installing electronic feeding stations at the commercial partners of genetic suppliers. The data collection needs to be done on half-sibs of the candidates for selection because the relationship has to be high enough to generate EBVs with high accuracy. In addition to targeting feed efficiency, pig breeding programs can benefit from individual feeding stations at the commercial level to document feeding behavior traits and robustness in the commercial environment.

Data for selection for robustness should also be collected on the commercial level. The variation of feed intake of a particular pig over time (i.e., its dispersion around the average course of the regression lines) may be used as a measure of the animal's sensitivity to environmental changes (Knap, 2009). Putz et al. (2018) used the root mean square error of the individual regression of feed intake or duration at the feeder on age as phenotypes to assess the resilience (ability to maintain productive and healthy life despite environmental perturbations [Mulder, 2017]) of pigs in a health-challenged environment. These traits presented moderate heritabilities and were moderately genetically correlated with mortality and the number of veterinarian treatments. This methodology is powerful and promising for pig breeding, and these traits can largely be used as a measure of sensitivity to a 
vast amount of environmental perturbances when individual feed intake data are collected at commercial farms.

\subsection{Conclusions}

This thesis investigated the existence and magnitude of GxE for feed efficiency of CB pigs kept under Brazilian commercial production circumstances and PB pigs kept under Dutch circumstances. I explored the possible causes of a lower-than-1 genetic correlation for feed efficiency between PB performance at the nucleus level and $\mathrm{CB}$ performance at the commercial level. Additionally, I compared the properties of different traits to represent feed efficiency and the implications of their adoption by pig breeding programs.

My main conclusions were as follows:

1. Collection of feed intake data on $\mathrm{CB}$ at commercial farms is worthwhile;

2. REI, RFI, and feed intake curves are the most interesting traits for pig breeding programs aiming to improve CB pigs' feed efficiency;

3. REI and RFI of CB pigs are sensitive to changes in diet ingredients, so breeding under a lower input diet needs to be considered; and

4. The current available data collected by breeding and genetic dissemination programs make it difficult to obtain accurate estimates of genetic correlations between performance in temperate and tropical climates.

For the future, the biggest challenge for pig breeding programs is to routinely generate data on pigs' feed efficiency that allow the improvement of feed efficiency across the diverse and sometimes challenging environments where $C B$ pigs are farmed around the globe.

Collection of phenotypes is time, human-capacity, and money consuming, but the collection of individual daily feed intake in the commercial environment is necessary. These data have to be collected routinely and have to be of high quality, and the routine and operation of the farm have to be maintained as on a commercial farm. Pigs phenotyped in commercial conditions have to be half-sibs of the selection candidates because the relationships have to be high to generate EBVs with high accuracy.

Pig breeding programs will benefit from individual feed intake data at the commercial level to document, in addition to individual feed intake, feeding behavior traits and to assess resilience in the commercial environment. 


\subsection{References}

ABPA, Brazilian Association of Animal Protein. 2017. Annual report 2017. http://abpa-

br.com.br/storage/files/final_abpa_relatorio_anual_2017_ingles_web.pdf

AHDB, Agriculture and Horticulture Development Board. 2017. 2016 Pig cost of production in selected countries. https://pork.ahdb.org.uk/media/274535/2016pig-cost-of-production-in-selected-countries.pdf

Bergsma, R., and S. Hermesch. 2012. Exploring breeding opportunities for reduced thermal sensitivity of feed intake in the lactating sow. J. Anim. Sci. 90:85-98.

Bloemhof, S., E. van ver Waaij, J. Merks, and E. F. Knol. 2008. Sow line differences in heat stress tolerance expressed in reproductive performance traits. J. Anim. Sci. 86:3330-3337.

Cai, W., D. S. Casey, and J. C. M. Dekkers. 2008. Selection response and genetic parameters for residual feed intake in Yorkshire swine. J. Anim. Sci. 86:287-298.

FAO. 2012. World agriculture towards 2030/2050, the 2012 revision. Rome, Italy: FAO.

Fragomeni, B. O., D. A. L. Lourenco, S. Tsuruta, K. Gray, Y. Huang, and I. Misztal. 2016. Modeling response to heat stress in pigs from nucleus and commercial farms in different locations. J. Anim. Sci. 94:4789-4798.

Gilbert, H., J. P. Bidanel, Y. Billon, H. Lagant, P. Guillouet, P. Sellier, J. Noblet, and S. Hermesch. 2012. Correlated responses in sow appetite, residual feed intake, body composition and reproduction after divergent selection for residual feed intake in the growing pig. J. Anim. Sci. 90:1097-1108.

Gilbert, H., Y. Billon, L. Brossard, J. Faure, P. Gatellier, F. Gondret, E. Labussière, B. Lebret, L. Lefaucheur, N. le Floch, I. Louveau, E. Merlot, M. -C. Meunier-Salaün, L. Montagne, P. Mormede, D. Renaudeau, J. Riquet, C. Rogel-Gaillard, J. van Milgen, A. Vincent, and J. Noblet. 2017. Review: Divergent selection for residual feed intake in the growing pig. Animal 1-13.

Habier, D., K. -U Götz, and L. Dempfle. 2007. Estimation of genetic parameters on test stations using purebred and crossbred progeny of sires of the Bavarian Piétrain. J. Livest. Sci. 107:142-151.

Herrero-Medrano, J. M., P. K. Mathur, J. ten Napel, H. Rashidi, P. Alexandri, E. F. $\mathrm{Knol}$, and $\mathrm{H}$. Mulder. 2015. Estimation of genetic parameters and breeding values across challenged environments to select for robust pigs. J. Anim. Sci. 93:14941502. 
Hidalgo, A. M., J. W. M. Bastiaansen, M. S. Lopes, B. Harlizius, M. A. M. Groenen, and D.-J. de Koning. 2015a. Accuracy of predicted genomic breeding values in purebred and crossbred pigs. G3: Genes|Genomes|Genetics. 5:1575-1583.

Hidalgo, A. M., J. W. M. Bastiaansen, M. S. Lopes, R. Veroneze, B. Harlizius, M. A. M. Groenen, and D.-J. de Koning. 2015b. Accuracy of genomic prediction using deregressed breeding values estimated from purebred and crossbred offspring phenotypes in pigs. J. Anim. Sci. 93:3313-3321.

Knap, P. W. 2005. Breeding robust pigs. Austral. J. Exp. Agric. 45:763-773.

Knap, P. W. 2009. Voluntary feed intake and pig breeding. In: D. Torrallardona, and E. Roura, eds. Voluntary feed intake in pigs. Wageningen Academic Publishers, Wageningen, the Netherlands. p. 13-35.

Knap, P. W., and L. Wang. 2012. Pig breeding for improved feed efficiency. In: J. F. Patience, eds. Feed efficiency in swine. Wageningen Academic Publishers, Wageningen, the Netherlands. p. 167-181.

Knap, P. W., and G. Su. 2008. Genotype by environment interaction for litter size in pigs as quantified by reaction norms analysis. Animal. 2:1742-1747.

Koch, R. M., L. A. Swiger, D. Chambers, and K. E. Gregory. 1963. Efficiency of feed use in beef cattle. J. Anim. Sci. 22:486-494.

Lopes, M. S., H. Bovenhuis, A. M. Hidalgo, J. A. M van Arendonk, E. F. Knol, and J. W. M. Bastiaansen. 2017. Genomic selection for crossbred performance accounting for breed-specific effects. Genet. Sel. Evol. 49:51.

Mathur, P. K., J. M. Herrero-Medrano, P. Alexandri, E. F. Knol, J. ten Napel, H. Rashidi, and H. A. Mulder. 2014. Estimating challenge load due to disease outbreaks and other challenges using reproduction records of sows. J. Anim. Sci. 92:5374-5381.

Mathur, P. K. 2018. Genotype-environment interactions in pig breeding. In: Proceedings of $11^{\circ}$ World Congress on Genetics Applied to Livestock Production. Proceedings, Auckland, New Zealand, 668.

Mulder, H. A. 2017. Is GxE a burden or a blessing? Opportunities for genomic selection and big data. J. Anim. Breed. Genet. 134:435-436.

Nakavisut, S., R. Crump, M. Suarez, and H-U. Graser. 2005. Genetic correlations between the performance of purebred and crossbred pigs. Proc. Assoc. Advmt. Anim. Breed. Genet. 16:99-102.

Neeteson-van Nieuwenhoven, A.-M., P. Knap, and S. Avendano. 2013. The role of sustainable commercial pig and poultry breeding for food security. Anim. Front. 3:52-57.

Putz, A. M., J. C. S. Harding, M. K. Dyck, PigGen Canada, F. Fortin, G. S. Plastow, and J. C. M. Dekkers. 2018. Novel resilience phenotypes from a natural disease 
challenge model in wean-to-finish pigs. In: Proceedings of $11^{\circ}$ World Congress on Genetics Applied to Livestock Production. Proceedings, Auckland, New Zealand.

Rashidi, H., H. A. Mulder, P. Mathur, J. A. Van Arendonk, and E. F. Knol. 2014. Variation among sows in response to porcine reproductive and respiratory syndrome. J. Anim. Sci. 92:95-105.

Rosé, R., H. Gilbert, T. Loyau, M. Giorgi, Y. Billon, J. Riquet, D. Renaudeau, and J.-L. Gourdine. 2017. Interactions between sire family and production environment (temperate vs. tropical) on performance and thermoregulation responses in growing pigs. J. Anim. Sci. 95:4738-4751.

Sevillano, C. A., H. A. Mulder, H. Rashidi, P. K. Mathur, and E. F. Knol. 2016. Genetic variation for farrowing rate in pigs in response to change in photoperiod and ambient temperature. J. Anim. Sci. 94:3185-3197.

Sevillano, C. A., J. Vandenplas, J. W. M. Bastiaansen, R. Bergsma, and M. P. L. Calus. 2017. Genomic evaluation for a three-way crossbreeding system considering breed-of-origin of alleles. Genet. Sel. Evol. 49:75.

Shirali, M., A. Doeschl-Wilson, C. Duthie, P. W. Knap, E. Kanis, J. A. M. van Arendonk, R. Roehe. 2014. Estimation of residual energy intake and its genetic background during the growing period in pigs. Liv. Sci. 168:14-25.

Silva, F. F., H. A. Mulder, E. F. Knol, M. S. Lopes, S. E. F. Guimaraes, P. S. Lopes, P. K. Mathur, J. M. S. Viana, and J. W. M. Bastiaansen. 2014. J. Anim. Sci. 92:38253824.

Tusell, L., H. Gilbert, J. Riquet, M. J. Mercat, A. Legarra, and C. Larzul. 2016. Pedigree and genomic evaluation of pigs using a terminal-cross model. Genet. Sel. Evol. 48:32.

USITC, United States International Trade Commission. 2014. Pork \& swine industry \& trade summary. http://www.usitc.gov/publications/332/pork_and_swine_summary_its_11.pdf van Milgen, J., J. Y. Dourmad, J. Noblet, E. Labussière, F. Garcia-Launay, S. Dubois, A. Valancogne, and L. Brossard, 2015. InraPorc: Where do we come from and where do we want to go? In: N. K. Sakomura, R. Gous, I Kyriazakis., and L Hauschild, eds. Nutritional modeling for pigs and poultry. CABI ed. 318p.

Wei, M., and J. H. J. van der Werf. 1994. Maximizing genetic response in crossbreds using both purebred and crossbred information. Anim. Produc. 59:401-413.

Wientjes, Y. C. J., and M. P. L. Calus. 2017. Board invited review: The purebredcrossbred correlation in pigs: A review of theory, estimates, and implications. J. Anim. Sci. 95:3467-3478.

Wong, W., W. Boylan, and W. Rempel. 1971. Purebred versus crossbred performance as a basis of selection in swine. J. Anim. Sci. 32:605-610. 
Xiang, T., O. F. Christensen, Z. G. Vitezica, and A. Legarra. 2016a. Genomic evaluation by including dominance effects and inbreeding depression for purebred and crossbred performance with an application in pigs. Genet. Sel. Evol. 48:92.

Xiang, T., B. Nielsen, G. Su, A. Legarra, and O. F. Christensen. 2016b. Application of single-step genomic evaluation for crossbred performance in pig. J. Anim. Sci. 94:936-948.

Young, J. M., and J. C. M. Dekkers. 2012. The genetic and biological basis of residual feed intake as a measure of feed efficiency. In: J. F. Patience, eds. Feed efficiency in swine. Wageningen Academic Publishers, Wageningen, the Netherlands. p. 153-166.

Zumbach, B., I. Misztal, S. Tsuruta, J. Holl, W. Herring, and T. Long. 2007. Genetic correlations between two strains of Durocs and crossbreds from differing production environments for slaughter traits. J. Anim. Sci. 85: 901-908.

Zumbach, B., I. Misztal, S. Tsuruta, J. P. Sanchez, M. Azain, W. Herring, J. Holl, T. Long, and M. Culbertson. 2008. Genetic components of heat stress in finishing pigs: Parameter estimation. J. Anim. Sci. 86:2076-2081. 
Summary 



\section{Summary}

One of the main goals of modern pig breeding is to improve feed efficiency of crossbred ( $\mathrm{CB}$ ) pigs across the diverse, and often challenging, environments in commercial farms. The main aim of this thesis was to investigate the existence and magnitude of genotype by environment interaction for feed efficiency in CB pigs kept under Brazilian commercial production circumstances and purebred (PB) pigs kept under Dutch circumstances. In pig breeding programs, PB boars are selected in a nucleus, and mated with crossbred dams to produce $C B$ growing-finishing pigs used for pork production in commercial farms. In this thesis, I investigate the possible causes of a lower than 1 genetic correlation for feed efficiency between the $\mathrm{PB}$ performance in the nucleus level and the CB performance in the commercial level $\left(r_{p c}\right)$, and compare the properties of different traits to represent feed efficiency and the implications of their adoption by pig breeding programs.

In Chapter 2, I estimated the genetic correlations between feed efficiency traits, growth performance, and carcass traits in $\mathrm{PB}$ and $\mathrm{CB}$ pigs, and compared three different traits representing feed efficiency: feed conversion rate (FCR), residual energy intake (REI), and residual feed intake (RFI). The results show that the inclusion of phenotypes recorded on $\mathrm{CB}$ pigs in commercial farms in the prediction of breeding values for $\mathrm{PB}$, has the potential to increase genetic progress for the performance of CB. Given the genetic correlations with growth performance traits and the $r_{p c}, R E I$ is an attractive feed efficiency parameter for a pig breeding program.

In Chapter 3, I investigated the presence of a genotype by feed interaction (GxF) for feed efficiency and growth performance traits in different growth phases (starter, grower and finisher) of $\mathrm{CB}$ pigs fed one of two diets. The diets were based on corn/soy or wheat/barley co-products. I found that GxF was absent for average daily feed intake, growth, and FCR, but present for lipid deposition, REI, and RFI. The magnitudes of GxF for REI and RFI depended on the phase of the pigs' growth. Breeding pigs for feed efficiency under lower-input diets such as wheat/barley/coproducts is recommended as feed efficiency will become more important, and lower-input diets will become more widespread in the near future.

In Chapter 4, I fitted feed intake and growth curves of CB pigs fed two diets, investigated the presence of GxF, and estimated genetic parameters for both curves. I found that GxF was absent for the curves' parameters. Given their medium to high heritabilities, these traits are a feasible alternative for pig breeding programs that are aiming to change the shape of feed intake and growth curves in $C B$ pigs. Selection for feed efficiency by changing the trajectory of curves that 
describe feed intake as a function of body weight seems to be a good alternative to selecting for average feed intake parameters. I recommend selecting pigs with flatter curves (as they will have better feed efficiency) and selecting pigs with higher feed intake precocity. Higher feed intake precocity means a higher feed intake in early stages of growth associated with a higher growth maturation rate and a consequently lower feed intake later in the finishing period.

In Chapter 5, I estimated the genetic correlations between growth performance and carcass traits of both PB and CB pigs in a temperate climate (the Netherlands, France and Canada) and a tropical climate (Brazil). To improve these traits in a tropical climate, higher genetic progress will be made by including phenotypes collected locally in CB pigs. This is true even though the high $r_{p c}$ would not require combined crossbred-purebred selection (CCPS) schemes.

In Chapter 6, I placed my work in a broader context, discussed the implications and formulated recommendations for future breeding for feed efficiency in growingfinishing pigs, with special attention to feed efficiency in the tropics, and recommended future research. I concluded that in the future, the biggest challenge facing pig breeding programs would be to routinely generate data on pigs' feed efficiency that allows the improvement of feed efficiency across the diverse and often challenging environments where CB pigs are farmed around the globe. 


\section{Sumário}





\section{Sumário}

Um dos mais relevantes objetivos dos programas modernos de melhoramento genético de suínos é a melhoria da eficiência alimentar de suínos cruzados (CB) observada nas mais diversas, e muitas vezes desafiadoras, condições ambientais das granjas comerciais. O objetivo geral desta tese foi investigar a existência e a magnitude da interação genótipo $x$ ambiente na eficiência alimentar de suínos $C B$ mantidos sob condições brasileiras de produção comercial, e suínos de linhas puras (PB) mantidos sobre condições holandesas. Em programas de melhoramento genético de suínos, varrões $P B$ são selecionados nas granjas-núcleo e posteriormente acasalados com marrãs cruzadas (F1) com o intuito de produzir leitões CB destinados à terminação em granjas comerciais para produção da carne suína. Nesta tese, investiguei possíveis causas de uma correlação genética para eficiência alimentar abaixo de 1 entre os desempenhos dos PB nas granjas-núcleo e dos CB nas granjas comercias $\left(r_{p c}\right)$, e comparei as propriedades de diferentes representações para a característica eficiência alimentar e as implicações de suas inclusões nos programas de melhoramento genético de suínos.

No Capítulo 2, estimei correlações genéticas entre características de eficiência alimentar, de crescimento e de qualidade de carcaça em populações de suínos PB e $C B$, e comparei três diferentes representações da característica eficiência alimentar: conversão alimentar (CA), consumo energético residual (CER), e consumo alimentar residual (CAR). Os resultados mostram que a inclusão de fenótipos coletados em suínos $C B$ em granjas comerciais nas predições de valores genéticos para $\mathrm{PB}$, tem o potencial de aumentar o progresso genético para $\mathrm{o}$ desempenho de CB. Dadas as suas correlações genéticas com características de crescimento e a $r_{p c}$, posso concluir que CER é uma representação da eficiência alimentar atrativa para inclusão em programas de melhoramento genético de suínos.

No Capítulo 3, investiguei a presença de interação genótipo x dieta (IGD) para características de crescimento e eficiência alimentar nas diferentes fases do crescimento (inicial, crescimento e terminação) de suínos CB alimentados com uma de duas dietas comerciais. As dietas foram formuladas à base de milho/soja ou trigo/cevada/subprodutos. Observei a ausência de IGD para o consumo médio diário de dieta, para o crescimento, e para a CA. Observei a presença de IGD para a deposição de lipídios, para o CER e para o CAR. A magnitude da IGD para CER e CAR foi dependente da fase de crescimento dos animais. O melhoramento genético de suínos para eficiência alimentar sob dietas formuladas à base de insumos com menor valor nutricional como trigo/cevada/coprodutos é recomendável, já que a 
característica eficiência alimentar se tornará mais importante e dietas formuladas à base de insumos com menor valor nutricional se tornarão mais usuais no futuro próximo.

No Capítulo 4, ajustei curvas de consumo alimentar e de crescimento de suínos CB alimentados com uma de duas dietas, investiguei a presença de IGD e estimei parâmetros genéticos para ambas as curvas. Observei ausência de IGD para os parâmetros de ambas curvas. Por apresentarem estimativas de herdabilidade médias ou altas, esses parâmetros se mostram uma alternativa viável para programas de melhoramento genético de suínos alterarem as curvas de consumo alimentar e de crescimento de suínos CB. A seleção para eficiência alimentar através da alteração da trajetória de curvas que descrevem a consumo alimentar como função do peso corporal aparenta ser uma alternativa interessante à seleção utilizando parâmetros baseados no consumo alimentar médio. Recomendo a seleção de animais com curvas mais planas (porque estes apresentarão melhor eficiência alimentar) e a seleção de animais com maior precocidade no consumo alimentar [maior precocidade no consumo alimentar significa um maior consumo alimentar nos estágios iniciais de crescimento associada a uma maior taxa de crescimento (maturidade) e consequentemente a um menor consumo alimentar na fase de terminação].

No Capítulo 5, estimei correlações genéticas entre características de crescimento e qualidade de carcaça em suínos PB e CB, em clima temperado (Holanda, França e Canadá) e em clima tropical (Brasil). Para a melhoria genética das características em clima tropical, maior progresso genético será obtido com a inclusão de fenótipos coletados localmente em suínos CB. Essa recomendação é válida, ainda que a alta $r_{p c}$ não demande esquema de seleção combinada puro-cruzado (CCPS).

No Capítulo 6, coloco meu trabalho em contexto amplo, discuto as implicações e formulo recomendações para futuro melhoramento genético da eficiência alimentar de suínos CB, com especial atenção para eficiência alimentar nos trópicos, e recomendo futura pesquisa científica dentro deste tema. Eu concluo que, no futuro, o maior desafio a ser enfrentado pelos programas de melhoramento genético de suínos será a geração rotineira de dados que permitam a melhoria genética da eficiência alimentar nas condições ambientais diversas e comumente desafiadoras onde suínos CB são criados ao redor do globo. 
Acknowledgments 


\section{Acknowledgments / Agradecimentos / Danksagung}

My thesis was built up of a collaborative project between Universidade Federal de Viçosa (UFV), Wageningen University \& Research (WUR) and Topigs-Norsvin through the multidisciplinary consortium project "Local Pork - Locally Adapted Pork Production in Brazil versus the Netherlands". I am first of all very grateful for the opportunity to take part in the consortium as a PhD student/candidate in the Animal Science Department (DZO) of UFV and in the Animal Breeding \& Genomics (ABG) of WUR.

I am overall grateful to my supervision team for the help in all the progress that I have made and everything that I have learned along all these years. I am glad to look back to 2014 and see a big transformation that brought me to 2018. Thank you guys for each single contribution to it.

John, as my daily supervisor at WUR you were always close to my work. Thank you for all the long hours in our meetings. Your science view, writing skills and patience are admirable. Thank you for all the improvement I achieved on my writing and on my way to communicate science through many corrections, critics and suggestions.

Hans, you arrived later on my project but just in time to give me a lot of motivation, nice ideas and really fruitful brainstorms. I admire your ability for helping us seeing our work in a broader view and to put it on perspective. You were crucial for me to end this PhD project in time. Thank you.

Simone, I learned from you that communication and a broad professional network are crucial to success in science. I admire the way you can build your network, lead people and manage projects. It is impossible to achieve success if the opportunity is not there. Thank you for guiding me, for the opportunity you gave me in UFV and the opportunities you created for me abroad.

Fabyano, I admire the way you can be genial and modest at the same time. Always helpful to colleagues surrounding you and always with a contagious humor. Thank you for all the help you gave me in the project and for everything I learned from you. I am happy to call you friend. Baum demais cara! 
Rob, I learned from you to see science a bit "out of the bubble". I admire your pragmatism. Thank you for many impressions about pig breeding, pig husbandry and pork production, and for many suggestions and comments on my work. I am happy to become a colleague of yours and hope to learn further from you at Topigs-Norsvin.

I am grateful for all the staff members of ABG and DZO for all the help. Special thanks to Lisette for always making my life so much easier, and for working with affection and attention to me and to everyone.

O meu grande obrigado a todos os colegas do DZO pelo aprendizado compartilhado e momentos de descontração em aula, no GDMA, na salinha e no Labtec. Obrigado especial aos amigos no DZO: Léo, Tiago, Sirlene, Laís, Karina e Rocha, aos amigos que fiz em Viçosa fora do DZO: Lets, Rodrigo Fló, Vitor, Inácio, Benício, Lemos, Colares, Mayra e Aline, e à esses dois amigos especiais que fiz em BH e Viçosa cuidou de aprimorar: Luís Fernando e Maria Alice. Os anos que passei em Viçosa são inesquecíveis. Obrigado tanto pelos momentos de amizade e companheirismo quanto pelos momentos trans, por terem tolerado a Kylie, e por terem se rendido aos encantos do Cottonete e da Mellanie. Love you all guys!

Luís, não posso deixar aqui de render um agradecimento especial à você por todas as coisas que dividimos, pela sua amizade e companheirismo. Você foi um amigo para todas as horas, todas mesmo. Obrigado por ter me feito uma pessoa melhor com seus conselhos e reflexões, por ter acompanhado minhas dificuldades, por ter torcido pelas minhas vitórias, por todas as discussões científicas e pelas revisões gratuitas no inglês. E claro, curtimos until the end! Espero que você tenha maturidade de devolver meus isqueiros.

Arthur, Tiago, Léo e Sirlene, obrigado pelas discussões e todas as "ajudas dos universitários" que vocês me deram principalmente no início do doutorado. Com certeza existem algumas impressões digitais de vocês no meu doutorado e serei sempre grato. Fico feliz de saber que vocês são colegas e amigos para toda a vida!

A um dos meus casais prediletos, Claudinha e Pierrito, obrigado por compartilharem comigo o escritório na UFV durante nosso quase um ano juntos em Viçosa. Nutro profunda amizade por vocês e adoro nossas polêmicas (ou não) conversas. Obrigado por tudo que vivi com vocês em Viçosa, no Peru, na Bélgica e em Wageningen. 
A big thanks to all my colleagues at $A B G$ for the knowledge shared especially in QDG and TLM, and also for the nice time we spent together at the coffee corner, the spot, de Vlaam, or anywhere else in the campus or in the city. A special thanks for my office mates at Maluma's Office, Claudia and Maria. Sharing office with you was just amazing. Claudia, again $(-)$, minha querida amiga, thank you for everything we share together being part at the same project, for your help in my work, and for turning from a simple colleague to a special friend and confident in these 4 years. Maria, mi hermanita, my dear friend and paranymph. Thank you for always bringing me up with all your energy and happiness, for hearing me, for your partnership, for bringing Toon around, for taking part in my professional and personal life. It was always a big comfort to have you around. Te amo linda! Never leave me! Shuwen, my dear friend and paranymph, thank you for sharing and being so close to me in our corridor office. All our long talks and exchange of point of views and life experiences were always so enjoyable for me. I hope I won't become a seller in China in the near future $(;)$. Thanks for following my progress and difficulties in all this years. Count on me and stay around girl! Laiza, I will never forget all your happiness and amazing humor, you were always so powerful in bringing me up. Bem menininha! Thanks for our partnership in our time together at WUR. I am happy I can call you friend. Stay in contact!

I am also grateful to all people I met in the Netherlands out of ABG who made me fall in love with the country and made my PhD time in the Netherlands amazing. Nelson Jr. thanks for all the moments of science we share at WUR, all the deep conversations and reflections. I admire you as a scientist, as a human being and as a friend. Of course we also had lots of fun and enjoyed this amazing country we love! I am waiting for this big present life must give me: you coming back to the NL! Stephan, you were one of the best unexpected surprises Wageningen gave me, and I am happy that I mean the same for you. I had so much fun with you man! Thanks for all the things we share, culture exchange, moments of fun around, and especially science experience and expectations. I am sure we will keep this friendship close the following years in the Netherlands and wherever the future will bring us. Dankje Jan! That's all!... Ja ja, lekker makkelijk! (;) Thanks for your friendship, partnership and your support in that moments that I really needed a shoulder. Thanks for being so open to me, sharing your culture, showing me around, and for all the moments of fun. I admire you and you can count on me! Vergiss es nicht! Hab dich lieb! Carlos, thank you for all the moments of confidence and to listen to aaallIII my dramas. I told you! The world was about to end, OMG!!!! It didn't $:$. Hahaha Thanks to you and to Bart for everything we share in 
Wageningen and in the Netherlands. Love you guys! Carol, friend, the world is so small. From being my veteran in Veterinary College of UFMG till now my colleague at Topigs-Norsvin. Thanks for becoming a confident friend. I admire you as a women, mother, scientist and professional. Count on me! Marco, we met for short but you were a great buddy. I feel like I know you for years! I hope we will keep on touch, you visit me in the North and me you in the South! Grazie, amico mio. Johanna you know I think you have several bad qualities :) haha. Girl you are a genuine person that I learned to love very fast. Hope you never get really apart. Thank you for being there, open my mind with such new ideas and being so open to me. Hab dich lieb! E claro pra fechar não podia faltar uma turminha de brasileiros! Obrigado pelos momentos de amizade, companheirismo e curtição em Amsterdam meus queridos Thiago, Lucas, Weliton e Jesuino! Se a Holanda ficar pequena a gente tem a Bélgica hehehe.

Big thanks to my housemates in Viçosa, Sirlene, Mayra, Luís e Aline, and in Wageningen Dogan, Maria, German and Thomas. Thank you guys for sharing the day-by-day life, for cooking and eating together and of course for the long discussions about science, geopolitics, social issues and about stupid things too.

Herzlichen Dank an alle meine lieben deutschen Freunde und Familien. Das Jahr, in dem ich in Havelberg gelebt habe, hat großen Einfluss auf mein weiteres Leben genommen. Besonders möchte ich mich bei Familie Groos und Familie Russ, sowie bei meinem Schwesterlein Wiebke und ihrer Familie bedanken. sie alle haben dazu beigetragen, dass ich mich in Deutschland nicht nur zu Hause sondern auch als Teil ihrer Familien gefühlt habe. Sie alle in der Nähe zu haben als ich in die Niederlande ging, war ein großer Trost für mich. Besonders an Wochenenden, Feiertagen, Geburtstagen und an Weihnachten. Auch wenn es um meine Doktorarbeit ging haben alle geduldig zugehört. Ein ganz besonderes Dankeschön geht an mein Schwesterlein Karo, die mich in all den Jahren der Promotion begleitet hat und so lieb ist meine deutsche Assistentin zu sein. Alle meine Lieben in Deutschland, ich hoffe dass wir unsere Beziehung in den nächsten Jahren in dieser Form aufrechterhalten werden. Ich habe euch sehr lieb!

A todos os amigos de Belo Horizonte meu muito obrigado pela presença. Não posso deixar de agradecer especialmente àqueles que compartilharam extensivamente meus anseios e frustrações nesse período do doutorado, Gabi, Ellen, Arthur, Anna, Sidney, Rubian, Jonathan, Marcelo e David. Eu amo vocês! 
Obrigado aos meus irmãos, Rodolfo e Rafael, minha cunhada Maria Cristina, meus sobrinhos Clarinha e João Miguel, e a todos os Mezêncio's, Lobo's, Godinho's e Damasceno's, pelo apoio, torcida, compreensão e acolhimento que sempre tive, por acreditarem no meu potencial e por compartilharem toda minha carreira acadêmica. $\mathrm{O}$ meu obrigado especial à minha irmã Larissa por além de todo apoio e torcida, ser minha amiga e confidente, e por toda a força nos momentos cruciais que possibilitaram que eu continuasse essa grande empreitada do doutorado. Te amo!

Mãe, obrigado por todo amor e suporte, por ser minha amiga, por me ouvir e me aconselhar sempre e por todo o delicado período do doutorado. Sua força e determinação durante a doença do meu pai foram cruciais para manter a família de pé e me deu força para seguir em frente. Obrigado por toda a força nos momentos cruciais que possibilitaram a execução desse doutorado. Saiba que te admiro, tenho profundo respeito pela mulher forte que você é, e te amo muito!

Pai, te dedico essa vitória. Você sempre foi um exemplo pessoal e profissional para mim. Aprendi com você o poder de transformação que a formação educacional tem nas nossas vidas. Obrigado por tomar para si os meus sonhos e anseios, e por todo o suporte que você e minha mãe me deram para continuar os estudos e buscar voos mais altos. Perder você no meio do meu doutorado foi um dos capítulos mais difíceis da minha vida. Queria muito poder ver sua felicidade e orgulho no termino dessa minha jornada. Sei que você está me assistindo e como sempre torcendo por mim. Muito obrigado por tudo. Te amo!

Dad, I dedicate to you this victory. You were always a personal and professional example for me. I learned from you the power of transformation that education has in our lifes. Thanks for taking as yours my dreams and whishes, and for all support my mom and you always gave me to be ambitious and to keep on my studies. To lose you in the middle of my PhD was one of the worst and toughest chapters of my life. I would love to see your happiness and proud by the end of this journey of mine. I know you are watching and supporting me. Thank you for all. Love you! 
Curriculum vitae 



\section{About the author}

Rodrigo Mezêncio Godinho, was born on $11^{\text {th }}$ of November of 1985 in Belo Horizonte, Minas Gerais, Brazil. As he was fifteen years old, he was accepted by the Technical College (COLTEC) of Universidade Federal de Minas Gerais (UFMG, Belo Horizonte, Brazil), in which he attended concomitant to the high school course, the technical course in Clinical Pathology. As he was eighteen years old, he spent a year with German host families participating in the Youth Exchange Program of Rotary International being hosted by the Rotary Club Havelberg (Havelberg, SachsenAnhalt, Germany) and studying a high school year at Pestalozzi Gymnasium Havelberg. He did his BSc in Veterinary Medicine at UFMG from 2006 to 2011. In the beginning of his BSc course he became a Junior Researcher in the area of genetics, working during four years with model animals (rodents and quail) as a tool to study evolution, quantitative genetics and animal breeding. In 2012, he started his MSc in Department of Animal Science of the Veterinary College of UFMG. In 2014 he defended his MSc thesis entitled "Inbreeding and Heterosis on Performance and Reproductive Characteristics in Meat Type Quail" under the supervision of Professor Martinho de Almeida e Silva. In 2014, he decided to move to Viçosa after being accepted as a PhD student in Universidade Federal de Viçosa (UFV, Viçosa, Brazil). In 2015, he got enrolled as a PhD candidate at Animal Breeding and Genomics (ABG) in Wageningen University \& Research (WUR, Wageningen, the Netherlands). His PhD project was one of four PhD projects in the "Local Pork - Locally Adapted Pork Production in Brazil versus the Netherlands" Consortium, a multidisciplinary project built in a partnership between UFV, WUR and Topigs-Norsvin. During his PhD project he spent time in both UFV and WUR developing the project "Genotype by Environment Interaction for Feed Efficiency in Growing-Finishing Pigs in Brazil versus the Netherlands". The results of the project are presented in this thesis. 


\section{Peer reviewed publications}

Godinho, R. M., J. W. M. Bastiaansen, C. A. Sevillano, F. F. Silva, S. E. F. Guimarães, and R. Bergsma. 2018. Genotype by feed interaction for feed efficiency and growth performance traits in pigs. J. Anim. Sci. 96:4125-4135.

Godinho, R. M., Bergsma, R., Silva, F. F., Sevillano, C. A., Knol, E. F., Lopes, M. S., Lopes, P. S., Bastiaansen, J. W. M., and S. E. F. Guimarães. 2018. Genetic correlations between feed efficiency traits, and growth performance and carcass traits in purebred and crossbred pigs. J. Anim. Sci. 96:817-829.

Costa, E. V., Ventura, H. T., Figueiredo, E. A. P., Silva, F. F., Glória, L. S., Godinho, R. M., Resende, M. D., and P. S. Lopes. 2016. Multi-trait and repeatability models for genetic evaluation of litter traits in pigs considering different farrowings. Rev. Bras. Saúde Prod. Anim. 17:666-676.

Vidal, T. Z. B., Fontes, D. O., Ferreira, F., Godinho, R. M., Silva, M. A., and G. S. S. C. Corrêa. 2014. Total methionine + cystine level for European quail from hatch to 21 days of age. Arq. Bras. Med. Vet. Zootec. 67:242-248.

Ferreira, F., Corrêa, G. S. S., Corrêa, A. B., Silva, M. A., Felipe, V. P. S., Wenceslau, R. R., Freitas, L.S., Santos, G. G., Godinho, R. M., Climaco, W. L. S. Dalsecco, L. S., and J. G. Caramori Junior. 2014. Carcass traits of EV1 quail strain fed different methionine+cystine level diets. Arq. Bras. Med. Vet. Zootec. 6:1855-1864.

Carmo, E. D. C., Godinho, R. M., Araújo, N. P., Svartman, M., and F. N. Vieira. 2014. Range extension of Bibimys labiosus (Winge, 1887) (Mammalia: Rodentia: Cricetidae) to western Minas Gerais state, Southeastern Brazil. Check List: Journal of species lists and distribution. 10:602-606.

Ferreira, F., Corrêa, G. S. S., Corrêa, A. B., Silva, M. A., Felipe, V. P. S., Wenceslau, R. R., Freitas, L. S., Godinho, R. M., and N. J. L. Dionello. 2012. Methionine + Cystine requirement for European quail during the growing phase. Arq. Bras. Med. Vet. Zootec. 64:120-126.

Ferreira, F, Corrêa, G. S. S, Corrêa, A. B., Silva, M. A., Felipe, V. P. S., Freitas, L. S., Wenceslau, R. R., Lima, C. A. R, Santos, G. G., Godinho, R. M., Caramori Junior, J. G., and C. H. F. Vasconcellos. 2012. Total methionine + cystine diet content for EV2 strain of European quail during the growing period. Arq. Bras. Med. Vet. Zootec. 64:665-674.

The complete list of publications which includes publications in conference proceedings can be found in the online CV:

Lattes: $\quad$ http://lattes.cnpq.br/0162043069147780

Researchgate: https://www.researchgate.net/profile/Rodrigo_Godinho2 
Training and supervision plan 
Training and supervision plan

The Basic Package (3 ECTS)

Year

WIAS Introductory Course

2015

Ethics and Philosophy in Life Sciences

2015

WIAS Course on Essential Skills

2015

\section{Scientific Exposure (10 ECTS)}

\section{Conferences}

5th International Conference on Quantitative Genetics (ICQG)

Madison, USA

12th Brazilian Symposium of Animal Breeding (SBMA)

Ribeirão Preto, Brazil

54th Annual Meeting of Brazilian Society on Animal Science

(SBZ), Foz do Iguaçú, Brazil

68th Annual Meeting of the European Federation of Animal

Science (EAAP), Talinn, Estonia

11 th World Congress on Genetics Applied to Livestock

Production (WCGALP), Auckland, New Zealand

\section{Presentations}

Poster presentation at ICQG, Madison, USA

Poster presentation at SBMA, Ribeirão Preto, Brazil

Oral presentation at SBZ, Foz do Iguaçú, Brazil

Oral presentation at EAAP, Talinn, Estonia

Oral presentation at WCGALP, Auckland, New Zealand

\section{In-Depth Studies (19 ECTS)}

Disciplinary and Interdisciplinary courses

Statistical Methods in Genomic Selection

Mixed Models Applied to Breeding and Genetics

Data Analysis on Animal Breeding and Genetics 
Genomic Prediction $\quad 2014$

Genomic Selection in the Era of Genome Sequencing 2016

Genomic tools 2017

Animal Breeding $\quad 2017$

Design of Breeding Programs with Genomic Selection 2017

Advanced statistics courses

Bayesian Statistics 2014

PhD Students' Discussion Groups

Quantitative Genetics Discussion Group 2015-2018

Professional Skills Support Courses (3 ECTS)

Workshop Publicase: Writing the Medical/Biological 2014

Scientifical Paper in a Week

Project and Time Management 2016

The Final Touch: Writing the General Introduction and Discussion 2018

Research Skills Training (6 ECTS)

Writing Research Proposal 2015

Getting started with ASReml 2015

Didactic Skills Training (1 ECT)

Internship in Education 2016

Education and Training Total 42 ECTS 
Colophon 


\section{Colophon}

This work is financially supported by the Netherlands Organisation for Scientific Research (NWO) through the LocalPork project W 08.250.102 in the Food and Business Global Challenges Program.

The cover of this thesis was designed by Piotr Sell.

This thesis was printed by Digiforce Print \& Logistics, Wageningen, the Netherlands.

ISBN 978-94-6343-552-9

DOI: $10.18174 / 465136$ 